$$
\text { PEDRO F. DE ANDREA }
$$

\title{
Miguel Angel Asturias
}

\author{
A NTICIPO BI B LIOGRA F I CO
}

MEXICO, 1969 



\section{P R O L O G O}

"Cada año los países de nuestra América ensayan un nombre. Alguna vez fue Alfonso Reyes, otra Juana de Ibarbourou y últimamente, el maestro Rómulo Gallegos. Sin embargo, parece ser que tenemos poca audiencia en Suecia... ¿Qué es lo que pasa?... ¿Existe una repulsión por todo lo latinoamericano debido a que se nos considera todavía con plumas en la cabeza? Algunas quedan, pero otras ya han escrito páginas inmortales. ¿Para obtener el Premio Nobel, el escritor o poeta además de sus condiciones, tiene que estar respaldado por una escuadra, aviones a chorro y montones de dólares o de monedas fuertes?... Lo cierto es que la América Latina, fuera de Gabriela Mistral, no ha logrado que se le dé a otro de los suyos..."

Así opinaba Miguel Angel Asturias en un ensayo publicado en $E l$ National ${ }^{1}$ de Caracas, hace unos años. $\mathrm{Y}$ no se crea que esta mordacidad brotaba de un resquemor personal. No pensaba en sí mismo, sino que en turno, venia solicitando el esquivo Premio, para Alfonso Reyes, Pablo Neruda, Rómulo Gallegos y, por último para el autor de El Aleph. "Ya veremos si esta vez, que jugamos a Jorge Luis Borges, la apuesta nos sale", concluye Asturias.

No sospechaba que años más tarde, el 19 de octubre de 1967, día de su cumpleaños, sin respaldo de "una escuadra, aviones a chorro y montones de dólares" y tan sólo armado de su epopeya literaria, ganaría el inaccesible galardón.

La magia del Premio Nobel atrae el interés de la prensa mundial. Provoca una catapulta de comentarios sobre la valía y significado de su obra. Promueve la lectura y relectura de sus libros. Impulsa a los estudiosos a la búsqueda de referencias precisas respecto a su vida y a su creación fabulesca. No las encuentran puesto que no existe ${ }^{2}$ una recopila-

1 Reproducido en Papeles, 5 (Caracas, nov.-ene. 1967-1968), pp. 6-7.

$2 \mathrm{Ya}$ muy adelantado el presente anticipo bibliográfico, llegaron a mis ma. nos los siguientes trabajos:

a) Yuri Pevtsov: Migel' Ankbel Asturias: biobibliograficberkii ukazatel. Mascí, Vses, kn. Palati, 1960. 28 pp. La bibliografía propiamente dicha, ocupa las páginas 17-27. Registra unas 125 fichas. Un laudable esfuerzo pionero. Desafortunadamente hace mucho que está agotado y por lo tanto, este folleto es casi imposible de obtener. Además, como muy pocos manejan el ruso, su consulta es aủn más limitada.

b) Ray A. Verzasconi: "Bibliografía de y sobre Miguel Angel Asturias", Corvallis, Oregón, 1968. Mecanografiada. El Dr. R. A. Verzasconi escribió su tesis doctoral sobre Astutias en 1965. Pero la mayor parte de su bibliografía fue recopilada con posterioridad, patalela a la mía. Véase ficha 489. 
ción bibliográfica adecuada, conmensurable con su magnitud de escritor internacional.

Para rectificar en parte, tal anomalía, emprendí esta aventura bibliográfica. Ha resultado laboriosa, en extremo. Además de la labor rutinaria en esta clase de investigaciones, hay que añadir el sobrecargo que lleva en si un Premio Nobel. Esto es, la inflación de artículos y notas que proliferan en diarios y revistas mundiales. Todo lo cual aumenta, de manera considerable, el campo de las pesquisas y multiplica las dificultades.

No obstante los obstáculos, la cosecha ha sido copiosa. Téngase en cuenta que la presente bibliografía de 1460 fichas, es tan sólo un anticipo, como lo indica el subtítulo. Representa un poco más de la mitad ${ }^{3}$ de las cédulas reunidas hasta la fecha. He tenido que reducirla puesto que su publicación en una revista, impone límites de espacio y tiempo.

Pese a sus limitaciones, integra una guía orientadora. Se agrupa en tres secciones. La primera y segunda abarcan en forma representativa las diversas manifestaciones creadoras de Miguel Angel Asturias: ensayos, poesias, narrativa, teatro, antologías, ${ }^{4}$ traducciones. La sección tercera reúne un variado repertorio de referencias críticas; libros, tesis, homenajes, conferencias y hemerografía.

El lector advertirá que las cédulas bibliográficas provienen de las más variadas latitudes; desde Brasil, hasta Japón, desde Africa del Sur hasta Noruega. Manifiestan diferentes intensidades y enjuiciamientos disímbolos.

Esta bibliografía debería estar desprovista de anotaciones y apostillas. Sin embargo, he intentado fugarme del marco de un simple repertorio árido y descarnado. En la medida que me lo ha permitido el espacio, he desglosado el mayor número posible de ensayos, entrevistas y reseñas, para brindar al estudioso, material biocrítico. ${ }^{5}$ No he omitido la anécdota reveladora ni la frase humorística. Estos elementos suelen proporcionarnos elocuentes datos psicobiográficos, que descubren al hombre e iluminan al escritor.

Al extractar las citas valorativas, me he guiado por diversos criterios. En la mayoría de los casos he intentado captar la idea medular del crí-

3 Lo excluido, más lo pendiente por recopilar, entrará en un libro en vías de realización.

4 Como muestra del gracejo asturiano, transcribo su concepto sobre las antologías:

- ¿Qué privilegio tienes facedor de antologias?

-Que otro no tengo que el del antojo.

- Y lo acusas?

Como un rey.

- ¿Qué es entonces una antología?

-Una antojología.

-iUna antojología?

-El antólogo reúne en sus páginas lo que se le antoja y el lector busca en ellas, a su antojo, sus antojos..." [Véase Rubén Darío: Páginas de... Buenos Aires, Eudeba, 1963. Prólogo de Miguel Angel Asturias, p. 5.]

5 De preferencia he intentado desglosar estudios difíciles de obtener. 
tico. Otras veces, he transcrito un trozo que revela un ángulo novedoso, aunque este mismo ángulo, no sea lo esencial del ensayo.

En breve, las anotaciones que sazonan esta bibliografía, representan, en cápsula, los juicios y prejuicios de centenares de comentaristas. En su conjunto, quizás pueda considerarse como una especie de Pequeña bistoria de la critica literaria asturiana.

Ahora bien, un escrutinio de este anticipo bibliográfico, nos permite captar a grandes rasgos, el estado actual de la crítica sobre Asturias.

En primer lugar, salta a la vista una desconcertante contradicción de juicios en la valoración de su obra. En la crítica literaria, la disimilitud de enjuiciamientos es lógica. Mas, en el caso de Asturias, las disparidades de criterios llegan, entre sí, a posturas irreconciliables. Se deben en buena parte, a la carencia de una adecuada bibliografía orientadora.

Bien ha señalado Enrique Anderson Imbert: "Una inteligencia sin un marco de referencias no es inteligencia."6 Cualquier estudio riguroso sobre Miguel Angel Asturias, se verá siempre entorpecido si el crítico, aún el más idóneo, no cuenta con una bibliografía que le ubique dentro de su tema, que le sirva de auto-control, que apoye su sensibilidad artística, y que le permita valorar sus conclusiones frente a los juicios de otros investigadores.

En segundo lugar, queda manifiesto el nutrido número de comentarios efímeros frente a la escasez de estudios rigurosos, profundos y valederos.7 Ello se debe en parte, al caudaloso y abigarrado "torrente" de crónicas aparecidas en la prensa mundial a raíz del Premio Nobel. Pero aún estas notas, en apariencia nimias y repetitivas, tienen su valor. Testimonian la repercusión internacional de su personalidad y subrayan su fortuna literaria. Han servido para promover una más amplia divulgación de sus libros. Como consecuencia, ya tenemos indicios ${ }^{8}$ de que estamos en vísperas de una eclosión de estudios de mayor solidez.

Una nueva mirada sobre esta bibliografía, revela otro grave problema; el desnivel entre el caudal de estudios críticos, frente a la virtual ausencia de investigaciones recaudadoras de material y datos inéditos o no recopilados. Queda por sacudir la polilla de múltiples publicaciones americanas y europeas que esconden, centenares de sus artículos, además de un buen caudal de poesías y cuentos $^{9}$ que esperan asimismo, su turno de

- La crítica literaria contemporánea, Buenos Aites, Platania, 1957, p. 112.

7 He señalado algunos de estos trabajos importantes a lo largo de la bibliografía.

8 Günter W. Lorenz consigna que están en proceso de elaboración 50 tesis sobre diferentes temas asturianos, en Francia, Italia, Suecia, España, Bélgica, Rumania, República Democrática Alemana, Estados Unidos, Unión Soviética y Latinoamérica. Hubiera sido interesante que ampliara su afirmación, proporcionándonos autores, títulos y lugates. Véase Günter W. Lorenz: Miguel Angel Asturias. Porträt \& Poesie. Berlín, 1968, p. 317.

9 Ultimamente, Claude Couffon ha dado a conocer el primer cuento de As. turias: "El toque de ánimas", que se habia publicado en Studium, 8 (Guatemala, en.-mar. 1922). Véase ficha núm. 113. La traducción al francés, con el título "La cloche du purgatoire", se publicó en Le Monde, 7506 (París, 19 mar. 1969), p. VIII. 
exhumación. Con sólo internarse en las páginas de El Imparcial10 de Guatemala y El Nacional de Caracas, muy copiosa sería la cosecha. Ultimamente, Asturias colabora en Excélsior de México. ${ }^{11}$

En la sección hemerográfica ${ }^{12}$ he registrado una minima muestra de su labor periodística. Falta inventariar toda una serie de tempranas y efímeras publicaciones guatemaltecas y francesas que nos proporcionarían valiosas sorpresas. Pero ello requiere un tratamiento aparte. No obstante, hay que hacer hincapié en que, es de primordial importancia que los investigadores centren sus esfuerzos en el rescate de todos estos éscritos. Sin la disponibilidad de su obra, la más completa posible. ${ }^{13}$ los estudios relativos a la varia invención asturiana, tendrán siempre bases inseguras.

Ahora bien, un análisis minucioso de la presente bibliografía, nos permite adelantar algunos temas de la problemática asturiana que exigen una mayor exploración.

Asturias intenta una gran innovación y vivificación del idioma. $\mathrm{Ha}$ creado una nueva lengua, que él mismo describe como, "español que deja de ser español, siendo español". ${ }^{14}$ Pues bien, todo este complejo y deslumbrante universo idiomático, aún no ha sido sometido a un metódico, documentado y riguroso análisis de concordancias, aprovechando los modernos auxilios de las calculadoras electrónicas.

Los investigadores olvidan que, además de novelista, poeta y dramaturgo, Asturias reclama especial jerarquía como periodista. Este aspecto de su labor, no ha sido valorado aún. Su estudio, lógicamente, tiene que ser concomitante con el rescate de su obra periodística.

No se ha ahondado lo suficiente en el campo de las influencias sobre el novelista guatemalteco de Quevedo, Joyce, etc. Tampoco se ha valorado a Asturias en toda su dimensión como crítico literario. Menos aún se ha investigado, detenidamente, la función del paisaje guatemalteco en su obra.

Estas son tan sólo algunas sugerencias que emanan del escrutinio de la bibliografía. El estudioso atento, puede fácilmente advertir otros temas que exigen investigación.

10 Véase ficha núm. 447.

11 Véase mi Miguel Angel Asturias en México. México, Cle., 1969.

12 Véanse fichas núms. 111-312 y 401-405.

13 De especial interés sería la reimpresión de su tesis, Sociología guatemalteca; el problema social del indio. Guatemala, 1923. Hoy en día es casi imposible consultar este incunable del siglo xx. No sólo tiene atractivo por ser su primera obra, sino que reviste singular valor documental. En la vertiente sociopolitica del libro, abraza ya la postura de escritor comprometido. "Deja jurado" su empeño "en la resolución del problema indigena [que] lleva en sí, el afianzamiento de las libertades, la formación de la nacionalidad guatemalteca". Con el tiempo, cambiaría de opinión en lo relativo a los procedimientos [véase "Mes ancêstres mayas", Réalités 268, París, 1968, pp. 50-52]. Mas no sucede así con la idea esencial de la emancipación del indígena. En el aspecto formal se vislum. bra toda una voluntad de estilo. Su interés aumentatía si al volverse a publicar, llevara anotaciones del propio autor. [Véase también ficha núm. 1.]

14 Véase ficha núm. 775. 
El análisis pormenorizado de esta recopilación requiere un tratamiento especial que rebasa el límite de este prólogo somero.

Con todo, interesa aludir al prolífico número de encomios que han entrado en este repertorio. Hay que subrayar, para disipar posibles suspicacias, que han sido registrados con rigor, como cualquier otro asiento, sin ánimo de preferencia. Es verdad que mi admiración por la obra literaria de Miguel Angel Asturias impulsó este trabajo, pero también es cierto que, en el manejo del material recopilado, intenté obrar con la mayor objetividad posible.

Este anticipo bibliográfico responde a la urgencia de poner de inmediato a la disposición de los estudiosos, un adecuado repertorio de referencias.

Es de esperarse que coadyuve a plasmar una crítica menos contradictoria, menos arbitraria, a la par que más sólida, valedera y profunda. Confío en que permita el despliegue de renovadores enfoques, nuevas interpretaciones y novedosos acercamientos al maravilloso cosmos fabulesco de Miguel Angel Asturias.

Me place manifestar aquí mi aprecio a la gentil Sra. Blanca Mora y Araujo de Asturias por su primer "envión" orientador.

Agradezco de singular manera, el bondadoso suministro de datos del Dr. Alfredo A. Roggiano. Hago manifiesto mi agradecimiento: al Sr. Rodrigo Asturias por su providencial ayuda y hospitalidad, al Prof. Alfonso Enrique Barrientos por su gentileza al poner en mis manos, valiosos recortes de periódicos guatemaltecos, al "asturianista" alemán, Günter W. Lorenz, por sus preciados informes. Asimismo, hago patente mi reconocimiento a los profesores, Giuseppe Bellini, Ernesto Dethorey, Paul Alexandru Georgescu, Vera Kuteishchikova, Yuri Pevtsov, Stefan Pieczara y Emil Volek, por sus referencias, así como a otros estudiosos cuyos nombres se indican a lo largo de la bibliografía.

Muy en especial, quiero dejar constancia de gratitud a mi esposa Ana María, por su estímulo y paciencia al ayudarme a redactar y revisar el texto. Sin su colaboración, hubiera sido más ardua la tarea.

Los crrores, naturalmente, corren por mi cuenta. Agradezco de antemano el envío de rectificaciones e informes adicionales relativos a Asturias: ensayos, reseñas, tesis, etc., para incluirlos en mi libro en preparación.

Apartado Postal 32-079.

Pedro F. de Andrea

México 1, D. F. México. 



\section{A. OBRA DE MIGUEL ANGEL ASTURIAS}

\section{ENSAYOS}

1. Sociología guatemalteca. el problema social del indio. Tesis presentada a la junta directiva de la Facultad de Derecho, Notariado y Ciencias Políticas y Sociales, Universidad Nacional... por Miguel Angel Asturias, ex Delegado al Congreso Internacional de Estudiantes celebrado en la ciudad de México; Guatemala, Tipo. grafía Sánchez y de Guise, diciembre, 1923, 59 pp.

Su primer libro. Una rareza bibliográfica. Pocos han logrado consultarlo. De ahí que se suele indicar erróneamente el año 1922 como fecha de publicación. Reviste singular importancia no şólo pur ser libro primogénito, sino porque encierra un especial valor testimonial, precursor.

Para que el lector tenga una orientación del contenido transcribimos su tabla de inaterias.

EL PROBLEMA SOCIAL. DEI, INDIO

Capítulo I. Introducción: 1. El problema indigena. 2. Sociología guatemalteca. 3. Aspecto nacionalista del problema. 4. Este estudio.

Capítulo II. Sociografía indigena: 5. Cuestión histórica. 6. Epoca prehispánica. 7. Epoca colonial. 8. De la Independencia a nuestros días, 9. Resumen.

Capítulo II. Sociorganología: 10. El individuo. Cómo es un indio. 11. Territorio. 12. Propiedad de la tierra. 13. Producción. 14. Habitabilidad. 15. Su vida política. 16. Su vida civil. 17. Su vida religiosa. 18. Su vida privada. 19. La familia indigena.

Capítulo IV. La población: 20. Población guatemalteca. 21. Civilización indigena. 22. Civilización moderna. 23. Censos. 
Capítulo v. Sociopatia: 24. Fenómenos degenerativos. 25. Degeneración física. 26. Degeneraciốn psíquica. 27. Etiología.

CApítulo vI. Terapéutica social: 28. Terapéutica social. 29. Medios para retardar el mal. 30. Medios para destruir el mal. 31. Conclusiones.

2. La arquitectura de la vida nueva. Guatemala, Editores Goubaud y Cía., 1928.

Conferencias. Ofrece a sus compatriotas "un granero" de ideas encaminadas a fortalecer y alegrar su vida diaria. Agiles "consejos" de higiene mental y social.

3. Carta aérea a mis amigos de América. Buenos Aires, Casa impresora Francisco A. Colombo, 1952. $12 \mathrm{pp}$.

Suscrito en La Paz, Bolivia, oct. 1952. Elogio al pueblo boliviano "por la nacionalización de las minas".

4. Rumania; su nueva imagen. Xalapa, Universidad Veracruzana, 1964. 227 pp. 28 láminas.

Una nueva faceta de MAA: la de cronista. Pero aun como "pintor" de otro país aprovecha cualquier oportunidad para plantear su tema favorito: lo mítico indígena es ingrediente literario positivo en la creación americana de obras progresistas, revolucionarias. Véanse, pp. 103-104.

5. Latinoamérica y otros ensayos. Madrid, Guadiana de Publicaciones, S. A., 1968. 87 Pp.

Prólogo de Josué de Castro, pp. 7-9. Entrevista de Guillermo Medina, pp, 11-27. ¿Influyó o no influyó Valle-Inclán en Ia creación de MAA? "Han dicho que el estilo de El señor Presidente se parece al Tirano Banderas y que yo me inspiré en esta obra de don Ramón, al que yo leía en mi juventud con admiración. Pero El señor Presidente está escrito antes que Tirano Banderas", pp. 26-27. Con esta afirmación categórica de MAA, queda concluida una larga polémica.

\section{POESIA}

6. Rayito de estrella; fantomima. Paris, Imprimérie Française de l'Edition, 1929.

7. Emulo Lipolidón; fantomima. [Guatemala], Tipografía América, 1935 [25 pp.].

Dedicado a Alfonso Reyes, Rafael Alberti, Mariano Brull, Luis Cardoza y Aragón, Arturo Uslar Pietri, Francis de Miomandre, Alejo Carpentier, Georges Pillement, etc. Edición de 200 ejemplares, fuera de comercio. Suscrito en París, 1931-32.

8. Sonetos. Guatemala. Tipografía América, 1936 [edición no venal].

9. Alclasán; fantomina. Guatemala, Tipografía América, 1940 [12 pp.] [dedicada a Federico Garcia Lorca. Edición de 200 ejemplares fuera de comercio]. 
10. Con el rebén en los dientes. Guatemala, Lito. B. Zadik y Cía., 1942.

"Te canto, Francia!, junto a los altos hornos tropicales, donde el sudor corre por la piel como las lagartijas; te canto antes que tus muertos se levanten de filo en la batalla sonámbula de los que no están vencidos".

11. Anoche, 10 de marzo de 1543. Guatemala, Talleres tipográficos de Cordón, 1943 [19 pp.].

Impresión de 400 ejemplares para conmemorar el Cuarto Centenatio de la fundación de la ciudad de Guatemala. Edición numerada "con la cifra de cuatrocientos años, 1543-1943", reza el colofón.

12. Ejercicios poéticos en forma de soneto sobre temas de Horacio. Buenos Aires, Ediciones "Botella de Mar", 1951. 43 pp.

Dieciocho dibujos de L. Seoane. Plaquette que reúne 17 sonetos inspirados en tópicos y motivos del poeta latino.

13. Alto es el sur; canto a la Argentina. Buenos Aires [pero el pie de imprenta es de La Plata, Talleres Moreno, 1952].

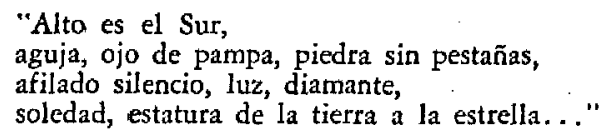

14. Bolivar; canto al liberiador. San Salvador, Ministerio de Cultura, 1955. $14 \mathrm{pp}$.

Dibujo de Camilo Minero. Hay también: edición mexicana, Horizonte, 1961 y edición guatemalteca, Landivar, 1966.

"Y es a todo pavor, cuchillo en mano, que se busca en las conchas coloniales la libertad del hombre, perla rara".

15. Nombre custodio e imagen pasajera. La Habana, Talleres de Ũcar, García, S. A., 1959. 13 pp. (Colección "Laura", 1).

Dibujo de Fayad Jamis. Consta de 300 ejemplares. Homenaje de la librería "La Tertulia" a MAA.

16. Clarivigilia primaveral. $1^{\text {a }}$ ed. Buenos Aires, Editorial Losada, S. A., 1965. 121 pp. (Poetas de ayer y de hoy).

Suscrito: París verano 1963; Sinaia (Rumania) invierno 1964; Venecia, Nápoles, Milán, Roma, Génova 1964; terminado en Génova el 13 julio de 1964.

$2^{\mathrm{a}}$ ed. 1967. Se considera su mejor obra poética. Interesa señalar que originalmente MAA redactó Clarivigilat... "en prosa, en forma de novela, pero insatisfecho del resultado... acudió a la poesía". Véase Bellini: "Miguel Angel Asturias en Italia".

17. Sonetos de Italia. Varese-Milán, Istituto Editoriale Cisalpino, 1965. $18 \mathrm{pp}$.

Presentación de Giuseppe Bellini. Edición de 300 ejemplares fuera de comercio, publicada por la Università Luigi Bocconi, Cattedra di letteratura Ispano-Americana. Nuestro ejemplar firmado por el autor es el número 91. Lleva una fotografía de Asturias tomada en Venecia. Contiene cuatro sonetos, "Otras ciudades, pero no Venecia", "Venecia la cautiva", "Los gatos de Venecia" y "Corpaccio". 


\section{NOVELAS, CUENTOS, LEYENDAS}

a. LEYENDAS DE GUATEMAI.A

18. Leyendas de Guatemala. $1^{\text {a }}$ ed. Madrid, Ediciones Oriente, 1930. 207 PP.

Se acabó de imprimir en la imprenta Argis el dia 18 abril de 1930. Sc ilustró con motivos ornamentales mayas. Suscrito, París 1925-1930. Contiene: Indice alfabético de modismos y frases alegóricas, pp. 163. 207.

19. Leyendas de Guatemala. 2a ed. Carta-prólogo de Paul Valéry, pp. 9-10, Buenos Aires, Ed. Pleamar, 1948. 197 pp.

Aumentada con "Brujos de la tormenta primaveral" y "Cuculcán". Carta de Paul Valéry a F. de Miomandre. Dibujos de Toño Salazar.

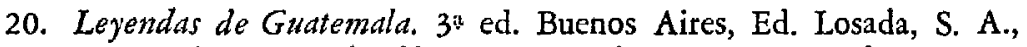
1957, 169 pp. (Colección Contempotánea, 112) [4. ed. 1967; 5: ed. 1968].

21. Leyendas de Guatemala. [Lima]. Editora Latinoamericana [1959], 191 pp. (Primer Festival del Libro Centroamericano, 3) [director, M. A. Asturias].

22. Leyendas. San Salvador, Departamento Editorial del Ministerio de Cultura, 1960. 64 pp. (Colección Caballito de Mar, 9) [en esta edición sólo se reproduce un fragmento].

23. Leyendas de Guatemala. Con una carta de Paul Valéry. Madrid, Aguilar, 1968. 470 pp. 23 láms. (Colección Crisol, 027).

b. EL SEÑOR PRESIDENTE

24. El señor Presidente. $1^{\text {a }}$ ed. México, Editorial Costa-Amic, 1946, $306+10 \mathrm{pp}$. de vocabulario [suscrito de la siguiente manera: Guatemala, dic. 1922; París, nov. 1925 y 8 dic. 1932].

25. El señor Presidente. $2^{3}$ ed. Buenos Aires, Editorial Losada, 1948. 276 pp. (Biblioteca Contemporánea, 221).

$3^{a}$ ed. 1952 de la misma editorial pero en la Colección "Novelistas de España y América"; $4^{n}$ ed. 1955; $5^{4}$ ed. 1959; 6" ed. 1964; $7^{n}$ ed. 1966; 8a ed. 1967; $9^{\mathrm{n}}$ ed. $1967 ; 10^{\mathrm{a}}$ ed. 1968.

26. El señor Presidente. La Habana. Editora Popular de Cuba y del Caribe [representante de la "Organización de los Festivales del Libro" y Ediciones "La Tertulia"]. s. f. [ca. 1959], 380 pP. [Biblioteca Básica de Cultura Cubana: Director, Alejo Carpentier].

c. HOMBRES DE MAIZ

27. Hombres de maiz. $1^{\text {a }}$ ed. Buenos Aires, Editorial Losada, S. A, 1949. 284 pp. (Novelistas de España y América) [suscrito en Guatemala, 1945; Buenos Aires, 1949. $2^{\mathrm{a}}$ ed. 1953; $3^{\mathrm{a}}$ ed. 1957; $4^{a}$ ed. $1966 ; 5^{a}$ ed. 1967$]$. 
ch. VIENTO FUERTE

28. Viento fuerte. $1^{\text {n }} \mathrm{ed}$. Guatemala, Editorial del Ministerio de Educación Pública, 1949. 224 pp.

29. Viento fuerte. $2^{\text {a }}$ ed. Buenos Aires, Editorial Losada, S. A., 1950. 205 pp. (Novelistas de Nuestra Epoca) [3 $3^{a}$ ed. 1955; $4^{a}$ ed. 1962; 5: ed. 1967].

d. EL PAPA VERDE

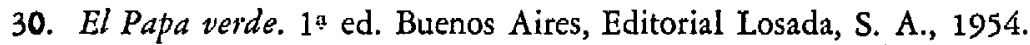
319 pp. (Novelistas de España y América).

Suscrito en Buenos Aires, 10 dic. 1952. Vocabulario, pp. 310-315. 29 ed. 1957; 3a ed. 1966; $4^{\mathrm{a}}$ ed. 1967.

e. WEEK-END EN GUATEMALA

31. Week-end en Guatemala. $1^{\text {a }}$ ed. ¿No sé las cosas que pasan?... ¡Mejor llamarlas novelas!... Buenos Aires, Editorial Goyanarte, 1956. 229 pP. [2" ed. 1958].

32. Week-end en Guatemala. La Habana, Imprenta Nacional de Cuba. 1960.

33. Week-end en Guatemala. Buenos Aires, Editorial Losada, S. A., 1967.

f. LOS OJOS DE LOS ENTERRADOS

34. Los ojos de los enterrados. $1^{\text {a }}$ ed. Buenos Aires, Editorial Losada, S. A., 1960. 480 pp. (Novelistas de Nuestra Epoca). Suscrito en Buenos Aires, 1952; Paris 1953, San Salvador 1954; Bue. nos Aires 1959. $2^{\mathrm{a}}$ ed. $1961 ; 3^{\mathrm{a}}$ ed. 1967 . Solapa de Marcel Brión.

g. EL ALHAJADITO

35. El albajadito. $1^{\text {a }}$ ed. Buenos Aires, Editorial Goyanarte, 1961. $141 \mathrm{pp}$.

36. El albajadito. $2^{n}$ ed. Buenos Aires, Editorial Losada, S. A., 1966. $160 \mathrm{Pp}$. (Biblioteca Clásica y Contemporánea, 317) [3 ed. 1968].

h. MUlatA DE TAL

37. Mulata de tal. $1^{\text {a }}$ ed. Buenos Aires, Editorial Losada, S. A., 1963. 284 pp. (Novelistas de Nuestra Epoca) [2a ed. 1967; $3^{a}$ ed. 1968].

i. EL ESPEJO DE LIDA SAL,

38. El espejo de Lida Sal. $1^{\text {a }}$ ed. México, Siglo Veintiuno Editores, S. A., 1967. 146 pp. (Colección: La Creación Literaria, Relatos y Leyendas) [2: ed. 1967]. 
j. EL MAL LADRON

39. El mal ladrón. Buenos Aires, Editorial Losada, S. A.,

En prensa. Saldrán en 1969 . ediciones simultáneas, en italiano y francés. Dato, cortesía de Miguel Angel Asturias Amado, hijo de MAA.

\section{TEATRO}

40. Soluna; comedia prodigiosa en dos jornadas y un final. Buenos Aires, Ediciones Losange, 1955. 77 pp. (Colección teatral, 26).

41. La audiencia de los confines; Crónica en tres andanzas. Buenos Aires, Editorial Ariadna, 1957. 78 pp. (Colección Coral 22).

"El autor se tomó la libertad de frasear con palabras del Obispo Las Casas, por tratarse de una obra de imaginación".

42. "Chantaje; tragicomedia en tres actos" [en MAA, Teatro. Buenos Aires, Losada, 1964].

43. "Dique seco; comedia en dos actos" [en MAA, Teatro. Buenos Aires, Losada, 1964].

44. "El Rey de la Altanería" [teatro, 1968?].

Juan Luis Meléndez menciona esta pieza. "También durante este festival Enrique Dávila conquistó métitos sobresalientes al dirigir "El Rcy de la Altaneria" de MAA con el Grupo Teatro de Medicina. Ver. J. L. Meléndez "El TAU y su ingente labor en pro del Teatro Universitalio", Revista de la Asociación de Estudiantes Universitarios de Guatemala, I-1 (Guatemala, jun., 1968), p. 47.

\section{ALGUNAS ANTOLOGIAS}

\section{a. ANTOLOGIAS DE OBRAS ASTURIANAS}

45. Torotumbo: La audiencia de los confines; Mensajes indios. Barcelona, Plaza y Janes, S. A., Editores, 1967. 201 Pp. (Prosistas de la lengua española).

Muestra antológica tealizada por el mismo autor. Contiene: nartación, teatro y poesía. Portada de R. Muntañola.

46. Antología de... Prólogo de P. Palomino, México, B. Costa-Amic, editor, 1968, xxxvıl +201 Pp. (Pensamiento de América, II serie, vol. 11).

Véase también Obras escogidas. 3 vols., Madrid, Aguilar, 19551968. Núms. 87,88 y 89.

b. ASTURIAS ANTOLOGO

47. Antología de la prosa rumana. Selección y traducción de Miguel Angel Asturias, Buenos Aires, Editorial Losada, 1967. 376 PP. (Biblioteca Clásica y Contemporánea, 338). 
48. Dario, Rubén: Páginas de... Selección y presentación de Miguel Angel Asturias, Buenos Aires, Editorial Universitaria de Buenos Aires, 1963. 103 pp. (Serie del Nuevo Mundo, 1).

Prólogo de MAA, pp. 5-11. "Un puente azul -escribe Asturias- tendido entre los mares más azules -el Caribe y el Mediterránto, los dos mares más azules y humanos-, es la poesía de Rubén... Pero $A z u l$, por qué... No pocas veces me lo he preguntado, iemeroso de que los eruditos salten de la penumbra de sus investigaciones, trayendo entre los dientes afilados, como un hueso, el Azur de Mallarmé... ¡Americanizar a Rubén Datio!, es lo que pedimos a los estudiosos, a los filólogos, a los eruditos, desde las páginas de esta antología, ame ricanizarlo... ¿Y qué son los frutos ya sazonados de Darío, sino pura, pura $\mathrm{y}$ auténtica poesía amcticana?".

49. Molina, Juan Ramón: Antología; verso y prosa. San Salvador, Ministerio de Cultura, Departamento Editorial, 1959. $238 \mathrm{pp}$.

Prólogo de MAA, pp. 9-32. "Juan Ramón, poeta gemelo de Rubén". También en Juan Ramón Molina: Sus mejores pảginas [Lima] Primer Festival del Libro Centroamericano, pp. 7-30.

50. Poesía precolombina. $1^{n}$ ed. Selección, introducción y notas de Miguel Angel Asturias, Buenos Aires, Compañía General Fabril Editora, 1960, 177 pp. (Colección Poetas) ["Introducción", PP.

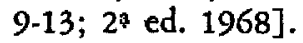

\section{ANTOLOGLAS GENERALES QUE CONTIENEN ESCRITOS DE ASTURIAS}

51. Anderson Imbert, Enrique y Eugenio Florit: Literatura bispanoamericana; Antologia e introducción bistórica. Nueva York, Holt, Rinehart and Winston, Inc., 1960. 780 pp. [MAA, pp. 703-706. "La leyenda de la Tatuana"].

52. Antología de la poesia centroamericana, tomo 1 [Lima, s. f.] 328 pp. (Primer Festival del Libro Centroamericano, 9) [MAA, Pp. 146-149, "Sonetos a los dicentes" y "¡Salve Guatemala!"].

53. Baeza Flores, Alberto: Las mejores poesias de amor centroamericanas. Barcelona, Editorial Bruguera, S. A. 1955. 123 pp. (Colección Laurel, 46).

MAA, pp. 85-86. "Invierno". Apunta Bacza Flores: "El molde es antiguo, sonoto, musical, dúctil, pero contiene una poesía de movidas imágenes $\mathrm{y}$ un corazón que sabe advertir las eternas novedades del amor $y$ del mundo".

54. Baeza Flores, Alberto: Antologia de la poesia bispanoamericana. Buenos Aires, Tirso, 1959. 303 PP. [MAA, PP. 151-152, "Invierno"].

55. Bellini, Giuseppe: La letteratura ispano-americana (II), Milán, La Goliardica, 1959. 222 pp. ["Fragmentos de El señor Presidente", en español, pp. 104-113].

56. Caillet-Bois, Julio: Antología de la poesia bispanoamericana. $2^{\text {a }}$ ed. Madrid, Aguilar, 1965. 2072 pp.

MAA, pp. 1291-1297. "Los indios bajan de Mixco", "Gozo de sílabas felices". "Nochebuena en América", "Sol de invierno". "Marimba tocada por indios" y "Meditación frente al Lago Titicaca". 
57. Cané, Luis: Poesias bellas y eternas; antología. Buenos Aires, Editorial Atlántida, S. A., 1960. 271 Pp. (Colección Oro de Cultura General, 148-149) [MAA, p. 244. "Rondel"].

58. Coluccio, Félix: Antología ibérica y americana del folklore. Buenos Aires, Guillermo Kraft Limitada, 1953. 320 pp. [MAA, PP. $173-$ 177, "Leyenda del Cadejo"].

59. Constenla, Julia: Crónicas de América. Prólogo y selección, Bucenos Aires, J. Alvarez, 1965. 124 pp. [Contiene "La Galla" de MAA].

60. Echeverría B., R. Amílcar: Antología de prosistas guatemaltecos; leyendas, tradición y novela. Guatemala, Imprenta Universitaria, 1957. 365 Pp. (Editorial Universitaria, 22).

MAA, pp. 99-116, 301-334. Contiene selecciones de Leyendas de Guatemala, El señor Presidente. Humbres de maiz y Viento fuerte. "El resucitador de nuestras figuras popol-vúhicas ya empolvadas, presentándolas, con nuevos brillos al salí de su troquel fantástico. Cumple lo que pedían los griegos al artista, que fuera en doble trilogía: poeta, bailarín $y$ visionario, para poder barruntar éxtasis, oráculos y máximas".

61. Echeverría, Amilcar: Cinco temas educativos on la poesia centroamericana. Guatemala, Ministerio de Educación Pública, 1960. 182 pp. (Biblioteca Guatemalteca de Cultura Popular, 39) [MAA, pp. 125-126. "Es el caso de hablar"].

62. Echeverria, Amílcar: Antología del cuento clásico centroamericano. Guatemala, Ministerio de Educación Pública, 1961 (Biblioteca Guatemalteca de Cultura Popular, 50) [MAA, pp. 47-57. "El Bueyón"].

63. Flores, Angel: Historia y antologia del cuento y la novela en Hispanoamérica. Nueva York, Las Americas Publishing Company, 1959. 696 pp. [MAA, Pp. 686-694. "Kinkajú"].

64. Flores, Angel: The Literature of Spanish America. (IV), Nueva York, Las Américas Publishing Company, 1967. 830 Pp. [MAA, pp. 97-119. "Leyenda de la Tatuana" y "Ocelotle 33"].

65. Garcini, Maria del Carmen y Eugenio Matus: Antologia del cuento bispanoamericano. La Habana, Editora del Ministerio de Educación, 1963. 239 pP. [MAA, pp. 100-109. "Ocelotle 33"'].

66. Gómez Benoit, Abelardo: Antologia contemporánea del cuento bispanoamericano. Introducción, selección y notas de... México, Instituto Latinoamericano de Vinculación Cultural, s. f. 266 pp. [MAA, pp. 83-104. "Ocelotle 33"].

67. Grupo Saker:ti: Poemas por la paz; Diez poetas. Guatemala, Ediciones Saker-ti, 1952 [contiene poemas de MAA]. 
68. Gutiérrez, Fernando: Poesía bispanoamericana. (II), Barcelona, Sayma, 1964 (Panoramas A-Z, 28) [MAA, Pp. 92-93. "Meditación frente al Lago Titicaca"].

69. Lamb, Ruth S.: Antología del cuento guatemalteco. México, 1959. [MAA, Pp. 54-65, "Ocelotle 33"].

70. Latino, Simón: Los cien mejores sonetos latinoamericanos. Selección y notas de... Buenos Aires, Editorial Nuestra América, 1963. $58 \mathrm{pp}$. (Cuadernillos de poesía, 10) [MAA, p. 49. "Soneto a María"].

71. Latino, Simón: Los cien mejores poemas latinoamericanos. Selección y notas de. . Buenos Aires, Editorial Nuestra América, 1963. $80 \mathrm{pp}$. (Cuadernillos de poesía, 28). [MAA, p. 78. "Creo en la libertad"].

72. Latino, Simón: Los mejores versos de amor. Selección y notas de... Buenos Aires, Editorial Nuestra América, 1963. 80 pp. (Cuadernillos de poesía, 33) [MAA, pp. 67-68. "Gozo de sílabas felices"].

73. Marsicovétere y Durán, Miguel: "Antología del cuento guatemalteco; selección y notas", Revista del Maestro, III:10 (Guatemala, jul.-sept. 1948), pP. 110-141 [MAA, pp. 113-117. "En la tiniebla del cañaveral"].

74. Orantes, Alfonso: "Cuentos de Guatemala". Selección y nota preliminar de..., Biblioteca Selecta II:13 (Panamá, ene. 1947), p. 54 [MAA].

75. Orlandi, Julio: Litieratura bispanoamericand. $3^{a}$ ed. Santiago de Chile, Editorial del Pacifico, S. A., 1966. 527 PP. [MAA, pp. 244254. "Cadáveres para la publicidad"].

76. Peralta, Jaime y Ulla Peterson: Diez cuentos de Hispanoamérica. Gotemburgo, Akademiförlaget-Gumperts, 1966. $10+115$ PP. [MAA, "El Bueyón"].

77. "Poesía de Guatemala", Escena, 26 (Guatemala, mar. 1957) [MAA, pp, 12-13].

78. Ribes, Francisco: Poesía de España y América. Selección y prólogo de... Madrid, Santillán, S. A. de Ediciones, 1964.88 pP. [MAA, p. 64. "Los indios bajan de Mixco"].

79. Sanz y Díaz, José: Antologia de cuentistas hispanoamericanos. Selección, prólogo, biografías y notas críticas por... Madrid, M. Aguilar, editor, 1946. 772 pP. (Colección Crisol, 152).

MAA, pp. 377-379. "El Hermano Pedro". "En Asturias -escribe el antologista - la naturaleza se anima en sus relatos; los árboles, los animales $y$ las aves revisten formas de mitológicas personalidades". 
80. Schultz de Mantovani, Fryda: Cuentos infantiles de América. Selección y prólogo de... Buenos Aires, Ediciones Culturales Argentinas, Ministerio de Educación y Justicia, 1961 [contiene cl cuento "Palomo Limón" de MAA].

81. Selser, Gregorio (ed.) : Antología; poemas para la batalla de Gnatemala. Buenos Aires, Editorial Alcándara, 1964. 199 PP. [MAA, pp. 119-121. "Salve, Guatemala!”].

82. Solórzano, Carlos: Teatro guatemalteco contemporáneo. Madrid, Aguilar, 1964 [MAA, Pp. 81-149. "Soluna"].

83. Valle, Rafael Heliodoro; Indice de la poesía centroamericana. Santiago, Chile, Ediciones Ercilla, 1941. 382 pp. (Biblioteca América).

MAA, pp. 311.318. "Antigua; Ciudad antigua", "Los indios bajan de Mixco", "Sol de invierno", "Gozo de sílabas felices", "Nosotros", "Signos" y "El amor".

\section{OBRAS DE CONJUNTO}

84. Poesia; sien de Alondra. $1^{\text {an }}$ ed. Buenos Aires, Argos, S. A., 1949. 253 pp. (Colección "Obras de Ficción").

"Flecha poética" de Alfonso Reyes, pp. 7-8. Caricatura por Toño Salazar. Recoge toda la producción poética de Miguel Angel Asturias, hasta aquella fecha. Abarca los años 1918 a 1948.

85. Teatro; Chantaje, Dique seco, Soluna y La audiencia de los confines. $1^{a}$ ed. Buenos Aires, Editorial Losada, S. A., 1964. 249 Pp. (Gran Teatro del Mundo)_[2" ed. 1967].

86. Obras escogidas. $1^{\mathrm{a}}$ ed., tomo I, Madrid, Aguilar, 1955, 1385 pP. (Colección Joya).

Prólogo de José Maria Souvirón. Contiene: Prosa; "Leyendas de Gua. temala", "El señor Presidente" y "Hombres de maiz". Poesia;" "Sien de Alondra", aumentada y "Ejercicios poéticos en forma de soneto sobre temas de Horacio". $2^{\mathrm{a}}$ ed. 1961; $3^{\mathrm{a}}$ ed. 1964.

87. Obras escogidas. $1^{\text {a }}$ ed., tomo II, México, Aguilar, 1961. 951 pp. (Colección Joya).

Contiene: "Viento fuerte", "El Papa verde", "Week-end en Guatemala". "Ocelotle 33", "La Galla", "El Bueyón", "Cadáveres para la publicidad", "Los Agrarios" y "Torotumbo", 2" ed. Madrid, 1968.

88. Obrtss escogidas. $1^{3}$ ed., tomo III, Madrid, Aguilar, 1966. 1380 PP. (Colección Joya).

Contiene: "Mulata de tal", "Los ojos de los enterrados" y "El alhajadito".

89. Obras completas. Prólogo de José María Souvirón, tomo I, Madrid, Aguilar, 1968. 1087 pp. (Biblioteca de Premios Nobel).

Contiene: Prosa; "Leyendas de Guatemala", "El señor Presidente" y "Hombres de maiz". Poesía; "Sien de Alondra" y "Ejercicios poéticos sobre temas de Horacio". $3^{\mathrm{n}}$ ed.; $1^{\mathrm{a}}$ en esta colección. 
90. Obras completas, tomo II, Madrid, Aguilar, 1968. 937 PP. (Biblioteca de Premios Nobel).

Contiene: "Viento fuerte", "El Papa verde", "Week-end en Guatemala", "Ocelotie 33", "La Galla", "El Bueyón", "Cadáveres para la publicidad", "Los Agrarios" y "Torotumbo". $2^{\mathrm{a}}$ ed.; $1^{\mathrm{a}}$ en esta co. lección.

91. Obras completas, tomo III, Madrid, Aguilar, 1968. $1108 \mathrm{pP}$. (Biblioteca de Premios Nobel).

Contiene: "Mulata de tal", "Los ojos de los enterrados" y "El alhajadito". 2a ed.; $1^{\text {a }}$ en esta colección. Distan mucho estas "obras" de ser "completas". Es de esperarse que se publiquen tomos adicionales que recojan: su tesis, El problema social del indio, de tan difícil consulta; por lo menos parte de los numerosos artículos y ensayos dispersos en periódicos y revistas; poemas inéditos y la "Autobiografia" de la cual ya se han publicado fragmentos en Bellini: La Narrativa di MAA. Milán, 1966.

\section{MISCELANEA}

92. [Acta], Acuerdo de fundar la Asociación de Periodistas de Guatemala, Revista A. P. G., 28 (Guatemala, abr. 1968), portada.

Se reproduce la proclama de la fundación de A.P.G. el día 16 abr. de 1947 en la cual aparece la firma de MAA como socio fundador.

93. [Asturias], Bellas Artes presenta: La audiencia de los confines, El adelantado de Dios, de Miguel Angel Asturias. Première Mundial [en el] Conservatorio Nacional. Programa (Guatemala, 13-21 sept. 1961), 4 pp.

Representación de su obra teatral en tres actos. Director: Luis Domingo. Asistente de Director: Rubén Morales Monroy. Como Fray Bartolomé de las Casas actuó: Manuel Lisandro Chávez. Publicidad y propaganda: Arqueles Morales.

94. "Autobiografia", obra inédita [G. Bellini en La Narrativa di $M A A$. Milán, 1966, adelanta varios trozos].

95. Bolivia; an Undiscovered Land. MAA en colaboración con Jean Manzon y F. Díez de Medina, Toronto-London, George G. Harrap, 1961 [hay también edición francesa, Neuchatcl, 1960].

96. (Disco) Voz viva de América Latina. Voz del autor, con cuaderno adjunto: texto de la grabación presentado por Augusto Monterroso. México, unam, 1967 (VVAl.LD No 79/80.33 1/3).

Contiene las siguientes selecciones tomadas de El señor Presidente: "En el portal del señor", "Cara de ángel" y "Todo el orbe cante".

97. (Disco) Archivo de la palabra. Voz del autor, presentación anónima, Buenos Aires, Antología Sonora, 1957 (331/3) Icontiene: "Alto es el Sur", "Bolívar", "Leyenda del tesoro" y "Del lugar florido"].

98. [Epistolario entre Alfonso Reyes y Miguel Angel Asturias]. Quince cartas que abarcan los años 1930-1959. Véase Alicia Reyes "Tikis": "Miguel Angel Asturias y Alfonso Reyes", Boletin Alfonsino, 
2 (Montevideo, 1967-1968), pp. 8-9. Curiosa la carta confeccionada por MAA que lleva un "Collage à la manière de Matisse".

99. Iconografía de Miguel Angel Asturias; Premio Nobel de Literatura 1967. Guatemala. Municipalidad de Guatemala, Sección de Relaciones Públicas, 1967. $8 \mathrm{pp}$. (Cuadernos Municipales, 1).

"Pequeño folleto que recoge parte de la iconografía" de MAA. Tiene carácter popular y reproduce lo fotografías en blanco y negro: 19241967.

100. "Molina, Juan Ramón; poeta gemelo de Rubén", "Prólogo" a Juan Ramón Molina, Antología; verso y prosa (San Salvador, 1959), pp. 9-32.

También en Molina; Sus mejores páginas [Lima, s.f.], pp, 7-30. (Primer Festival del Libro Centroamericano). Asimismo en Nueva Revista Cubana, I:3 (La Habana, oct.-dic., 1959) y en Guion Literario, IV:42 (San Salvador, jun. 1959).

101. "Poètes d'aujourd'hui". La Editorial Pierre Seghers tiene planeada una obra dedicada a MAA en su serie "Poètes d'aujourd'hui". Véase Bareiro Saguier: "La literatura latinoamericana en Francia", Mundo Nuevo, 30 (París, dic. 1968), p. 62.

102. "'Portadilla' a Adriano González León: Las bogueras más altas. Cuentos". (Buenos Aires, Editorial Goyanarte, 1959), Pp. 9-10. "Contraste - dice MAA- de paisaje estático y de un azogado movi. miento de cosas humanas, de donde extrae su secreto Adriano González León, dueño de una prosa colorida, ágil, quebrada en las palabras y no totalmente hecha, sino en vias de crecimiento para libros futuros'. Nota. González León acaba de recibir el importante "Premio Biblioteca Breve" con su novela País portátil.

103. 'Le roman latino-américain et la situation actuelle", Conferencias, Institut des Hautes Etudes de l'Amérique Latine (París, 30 nov. 7,14 y 21 dic. 1962).

104. "Presentación' de Rubén Darío: Páginas..." (Buenos Aires, Eudeba, 1963), PP. 5-11.

105. "'Prólogo' a La conjura de Xintum de E. Abreu Gómez" (San Salvador, Ministerio de Cultura, 1958), pp. 11-14.

106. "'Prólogo' a Poesía precolombina", Buenos Aires, 1960, pp. 9-13.

107. ' 'Prólogo' a Francisc Pacurariu: Introducere in literatura americii latine". (Bucarest, 1965), pp. 5-7.

108. [Televisión]. "El espejo de Lida Sal", Hablemos de libros (Buenos Aires, 15 nov. 1967).

Comentarios en el programa de televisión, Canal 13, Radio Excélsior (10 nov. 1967). Se presentó El espejo de Lida Sal acompañado de material gráfico. "Uno recorre... Guatemala, paisajes dormidos pais verde..." que trasciende a través de sus mitos...

109. "'Textos interpretativos' de MAA en español, Gálvez Suárez, In- 
dios de Guatemala" (Guatemala, Ed. B. Zadik \& Co. 1941), 12 pp. [reproducciones de 10 pinturas indigenas guatemaltecas].

110. Soluna.

Esta pieza ha sido filmada en cinta de corto metraje pot el director Marcos Madanés. Véase Novedades (México, 13 jul. 1968), p. 6.

\section{HEMEROGRAFIA EN ESPAÑOL DE ASTURIAS}

111. "Sursum Corda", El estudiante, 7 (Guatemala, 22 feb. 1920).

112. "Sábado de Gloria", El estudiante, 18 (Guatemala, 1 abr. 1920).

113. "Toque de Animas", Studium, I:8 (Guatemala, ene.-mar. 1922).

114. "Entrevista con Unamuno", El Imparcial (Guatemala, 24 nov. 1924).

115. "Las señoritas de la vecindad", Studium, III:14 (Guatemala, oct.nov. 1924).

116. "Entrevista con Blasco Ibáñez", El Imparcial (Guatemala, $1^{9}$ ene. 1925).

117. "José Ingenieros; su obra, sus opiniones y personalidad", Repertorio Americano, XI (San José, C. R. 1925), pp. $177-179$ [suscrito en París y tomado de El Imparcial de Guatemala].

118. "Pueblos nuevos y hombres viejos", Repertorio Americano, XII (San José, C. R. 1926), pp. 18-19.

Tomado de El Imparcial de Guatemala. Aboga MAA por una participación más activa de la juventud en el desarrollo del pais.

119. "Los premios literarios", El Imparcial (Guatemala, 21 ene. 1927).

120. "Ballets rusos", El Imparcial (Guatemala, 6 jul. 1927).

121. "Poesía china", El Imparcial (Guatemala, 10 ene. 1927).

122. "Indiscreciones anticlericales", El Imparcial (Guatemala, 5 feb. 1927).

123. "Suetonio Pimienta", El Imparcial (Guatemala, 9 feb. 1927).

124. "Flores y besos", El Imparcial (Guatemala, 10 jul. 1927).

125. "Escalera abajo", Revista de Avance, III (La Habana, 1928), p. 54.

126. "Gozo de sílabas felices", Repertorio Americano, XVI (San José, C. R. 1928), p. 7 [fechado en París, 1927].

127. "Antigua: ciudad antigua", Repertorio Americano, XVII (San José, C. R. 1928), p. 373. 
128. "La barba provisional", Revista de Avance, IV:32 (La Habana, 15 mar. 1929), pp. 68-74 [narración].

129. "Poemas", Repertorio Americano, XVIII (San Josế, C. R. 1929), p. 222.

Se incluyen las siguientes composiciones: "Retrato", "Confesión secre. ta" y "Mi pena tiene fitmo de azucena".

130. "Poemas", Repertorio Americano, XIX (San José, C. R. 1929). p. 320 [suscrito en París, 1929; "Muestrario", "Foro" y "Suma minima"].

131. "Noche buena de América", Repertorio Americano, XIX (San José, C. R. 1929), p. 382 [fechado en París, 1929].

132. "Idearium de España", Repertorio Americano, XIX (San José, C. R. 1929), pp. 165-166, 229-230 [suscrito en Burgos, El Escorial y Madrid, 1929].

133. "Cardoza y Aragón", El Imparcial (Guatemala, 14 sept. 1929).

134. "Teatro, 1930", El Imparcial (Guatemala, 17 oct. 1929).

135. "De la tierra a la luna", El Imparcial (Guatemala, 23 oct. 1929).

136. "Cleopatra", El Imparcial (Guatemala, 18 oct. 1929).

137. "El uso de razón", El Imparcial (Guatemala, 21 oct. 1929).

138. "La disciplina", El Imparcial (Guatemala, 26 oct. 1929).

139. "El mono velludo de Eugene O'Neill", El Imparcial (Guatemala, 30 oct. 1929).

140. "Viajeros de viaje", El Imparcial (Guatemala, 9 nov. 1929).

141. "Santa Clotilde", El Imparcial (Guatemala, 16 nov. 1929).

142. "Instrucción pública", El Imparcial (Guatemala, 22 nov. 1929).

143. "Mentalidad nueva", El Imparcial (Guatemala, 27 nov. 1929).

144. "Tristan Bernard", El Imparcial (Guatemala, 25 nov. 1929).

145. "Gleba", El Imparcial (Guatemala, 29 nov. 1929).

146. "Guatemala en Sevilla", El Imparcial (Guatemala, 6 dic. 1929).

147. "Populismo", El Imparcial (Guatemala, 7 dic. 1929).

148. "Femina doble", El Imparcial (Guatemala, 11 dic. 1929).

149. "Femina triunfa", El Imparcial (Guatemala, 10 dic. 1929).

150. "Millonarios", El Imparcial (Guatemala, 14 dic. 1929).

151. "Nuevas formas políticas", El Imparcial (Guatemala, 21 dic. 1929). 
152. "María", Repertorio Americano, XXI (San José, C. R. 1930), p. 304 [fechado en París, 1930].

153. "Rayito de estrella", Repertorio Americano, XX (San José, C. R. 1930), p. 200 [poema].

154. "Rayito de estrella", La Pajarita de Papel, III:19-21 (Tegucigalpa, oct.-dic. 1951), p. 137.

155. "Rayito de estrella", Cultura, 46 (San Salvador, oct.-dic. 1967), pp. 56-60.

156. "Leyenda de la Tatuana", Repertorio Americano, XXII (San José, C. R. 1931), pp. 271 y 276 [narración tomada de Leyendas de Guatemala].

157. "Leyenda de la Tatuana", suplemento especia! en homenaje a MAA del diario El Gráfico (Guatemala, 11 nov. 1967), pp. 3 y 15.

158. "Leyenda de la Tatuana", Horizonte, XIII:87-88 (Guatemala, nov.-dic. 1967), p. 8.

159. "Leyenda de la Tatuana", Diario de Centroamérica, Supl. de Arte y Literatura, V:231 (Guatemala, 9 dic. 1967), pp. 1-7.

160. "Poro", El Universal Ilustrado, XV:746 (México, 27 ag. 1931), p. 41 [poema].

161. "Cosas lejanas; El Conde Herman Keyserling en el teatro de la Princesa", Repertorio Americano, XXII (San José, C. R. 1931), Pp. 49 y 63.

Suscrito en Madrid, 1930. Consideraciones relativas a una conferencia de Keyserling en la cual, el filósofo diserta sobre las diferencias entre las culturas norte $\mathrm{y}$ sudamericanas.

162. "En la jaula de la torre Eiffel; Landívar", Repertorio Americano, XXIV (San José, C. R. 1932), p. 304.

163. "Andrés Eloy Blanco", El Imparcial (Guatemala, 14 may. 1933).

164. "El Pireo", Repertorio Americano, XXVI (San José, C. R. 1933), p. 48 [fechado en el Pirco, 1930].

165. "Leyendas del Sombretón", Repertorio Amevicano, XXVI (San José, C. R. 1933), pp. 43-44.

166. "Oscar Mirón Alvarez y su poesía", Revisła de Educación (Guatemala, ag.-sept. 1939), pp. 262-264.

167. "Poemas inéditos", Letras de México, 11:14 (México, 15 feb. 1940 ), p. 3.

Siete poemas suscritos en Guatemala en 1939. Un dibujo de Asturias por Toño Salazar. "Poema", "Padre nuestro", "Amada tropical", "Isla feliz", "Pozo", "Ropa interior" e "Inviemo". 
168. "Gaspar Ilom", Revista de Guatemala, II:2 (Guatemala, oct.dic. 1945), Pp. 31-47.

169. "Reseña a Ulises de James Joyce (Buenos Aires, Rueda, 1945)", Suma bibliográfica, I:1 (México, abr. 1946), pp. 17-18.

"Libro magistral... endiabladamente caprichoso en el juego de síla. bas y palabras para la interpretación del subconsciente... de fuera hacia adentro de las realidades de un día, pasmosamente múltiples", apunta MAA. Valiosa reseña ya que Joyce es uno de sus autores fa: voritos.

170. "El escritor frente al espejo; León Felipe", Suma bibliográfica, I:1 (México, abr. 1946), pp. 11-12. MAA subraya el tenaz empeño de León Felipe en la búsqueda de la perfección poética.

171. "México, 1946. El escritor frente al espejo; León Felipe", La Hora Dominical, I:1017 (Guatemala, 29 oct. 1967), p. 36 [reproducción de la reseña anterior].

172. "Maximón; divinidad de agua dulce", Revista de Guatemala, IV: 4 (Guatemala, abr.-jun. 1946), pp. 18-26.

173. "El libro del mes: Santiago en América", Suma bibliográfica, I:2 (México, may. 1946), pp. 9-10 [reseña del libro de Rafael Heliodoro Valle].

174. 'El libro del mes: Santiago en América", La Hora Dominical, I:1, 017 (Guatemala, 29 oct. 1967), p. 37 [reproducción de la misma reseña].

175. "El libro del mes: La Hora Dominical", V:811 (Guatemala, 15 dic. 1963), pp. 11-12.

176. "Los brujos de la tormenta primaveral", Cuademos Americanos, V:4 (México, jul.-ag. 1946), pp. 228-241.

Describe - MAA- la Semana Santa en el pueblo guatemalteco de San. tiago Atitlán [natración].

177. "Maximón: divinidad de agua dulce", Terres latines (México, verano 1946), Pp. 25-36.

178. "El señor Presidente", Repertorio Americano, XXX:6 (San José, C. R., mar. 1950), p. 6 [MAA explica cómo desarrolla su novelística].

179. "Rafael Landivar; poeta americano", Universidad de San Carlos, XXI (Guatemala, oct.-dic. 1950), pp. 17-31.

Landívar "se adelantó casi dos siglos a los poetas que ahora están libertando la literatura americana de los amarres europeos, y por eso debe considerársele como uno de los abanderados de los tiempos de hoy", escribe MAA.

180. "Meditaciones del pie descalzo", Sexto continente, 7-8 (Buenos Aires, nov. dic. 1951), p. 70 [poema]. 
181. "Meditaciones del pie descalzo", Revista Nacional de Cultura, 116 (Caracas, may.-jun. 1956), pp. 104-109.

182. "Meditaciones del pie descalzo", Bayoán, 25 (Río Piedras, P. R., jul.-sep. 1967).

183. "Meditaciones del pie descalzo", Esparavel, 10 (Bogotá, may. 1968), p. 1 [fragmento].

184. "Bacchum in remotis Carmina Rupibus", Libros de boy, 7 (Buenos Aires, nov. 1951), p. 444 [de "Ejercicios poéticos en forma de soneto sobre temas de Horacio"].

185. "Carta aérea a mis amigos de América", Repertorio Americano (San José, C. R., feb. 1953), p. 37.

186. "Poemas", Poesía de América, II:2 (México, jul.-ag. 1953), pp. 31-37. ["Nombre custodio", "Alto es el Sur" y "Autoquiromancia"].

187. "Rosa de los manjares", El Nacional (Caracas, 13 may. 1954).

188. "La biblia de los indios quichés o biblia de América", El Nacional (Caracas, 9 ag. 1954).

189. "Escritor y desterrado", Aurona, 2 (Santiago de Chile, dic. 1954), pp. 62-65.

190. "¡Americanos todos!...", Ficción, 1 (Buenos Aires, may.jun. 1956), pp. 54-77 [narración suscrita en Buenos Aires, 1955].

191. "Naique Bueyón Cuyque", El Popular (México, 14 jul. 1955) [cuento].

192. "Barba Jacob; El hechizado", La Nación (Buenos Aires, 15 mar. 1956).

Asturias apunta peculiaridades de Barba Jacob: "Ilora por la imperfección del verso, con el dolor del poeta-niño que no encuentra cómo decir lo que quiere. Por fin se consuela. Una pequeña chispa ha surgido en su mente. Chispa que se le hace luz, luminaria, incendio".

193. "Barba Jacob, El hechizado", Brecha, I:10 (San José, C. R., jun. 1957), pp. 9-10.

194. "Porfitio Barba Jacob", Versión, V:1 (Mendoza, Arg., otoño 1958), pp. 32-36.

".. Sílaba a sílaba acariciaba el verso. Palabras sin aristas, redondas y sensuales. Encadenamientos sonoros en que las voces se ordenaban en nuevos sonidos, sorprendentes sonidos, al ligarse entre ellas... El nos inicia en lo que es la poesia, esencialmente".

195. "Leyenda del Cadejo", Nicaragua indigena (Managua, jul.-dic. 1956), pp. 45.48.

196. "La leyenda del Cadejo", Brecba, I:9 (San José, C. R., may. 1957), pp. 24-25. 
197. "Un mundo feliz", El Nacional (Caracas, 20 sep. 1956).

198. "Señor del agua", El Nacional (Caracas, 20 sep. 1956).

199. "Retrato", Cordillera, X:2 (La Paz, Bolivia, sep.-oct. 1956), p. 28.

"Había los ojos oscuros, de vino los labios en la cara pálida, suave el continente, más suave que el fino coloquio del viento, la nube y el ave".

200. "Idolas negras", El Nacional (Caracas, 8 nov. 1956) [poema].

201. "Réquiem literario: Pablo Rojas Paz y su último cuento 'El caballo del ciego" ". Ficción, 4 (Buenos Aires, nov.-dic. 1956), Pp. 77.79.

En este réquiem, MAA entreteje aspectos del cuento de Rojas $P_{a z}$ con su muerte.

202. "Un pintor argentino: Ramón Gómez Cornet", El Naciond (Caracas, 22 nov. 1956).

203. "Isaac J. Pardo: Esta tierra de gracia", Ficción, 4 (Buenos Aires, nov.-dic. 1956), Pp. 149-150.

Reseña. Esta imagen de Venezuela en el siglo XvI "es la obra de un erudito en lenguaje de cuento".

204. "Vedetismo", El Nacional (Caracas, 21 mar. 1957).

205. "Letras americanas: Abreu Gómez, La conjura de Xinum, Fábula guerrera", Ficción, 6 (Buenos Aires, mar.-abr. 1957), pp. 115-117.

Reseña. Comenta MAA " $\mathrm{La}$ gran literatura americana ha sido siempre testimonio de nuestras luchas. La literatura indígena, oral y escrita; el alegar de los españoles, empezando por Bernal;... tal y como ahora, en forma ejemplar, lo realiza Ermilo Abreu Gómez".

206. "'Prólogo' a Abreu Gómez, La conjura de Xinum", Guión literario, III:35 (San Salvador, nov. 1958), p. 8 [transcripción].

207. "Gertrude Stein; escritora del reino musical", El Nacional (Caracas, 9 may. 1957).

208. "Se fabrican novelas", El Nacional (Caracas, 20 may. 1957).

Al llegar a París MAA toma "el pulso a la novela". Sorprendido se da cuenta que es un "producto sintético", fabricado por las editoriales con base en premios literarios, "perfectamente comercializados".

209. "Se fabrican novelas", Negro sobre blanco, 8 (Buenos Aires, nov. 1958), PP. 78-79.

"La verdad que si soy novelista, pero 'no hago novelas', no las 'fabrico', las tengo adentro, y las escribo sencillamente, sin prisa, sin idea de que van a publicarse, de que van a ser leidas, premiadas. $Y$ he aquí acaso la diferencia posible entre lo que ahora se fabrica, como novela, en Europa, producto de fuera para adentro, y de lo que hacemos los escritores americanos, sacamos las novelas de nuestro ser, de nuestra sangre, de nuestras raíces". 
210. "Se fabrican novelas", Diario de Centroamérica, Supl. de Arte y Literatura, V:231 (Guatemala, 9 dic. 1967), p. 6 [reproducción de este revelador ensayo].

211. "Letras americanas; poesía en disco", Ficción, 7 (Buenos Aires, may.-jun. 1957), pp. 134-135.

"Este reencuentro con las comunicaciones orales de pensamientos, sentimientos y estados de ánimo, en el disco, tiene... amplios alcances... Allí está escrita, en el libro, y allí estấ hablada en el disco. El poeta tiene ya los dos vehículos. El formal y el trascendente... Los discos de nuestros poetas se escucharán no sólo en los salones, sería lo menos importante, sino en los mitines y en las reuniones de casas, en las plazas $y$ en las escuelas, en los talletes..."

212. "Gabriela Mistral", Ficción, 8 (Buenos Aires, jul.-ag. 1957), pp. 49-50.

"La primera vez que la vi, fue en Guatemala. Surcábamcs juntos el más maravilloso lago del mundo, a dos mil metros, el Lago de Atitlán. Ella dijo: 'Estoy pensando en los indios a los que deben devolverles sus tierras... en todos nuestros países...' No le inquictaba la belleza del panorama, le inquietaban los indios, el hombre, la vida humana", afirma MAA hermanándola con su propio sentir social.

Un dato curioso. En su tesis de grado -El problema social del indio-, publicada en el lejano 1923, MAA sólo cita tres o cuatro autoridades en sociología indígena y a una sola escritora: Gabriela Mistral.

213. "Gabriela Mistral", El Naciontl (Caracas, 1 ag. 1957), p. 3. Sección literaria.

"La tiqueza poética de Gabriela Mistral, bajo la cáscara de sus versos, es por entero americana. ¿Dónde nació esta voz? En el aula sencilla de la escuela rural, junto al niño campesino, en el trabajo silencioso de Chile... No dejó de estar en su América".

214. "Guatemala", El Popular (Montevideo, 1958) [poema].

215. "Guatemala", Revista conservadora del pensamiento centroamericano, XLIX:49 (Managua, oct. 1964), p. 68.

216. "Rafael Alberti: poeta y pintor", El Nacional (Caracas, 27 feb. 1958).

217. "Letras americanas: La bibliografía de nuestra América", Ficción, 14 (Buenos Aires, jul.-ag. 1958), pp. 112-113.

Le duele a MAA, que la producción editorial latinoamericana, tan rica en su conjunto, se divida por naciones, restándole valor. Ya que en el fondo el idioma es uno, Astutias reclama una publicación o centro totalizador que "presente la bibliografía americana en un solo cuerpo, que abarque todo el continente de habla hispana".

218. "Kinkayú", Cuadernos Americanos, XVII:100 (México, jul.-oct. 1958), pp. 528-536 [leyenda].

219. "El espejo de Lida Sal", Ficción, 17 (Buenos Aires, ene.-feb. 1959), pp. 24-39.

Narración que posteriormente será incluida en su libro publicado en México, Espejo de Lida Sal, Siglo XXI Editores, S. A. 
220. "El espejo de Lida Sal", Revista de la Universidad de México, XXII:2 (México, oct. 1967), Pp. 14-16.

221. "Relaciones, semejanzas, influencias de la literatura rusa y la literatura latinoamericana", La Universidad, LXXXIV:1-2 (San Salvador, ene.-jun, 1959), Pp. 325-330.

222. "Juan Ramón Molina, poeta gemelo de Rubén", Nueva Revista Cubana, I:3 (La Habana, oct.-dic. 1959), Pp. $42-59$.

"Rubén Datio y Juan Ramón Molina son... parte de esa geografía caprichosa, poetas gemelos saturados del sentido poético de la tierra centroamericana, donde la naturaleza toma la metáfora y la hace carne de reflejo".

223. "Juan Ramón Molina, poeta gemelo de Rubén", Guión Literario, IV:42 (San Salvador, jun. 1959), Pp. 3 y 5-6 [fragmentos].

224. "Miguel Hernández; destino y poesía", La Nación (Buenos Aires, 18 jun. 1959).

225. "Raúl Schurjin", El Nacional (Caracas, 9 jul. 1959).

226. "Tecún - Umán", Nivel, 7 (México, 25 jul. 1959), p. 6 [poema].

227. "Tecún - Umán", Revista Ariel, X:202 (Tegucigalpa, sep. 1968), Pp. 25-26.

228. "Poema a Tecún-Umán", Diario de Centroamérica, LXXXVII: 26136 (Guatemala, 9 dic. 1967), p. 4.

229. "Una revolución es un evangelio", Nueva Revista Cubana, II:1 (La Habana, ene.-mar. 1960), pp. 18-19.

Referencia a la Revolución Cubana, "Un nuevo despertar de América".

230. "Filmando con las hélices; Miniaturas de Ilobasco"; Guión literario, V:50 (San Salvador, feb. 1960), p. 7.

Comentarios sobre "la pequeña población de El Salvador, donde se fabrican los más diminutos pastores de barro que conocemos... sólo se consigue admirar toda su perfección con ayuda de una lupa".

231. "En la tiniebla del cañaveral", Brecba (San José, C. R., jul. 1960), pp. 23-25 [cuento].

232. "Fernando de Elizalde; El camino", Ficción, 26 (Buenos Aires, jul.-ag. 1960), pp. 123-126 [rescña].

233. "Las pildoras tranquilizadoras y la política de la evasión", Marcha, 1024 (Montevideo, 2 sep. 1960), p. 7.

234. "Enrique Amorim; 1900-1960", Fictión, 28 (Buenos Aires, nov.dic. 1960), pp. 54-55.

Evoca a su amigo uruguayo, al recibir la noticia de su muerte. "Una personalidad... un temperamento vigoroso, extraordinario... gran conversador, no sólo personalmente, sino a través de sus cartas". $Y$ añade MAA - con un toque irónico-, que ésta es una actividad generosa pe- 
ro "huérfana, por decir así, ya que los que escriben cartas experimen. tan la orfandad de la no respuesta, dado que los escritores hispanoparlantes, son sumamente perezosos y jamás contestan".

235. "El gran lengua", Cuadernos Americanos, XX:2 (México, mar.abr. 1961), pp. 200-204 [poesía].

236. "Habla el Gran Lengua", Cuadernos Americanos, XXI:6 (México, nov.-dic, 1962), pp. 219-222 [poesía].

237. "Miguel Otero Silva, Oficina $N^{\circ} 1^{\prime}$, La Nación (Buenos Aires, 19 may. 1961) [reseña].

238. "Si ya no hay hadas", Ovaciones, 52 (México, 23 dic. 1962), p. 3. Soneto dedicado a su nieto Sandino. Suscrito en París, 24 jul. 1962. Escribe MAA:

\footnotetext{
“Qué hadas mecerán, nieto, tu cuna?

Si ya no hay hadas, manos espaciales

la mecerán en vuelos siderales".

.......................
}

239. "Nietecito amigo", Ovaciones, 61 (México, 24 feb. 1963), p. 4. Otro soneto inspirado por su nieto:

"¡Que jamás te abandone la grandeza

de corazón, mi nietecito amigo

de tu corazoncito que no pesa

más que un grano de sucño luz o trigo!".

240. [Sobre la poesía], Guión literario, X:109 (San Salvador, ene. 1965), p. 6.

Se recoge su definición. Ver entrevista con Trigueros de León: $\mathrm{Cul}$. tura, I (San Salvador, ene.-feb., 1955).

241. "Habla en Génova". La Hora Dominical, I:892 (Guatemala, 27 jun. 1965), pp. 41-42.

Texto del discurso pronunciado en Génova, Italia, como presidente de la primera sesión del "Columbianum". Exhorta a los participantes de este coloquio "que encaren los problemas latinoamericanos... solicitando la colaboración de todos los sectores de actividad y pensa. miento" para superar "en la unidad las diferencias y conflictos actuales".

242. "Federico García Lorca y los putrefactos", Hoy en la Cultura, 22 (Buenos Aires, ag. 1965), p. 20 [protesta MAA contra la difusión comercial de un García Lorca tergiversado. El verdadero Federico fue un gran poeta civil].

243. "Federico García Lorca y los putrefactos", El Día (México, 19 sep. 1966), p. 9.

244. "Artesania oculta", Cultara Universitaria, IXXXIX (Caracas, oct.-dic. 1965), pp. 126-128 [poema. Fragmento de Clarivigilia primaveral].

245. "Artesanias ocultas", Cultura, 46 (San Salvador, oct.-dic. 1967), pp. 53-55. 
246. "Sonetos de Venecia", Integración, I:1 (San Salvador, oct.-dic. 1965), pp. 56-58.

Reproducción de lcs poemas que forman el libro, Sonetos de Italia. Milán, 1965.

247. "Poesias", La Hora Dominical, 1070 (Guatemala, 17 nov. 1968), p. 11.

"Otras ciudades", "Venecia la cautiva", "Carpaccio" y "Los gatos de Venecia"; o sea los cuatro poemas del libto Sonetos de Italta. Véase ficha anterior.

248. "Habla en la sombra", Gaceta de Cuba, V:48-49 (La Habana, ene.feb. 1966), PP. 48-49 [narración. Fragmento].

249. "Escritores latinoamericanos; su voz y su denuncia", Excélsior (México, 27 abr. 1966), p. 7A.

Conmina - MAA - a los literatos latinoamericanos a identificarse con la obra de Elio Vittorini que "fue lección viva del 'compromiso' con el hombre, que es a lo que aspiramos - al menos yo- los tscritores de nuestra América".

250. "Respuesta al homenaje", Lateinamerika (Rostock, Primavera 1966), pp. 53-58.

Es el texto ligetamente abreviado de su contestación al tributo que le rindió el Instituto Latinoamericano de la Universidad de Rostock. "Este homenaje tiene para mí el amplio significado de homenaje a todos los escritores de nuestra América que hablan por sus pueblos, que combaten con su pluma, que de sus libros hacen trincheras y de su verbo el dardo que no cesa de acusar, pues acusa siempre".

251. "Letanías del desterrado", Margen, 1 (París, oct.-nov. 1966), Pp. 102-103 [poesía. Suscrita en Roma, Invierno 1966].

252. "El vocero de la tribu", Ercilla, XXXIII:1690 (Santiago, 1967), p. 29.

253. "En medio del camino de la muerte", La Torre, Universidad de Puerto Rico, XV:55-56 (México, ene.-jun. 1967), pp. 273-284. "Haciendo de memorialista, en este año del centenario del nacimiento de Rubén Darío, evoco la imagen que conservo de aquel ídolo que mis diez y seis años sorptendieron una tarde en el 'Hotel Imperial' de la ciudad de Guatemala".

254. "Credo", El Despertador Americano, I:2 (México, may. 1967), p. 28 [poesía].

255. "La locura de fray Bartolomé", Zone Franca, III:42 (Caracas, feb. 1967), pp. 12-13.

Fray Bartolomé de las Casas era un "loco como Jesús, loco como el Quijote, loco como Bolívar", escribe Asturias.

256. "Los dos Quijotes; La locura de fray Bartolomé"; Excélsior (México, 18 jul. 1968), p. 7A [véase cédula anterior].

257. "Leyenda de las tablillas que cantan", Papeles, 4 (Caracas, may.jul. 1967). 
258. "Poesía", La Hora Dominical, I:1017 (Guatemala, 29 oct. 1967), p. 35.

Contiene: "El poeta invita a su amor", "Adoración de los pastores", "El amor", "Madrigal" y "Luna y niño".

259. "Panorama de la literatura latinoamericana", Jornada Poética, 12 (Arequipa, oct.-nov. 1967), PP. 1-3.

Trata principalmente de la influencia de los grandes escritores rusos en Latinoamérica. "Primero indirectamente, a través de la literatura universal, luego en forma directa, cuando se empieza a traducir al español los poemas de Pushkin, las novelas de Tolstoi, Turguenev y Dostoievski".

260. "Mágicos - Hombres- Mágicos", Culturn, 46 (San Salvador, oct.-dic. 1967), Pp. 49-55 [poema].

261. "Leyendas", Cultura, 46 (San Salvador, oct.-dic. 1967), pp. 30-36 [reproducción de dos leyendas, la de "El Cadejo" y la de "La Tatuana"].

262. "El alhajadito", Cultura, 46 (San Salvador, oct.-dic. 1967), pp. 62-70 [transcripción de algunas páginas].

263. "Leyenda de la campana difunta", Gacela literaria (Santiago, Chile, 5 nov. 1967).

264. "Cuatro poemas", "México en la Cultura", supl. Novedades, 972 (México, 9 nov. 1967), pp. 3 y 6.

265. "Cantar en medio de un mundo de imágenes que ya de por sí son estampas 'inigualables', 'Pórtico' de El espejo de Lida Sal', El Imparcial (Guatemala, 9 dic. 1967), pp. 17 y 23.

266. "Póttico", Diario de Centroamérica, Supl. de Avte y Literatura, $\mathrm{V}: 231$ (Guatemala, 9 dic. 1967), p. 2.

267. "'Pórtico' de El espejo de Lida Sal", Guatemala en Marcha, I:15 (Guatemala, 19 dic. 1967) [otra transcripción].

268. "Antigua y el Hermano Pedro en Leyendas de Guatemala", El Imparcial (Guatemala, 9 dic. 1967), pp. 17 y 23.

269. "Los cazadores celestes", El Imparcial (Guatemala, 9 dic. 1967), p. 17.

Tomado de Clarivigilia primaveral;

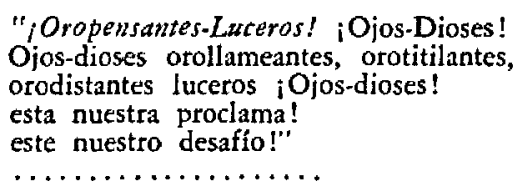

270. "Juan Hormiguero", Revista A. P. G. 27 (Guatemala, dic. 1967), pp. 33-34 [fechado en París, 1967. Cuento]. 
271. "Un cuento de su último libro; 'Juan Hormiguero"", El Impatcial (Guatemala, 9 dic. 1967), pp. 17 y 24 [cuento tomado de El espejo de Lida Sal. Véase asiento anterior].

272. "El primer capítulo de Mulata de tal. Brujo bragueta le vende su mujer al diablo de hojas de maíz; La prosa que canta en Miguel Angel Asturias", Diario de Centroamérica, LXXXVII:26136 (Guatemala, 9 dic. 1967), p. 7.

273. "Conferencias pronunciadas en la Academia de Suecia", Diario de Centroamérica (Guatemala, 26 dic. 1967), p. 1.

Analiza: los antecedentes de la literatura latinoamericana, las letras coloniales, el Romanticismo, el siglo $\mathrm{xx}$ y las características de la no. vela actual.

274. "Conferencias de...", El Maestro, 13 (Guatemala, ene.-mar. 1968), pp. 107-114.

275. "Entro a la Familia Nobel como el menos indicado entre todos los que podian haber sido escogidos", Diario El Gráfico (Guatemala, 12 dic. 1967), pp. 13 y 31.

-76. "Discurso de Miguel Angel Asturias", Impacto (Guatemala, 14 dic. 1967), pp. 13 y 16.

Discurso de MAA pronunciado ante el rey Gustavo Adolfo de Suecia, Véase también el Diario de Centro América (14 dic. 1967).

277. "Bolívar", El Maestro, 13 (Guatemala, ene.-mar. 1968), PP. 104106 [poema. Reproducción].

278. "Rubén Darío; poeta civil", Guatemala en Marcha, I:7 (Guatemala, 24 oct. 1967), p. 9 ["Rubén Darío fue eso, un gran poeta civil... un combatiente por su América"].

279. "El señor Presidente como mito", Studi di letteratura ispanoamericana (Milán, Istituto Editoriale Cisalpino [1967]), PP. 7-17.

Sobretiro sin fecha. Enfoque sobre su novela desde el punto de vista literario-politico-mítico. Resulta, pues, clave y cifra para el mejor entendimiento de su obra. "Nace El: señor Presidente, hablado no escrito... Y esto es importante subrayarlo. Fue deletreado. Era la época del renacer de la palabra, como medio de expresión y de acción mágica. Ciertas palabras. Ciertos sonidos. Hasta producir el encantamiento, el estado hipnótico, el trance..." Y termina MAA, ocupándose de "la atmósfera de El señor Presidente, el omnipresente, el mito, el todopoderoso, no solamente como expresión política, esto viene a ser secundario, sino como manifestación de una fuerza primítiva y como supervivencia, en el mundo actual, de esos resabios de las socjedades más arcaicas".

280. "El señor Presidente", La Hora Dominical, I:1017 (Guatemala, 29 oct. 1967), p. 30 [unas páginas de este libro].

281. "El señor Presidente", Culiura, 46 (San Salvador, oct.-dic. 1967), pp. $43-47$ [se reproduce un fragmento, cap. V]. 
282. "Poemas inéditos", Revista A. P. G. 27 (Guatemala, dic. 1967), p. 53.

Envio especial de maA para la Revista A.P.G. Suscritos en París, 20 de noviembre de 1967. Tres poemas: "A-B-C-Dia", "Alguien que se deshace" y "Sembrador de hombres".

A-B-C-Dia...

"Un día y otro dia y otro dia...

¿Qué osadía no vivir sólo un dia!

¿Qué rebeldia vivit en la baldía

existencia de un día y otro día!"

283. "Poemas", La Pájara Pinta, III:27 (San Salvador, mar. 1968), pp. 2-3.

"Bolívar". "Soledad frente al mar", "Dios de las palomas de la ausencia", "Credo", "Nocturno del entonces sin entonces" y "Mar y rosa".

284. "Mensaje de hombre a hombre; coexistencia poética", Excélsior (México, 15 ene. 1968), P. 7A.

Propone "una coexistencia poética entre poetas, traductores y lectores".

285. "Las novelas son los fíos... : El señor Presidente como fábula", Excélsior (México, 29 ene. 1968), pP. 7A y 20A.

286. "Credo", El Maestro, 13 (Guatemala, ene.-mar. 1968), p. 103 [poema. Suscrito en Caracas, 1955].

287. "Los brujos de la tormenta primaveral", La Pájara Pinta, III:27 (San Salvador, mar. 1968), Pp. 5-6.

288. "Mensaje internacional", Imagen, 21 (Caracas, 15-30 mar. 1968), p. 7 [sobre el teatro como puente de entendimiento internacional].

289. "Babel de babeles; el robot, nuevo seṇor", Excélsior (México, 29 mar. 1968), p. 7A.

Ensayo sobre la dicotomia de nuestros tiempos: el vivir del hombre dividido entre lo primitivo "conviviendo a favor de los dialectos, dragones aparecidos... y el robot, nuevo señor que viene a nuestro encuentro con la bandera de las ciencias electrónicas, el idioma de las siglas, la lengua cifrada y la publicidad".

290. "Tal y como somos; América, fábula de fábulas", Excélsior (México, 5 abr. 1968), pp. 7 y 8.

291. "La vida como gozo total; en medio del camino de la muerte", Excélsior (México, 19 abr. 1968), pp. 7A y 8A [concepto de la muerte en Rubén Darío].

292. "Texto del discurso de Miguel Angel Asturias en Estocolmo al recibir el Premio Nobel...", Boletin de la Comunidad Latinoamericana de Escritores, 1 (México, may. 1968), pp. 10-11.

293. "Desencanto; las grandes vacaciones", Excélsior (México, 13 may. 1968), p. 7A. 
294. "El sieteoficios del año 2000; arte y utilidad de ser eficaz", Excélsior (México, 24 may. 1968), p. 7A.

295. "La nueva mitologia; los 'Ersatz'", Excélsior (México, 21 jun. 1968), p. 7A.

296. "Crítica orientadora; nacer del arte nuevo", Excélsior (México, 28 jun. 1968), p. 7A.

Un llamado para que la crítica nos oriente en esta babsel que es el nacer del arte nuevo. "Situación angustiosa. Asistir al espectáculo y no participar, quedar fuera por falta de una preparación adecuada, a partir de la premisa absurda de que todo lo que es nuevo no es sino moda, improvisación, tomadura de pelo".

297. "Venta de cerebros; problemas del subdesarrollo", Excélsior (México, 8 jul. 1968), P. 7A.

298. "Adelante la deshumanización; la ciencia barrió con todo", Excélsior (México, 2 ag. 1968), p. 7A.

299. "Cuando la calle grita; el cartel, pintura que habla", Excélsior (México, 8 ag. 1968), Pp. 7A y 8A.

300. "De sueño y barro; arte de los mayas de Guatemala", Excélsior (México, 29 ag. 1968), pp. 7A y 8A.

301. "Mảs allá de la ficción; en busca del 'significado'", Excélsior (México, 5 sep. 1968), p. 7A.

302. "La angustia como literatura; política-ficción", Excélsior (México, 19 sep. 1968), pp. 7A y 8 A.

303. "El hombre en su cubil; 'ciudades satélites'", Excélsior (México, 3 oct. 1968), P. 7A.

304. "Arqueología americana; 'el robo como norma" ", Excélsior (México, 10 oct. 1968), p. $7 \mathrm{~A}$.

305. "Alimento de quimeras; "la penetrante ciencia-ficción" ", Excélsior (México, 15 nov. 1968), p. 7A.

306. "Móviles o estábiles; 'el espacio animado"", Excélsior (México, 3 dic. 1968), p. 7A.

307. "Caracterología del chofer; 'test' del semáforo", Excélsior (México, 10 dic. 1968), p. 7A.

308. "Compañera, madre, esposa...; ' la participación de la mujer" ", Excélsior (México, 24 dic. 1968), p. 7A.

309. "Museos dinámicos; crear ambiente, no exponer objetos", Excélsior (México, 31 díc. 1968), p. 7A.

310. "Cirugía siquiátrica;- complejos de fealdad", Excélsior (México, 15 ene. 1969), P. 7A. 
311. "América campesina; Gabriela Mistral", Excélsior (México, 30 ene. 1969), p. $7 \mathrm{~A}$.

Gabriela Mistral... veía venir esa otra literatura, el verso y la prosa invadidas por la realidad americana, el dolor del pueblo en el canto, la protesta del oprimido en la estrofa, el grito del que ve perdida su patria, en la novela.

312. "Debilidad de literatos; retrato de una vedette", Excélsior (México, 15 feb. 1969), p. $7 \mathrm{~A}$.

\section{B. TRADUCCIONES}

\section{TRADUCCIONES DE OBRAS ASTURIANAS}

a. POESIA

313. Messages Indiens. Traducción de Claude Couffon, París, Seghers, 1958. (Collection "Autour du Monde") [antología poética].

314. Autoquiromancia. Compilación de Vlastimil Marsicek y Alena Novohradská, Praga, Mladá fronta, 1961 [pequeña antologia. Versión checa].

315. Parla il Gran Lengua. Traducción de Giuseppe Bellini, Parma, Guanda, 1965. 139 pp. (Colección "Piccola Fenice", 23). $2^{\text {a }}$ ed. aumentada, 1968. Prólogo de Giuseppe Bellini, pp. 11-23. Antología poética.

316. Clarivigilia primaveral - Claireveillée de printemps. Traducción de René-L-F. Durand, París, Gallimard, 1966. 144 pp. (Collection "Poésie Monde Entier") [edición bilingüe].

317. Varlig Klarvaka. Traducción de Artur Lundkvist y Marina Torres, Estocolmo, Fibs Lyrikklubb, 1967, 101 Pp. [versión sueca de Clarivigilia primaveral].

318. Clarivigilia primaveral. Traducción al italiano de Amos Segala, Milán, Lerici [en preparación].

319. Sonetos de Tierra Santa. Traducción al hebreo de Moshé Lazar, Jerusalem, Universidad Hebrea, Departamento de Estudios Españoles y Latinoamericanos, 1968 [plaquette].

b. LEYENDAS DE GUATEMALA

320. Légendes du Guatémala. $1^{\text {a }}$ ed. Traducción de Francis de Miomandre. Carta-prólogo de Paul Valéry, Marseille, Les Cahiers du Sud, 1932. $140 \mathrm{pp}$. Ilus. con dibujos mayas y aztecas.

Premio Sylla Monsegur. $2^{\mathrm{a}}$ ed. Gallimard, 1953, $256 \mathrm{pp}$. En esta im. presión se han añadido "Les sourciers de l'orage..." y "Cuculcán".

321. Legendem aus Guatemala. Traducción de Fritz Vogelgsang. Wiesbaden Insel, 1960 [versión alemana]. 
322. Leyendas de Guatemala. Traducción de Stefan Pieczara [versión polonesa. En preparación].

c. EL SEÑOR PRESIDENTE

323. Monsieur le Président. Traducción de Georges Pillement, Francisca García e Yves Malartic, París, Bellenand, 1952. [2 ed. Pa. rís, Le Club Français du Livre, 1953. Premio Internacional del Club del Libro Francés].

324. Presidenten. Traducción de Karin Alin. Estocolmo, Tidens Förlag, 1956. 280 pp. Prólogo de Artur Lundkvist [versión sueca, $2^{\text {a }}$ ed. 1965].

325. Der Herr Präsidenten. Traducción de Jacob Bachmann, Genf Verlag Helmut Kossodo, 1957. $2^{\text {n }}$ ed. Hamburgo, 1962 [versión alemana].

326. O senbor presidente. Traducción al portugués por Antonieta Gó-

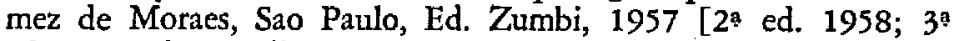
ed. Río, Ed. Brasiliense 1957].

327. L'uomo della Provvidenza. Traducción de Elena Mancuso, Milán, G. Feltrinelli, 1958. 346 pp.

Posteriormente se publicó con el título de $I l$ signor Presidente, 1967 [versión italiana de El señor Presidente.]

328. Sen'or Prezident; Roman. Traducción de M. Bylinkina y N. Trauberg, Moscú, Goslitizdat, 1959. 255 p. [versión rusa, con una introducción de L. Ospovat].

329. The President. Traducción de Frances Partridge, Londres, V. Gollancz, 1963 [versión inglesa].

330. El señor Presidente. Traducción de Frances Partridge, portada por Everett Aison, Nueva York, Atheneum Press, 1964. 287 pp.

331. Domnul Presedinte. Traducción por Paul Alexandru Georgescu, Bucarest, Biblioteca pentru toti, 1964 [versión rumana. Prólogo de Paul Alexandru Georgescu. Dato, cortesía del traductor].

332. El señor Presidente. Traducción al islandés, Reijkhavik, Mal og Menning [1964-5?] [dato, Negro sobre blanco, 33-34 (Buenos Aires, sept.-oct. 1964), p. 14].

333. Praesidenten. Traducción de Kirsten Schottländer. Copenhague, Forlaget Fremad, 1966 [versión danesa].

334. El senyor President. Traducción de Ramón Folch i Comarasa. Andorra la Vella, Edit. Andorra, 1968. 330 pp. (Colección Meritxell, 3) [versión catalana].

335. Nyai tong thong. Hanoi, Editorial Nha Xuat Van Hoc, 1964 [traducción vietnamesa]. 
336. El señor Presidente. Editorial Svoboda, Praga [versión checa].

337. El señor Presidente.

Hay traducción japonesa... Pero aún no he logrado verla ni obtener ficha correspondiente.

ch. HOMBRES DE MAIZ

338. Hommes de maïs. Traducción de Francis de Miomandre, París, Edition André Martell, 1953 [versión francesa].

339. Hommes de maīs. Traducción de Francis de Miomandre, París, Editions Albin Michel, 1967. $303 \mathrm{pp}$.

340. Die Maismänner. 'Traducción de Rodolfo Selke, Hamburgo, Eugen Claassen Verlag, 1956 [versión alemana].

341. Majsmänniskor. Traducción de Karin Alin, Estocolmo, Tidens Förlag, 1961. 365 pp. [versión sueca. Prefacio de Artur Lundkvist].

342. De doem van de maïs. Traducción de J. A. van Praag, Amsterdam-Amberes, wereld-Bibliotheek, 1962 [versión neerlandesa].

343. Uomini di mais. Traducción de Cesco Vian, Milán, Rizzoli, 1967 [versión italiana].

344. Hombres de maíz.

Editorial Svoboda, Praga [versión checa. En preparación].

345. Hombres de maiz.

Traducción de Stefan Pieczara [Versión polonesa. En preparación].

d. VIENTO FUERTE

346. L'Ouragan. Traducción de Georges Pillement, París, Editions Gallimard, 1955. $288 \mathrm{pp}$. (La Croix du Sud) [versión francesa].

347. Ypatab. Belgrado, Edit. Hoant, 1958 [versión yugoeslava].

348. Stormvind. Traducción de Karin Alin. Estocolmo, Tidens Förlag, 1965. 231 pp. [versión sueca].

349. Vento forie. Traducción de Cesco Vian, Milán, Rizzoli, 1966 [versión italiana].

350. The Cyclone. Traducción de D. Flakoll y C. Alegría, Londres, Owen, 1967 [versión inglesa].

351. Sturm. Traducción de Lene Klein, Neuwied und Berlín, Hermann -Luchterhand Verlag, 1967. 246 pp. [versión alemana].

352. Strong wind. Traducción de Gregory Rabassa, Nueva York, Delacorte, 1969. 242 pp. [versión inglesa].

353. Syklonen. Traducción de Axel S. Seeberg, Oslo, Tiden Norsk Förlag, 1968. 183 pp. [versión noruega]. 


\section{e. EL PAPA VERDE}

354. Le Pape vert. Traducción de Francis de Miomandre, París, Editions Albin Michel, 1956. 396 pp. [versión francesa].

355. Il Papa verde. Traducción de Attilio Dabini, Roma, Editori Riuniti, 1959. 310 pp. [versión italiana].

356. Zelenyi papa; roman. Traducción de M. Bylinkina, Moscú, Izdatel stvo Khudozhestvennoi literatury, 1964. 340 pP. [versión rusa. Prólogo de I. U. Pevtsov].

357. Gröna paven. Traducción de Karin Alin, Estocolmo, Tidens Förlag, 1966. 320 pp. [versión sueca].

358. El Papa verde. Bratislava, Ed. Slovensky Spisovatíl, 1967 [versión checa].

359. Der grïne Papst. Traducción de Lene Klein, Neuwied y Berlín, Hermann Luchterhand Verlag, 1966. 416 pp. [versión alemana].

360. El Papa verde.

Será publicado en inglés por Seymour Lawtence Incorporated en 1970, según carta de esta editorial.

f. WEEK-END EN GUATEMALA

361. Uik-end v Gvatemale; Vsconi byli amerikantsami. Rasskazy, Moscú, Pravda, 1958. 64 pp. [versión rusa. Prólogo de I. U. Dashkevich].

362. Week-end au Guatemala. Traducción de Georges Pillement. París, Editions Albin Michel, 1959. 287 pp. [versión francesa].

363. Uike-end v Gvatemale; rasskazy, Moscú, Izdatel'stvo inostrannoi literatury, 1961. 238 pp. [versión rusa. Prólogo de I. U. Pevtsov].

364. Week-end in Guatemala. Traducción de Lene Klein, Ostberlin, Volk und Welt Verlag, 1962 [versión alemana].

365. Vikend $v$ Guatemale. Traducción de Zdenek Hampejs y Marcela Svobodova, Praga, Ed. Literature Politica, 1962 [versión checa. Nota de Z. Hampejs].

366. Week-end en Guatemala. Pekin, Editorial Literaria del Pueblo, 1963 [versión china].

367. Week-end in Guatemala. Traducción de Giuseppe Bellini, Milán, Nuova Accademia, 1964. $360 \mathrm{pp}$. [versión italiana].

368. Tutti americani. Traducción de Giuseppe Bellini, Milán, Nuova Accademia, 1965.

Primera parte de la $2^{\mathrm{a}}$ ed. de Week-end en Guatemala, publicada en dos tomos. 
369. Cadaveri per la pubblicità. Traducción de Giuseppe Bellini, Milán, Nuova Accademia, 1965.

Segunda parte de la 2 ed. de Week-end en Guatemala, publicada en dos tomos.

370. Week-end i Guatemala. Traducción de Karin Alin, Estocolmo, Prisma, 1965 [versión sueca].

g. LOS OJOS DE LOS ENTERRADOS

371. Les yeux des enterrés. Traducción de Marie Castelan, París, Editions Albin Michal, 1962. 584 Pp. [versión francesa].

372. De begravdas ögon. Traducción de Karin Alin, Estocolmo, Tidens Förlag, 1968 [versión sueca].

373. Gli occhi che non si chiudono. Traducción de Cesco Vian, Milán, Rizzoli, 1968 [versión italiana].

374. Los ojos de los enterrados. Traducción de Yuri Dashkevich, Moscú, Ed. "Progreso", 1966 [prefacio de Jacobo Arbens].

375. Los ojos de los enterrados.

Se publicará en la República Democrática Alemana durante 1969 pot la Editorial Volk und Welt/Kultur und Fortschritt [véase Revista Puente, 3 (Dresden, 1968), p. 3 ].

376. Los ojos de los enterrados.

Será publicado en inglés por Seymour Lawrence Incorporated, en 1970, según carta de esta editorial.

h. EL ALHAJADITO

377. La flaque du mendiant. Traducción de Dominique Eluard y Alaide Foppa, París, Editions Albin Michel, 1966. 204 pp. [versión francesa].

378. La pozza del mendico. Traducción de E. Mancuso, Roma, Veutro, 1966 [versión italiana].

i. MULATA DE TAL

379. Une certaine mulâtresse. Traducción de Claude Couffon. París, Editions Albin Michel, 1965. 341 pp. [versión francesa].

380. Mulata de tal. Traducción de Waldemar Kabus, Genf y Hamburgo, Verlag Helmut Kossodo, 1965. 316 pp. [versión alemana].

381. Mulatta senza nome. Traducción de Cesco Vian, Milán, Mondadori, 1967 [versión italiana].

382. Mulata. Traducción de Gregory Rabassa, Nueva York, Delacorte Press, 1967. $307 \mathrm{pp}$. [versión inglesa].

383. Mulata. Traducción de Gregory.Rabassa. $2^{\mathrm{a}}$ ed. Nueva York: Dell, 1968. 
384. Mulattkvinnan. Traducción de Annika Ernstsson, Estocolmo, Tiden Förlag, 1968 [versión sueca].

j. JUAN GIRADOR

385. Juan Girador. París. Centre de Recherches de l'Institut d'Études Hispaniques, 1964. 27.pP. [cuento].

k. TOROTUMBO

386. Torotumbo. Traducción de R. L. F. Durand, París, Editions Seghers, 1966. 129 pp. (Collection "Hors serie") [cuento].

1. EL ESPEJO DE LIDA SAL

387. Le Miroir de Lida Sal. Traducción de Claude Couffon. París, Editions Albin Michel, 1967. 303 pp. [versión francesa].

m. EL BASTARDO

388. El bastardo.

La revista Inostrannaia literatura, anuncia que publicará en breve esta novela en ruso. Véase, Vera Kuteischikova, Literatura Soviéticd, 8 (Moscú, 1968), p. 168.

n. TEATRO

389. Solwna. Traducción de Jean y André Camp, París, Le Seuil, 1969. 126 pp. (Collection "Théâtre").

\section{ASTURIAS TRADUCTOR}

390. Los dioses, los béroes y los bombres de Guatemala antigua o el Libro del Consejo Popal Vub de los indios quiché. Traducción de la versión francesa del profesor Georges Raynaud por Miguel An. gel Asturias y J. M. González de Mendoza, París, Editorial ParísAmérica, 1927, XIVIII + 147 PP.

391. Los dioses, los béroes y los bombres de Guatemala antigua: Ana. les de los Xabil de los indios cakcbiqueles. Traducción de la versión francesa inédita, del profesor Georges Raynaud por Miguel Angel Asturias y J. M. González de Mendoza. París, Editorial París-América, 1928.

392. El libro del Consejo. Traducción y notas de Georges Raynaud, J. M. González de Mendoza y Miguel Angel Asturias, prólogo de Francisco Monterde, México, Ediciones de la Universidad Nacional Autónoma, 1939, 1964, XIV +223 Pp. (Biblioteca del Estudiante Universitario, 1):

393. Anales de los Xabil. Traducción y notas de Georges Raynaud, Miguel Angel Asturias y J. M. González de Mendoza, prólogo 
dc Francisco Monterde, México, Ediciones de la Universidad Nacional Autónoma, 1946, XIX +211 pp. (Biblioteca del Estudiante Universitario, 61).

394. Sartre, Jean Paul: Kean Nekrasof. Adaptación de la obra de Alejandro Dumas, traducción de Miguel Angel Asturias y Maria Martínez Sierra, Buenos Aires, Losada, 1957.

395. Bhattachacharya, Bhabani: El que cabalga un tigre... Traducción de Miguel Angel Asturias y Blanca de Asturias, Buenos Aires, Editorial Goyanarte, 1958.

396. Sartre, Jean Paul: Los secuestrados de Altona. Pieza en 5 actos. Traducción de Miguel Angel Asturias y Blanca de Asturias, Buenos Aires, Losada, 1961.

397. Simón, Claude: La bierba (novela). Traducción de Miguel Angel Asturias y Blanca de Asturias, Buenos Aires, Compañía General Fabril Editora, 1961. 187 pp.

398. Robbe-Grillet, Alain: En el laberinto. Traducción de Miguel Angel Asturias y Blanca de Asturias, Buenos Aires, Losada, 1962. $134 \mathrm{pp}$.

399. Sadoveanu, Mihael: Historias para ser contadas. Traducción de Miguel Angel Asturias y Blanca de Asturias, Buenos Aires, Editorial Losada, 1964. 271 Pp.

400. Antologia de la prosa rumana. Selección y traducción de Miguel Angel Asturias y Blanca de Asturias. Buenos Aires, Editorial Losada, 1967. $376 \mathrm{pp}$.

\section{HEMEROGRAFIA DE ASTURIAS EN TRADUCCION}

401. "Leyenda de la Tatuana", View, III:3 (oct. 1943), pp. $89-90$ [traducción al inglés por H. R. Hays].

402. "Mother if some winter's evening", Américas, II:7 (Washington, jul. 1950), pp. 37-38 [traducción de "Madre, si en invierno..."].

403. "Narodnoe tvorchestvo indeitsev Maiia", $V$ Zasbcbitu mirc, 17 (Moscú, 17 oct. 1952), pp. 70-74 ["El arte nacional de los indigenas mayas"].

404. "La barbe provisoire", Les Temps Modernes, X:107 (París, nov. 1954), pp. 637-649 [cuento. Traducción de Georges Pillement].

405. "El realismo tiene futuro", Komsomolskaya pravda (Moscú, ag. 1957). 
406. : "El pacto de amistad entre los escritores y la juventud", Literaturnaja gaceta (Moscú, 3 ag. 1957).

407. "Moscú en nuestro corazón", Pravda (Moscủ, 13 ag. 1957) [impresiones del VI Festival Mundial de la Juventud].

408. "Povod dla rasgovora", Literatmnaya gaceta (Moscú, 13 ag. 1957) ["Es el caso de hablar". Poesía. Traducción de O. Savich].

409. "Bugai; Rasskaz", Ogoniek, XXXV:48 (Moscú, nov. 1957), pp. 23-24 ["El Bueyón". Cuento].

410. "Vse oni byli amerikantsami; Rasskaz, Inostrannaia literaturd, 12 (Moscá, dic. 1957), pp. 61-78 ["Todos eran americanos". Cuento].

411. "Russkaia literatura v stranaj latinskoi Ameriki", Kultura i Zhizn, II:3 (Moscú, 1958), pp. 46-49.

"La literatura rusa en Latinoamérica". MAA menciona a Tolstoi, Dostoievski, Chejov, etc.

412. "Dlia hramads'koi dumky; Opovidannia", Vsesvit, II:10 (Moscú, oct. 1959), Pp. 93-102 ["En pro de la opinión pública". Cuento].

413. "Ocelotle 33", La literatura y la vida (Moscú, 1, 2, 5 jul. 1960).

414. "Ego Zelenoe Sviateishestvo; roman", Inostrannaia literatura, 12 (Moscú, dic. 1960), pp. 26-121.

Traducción al ruso de El Papa verde, novela. Edición especial de esta revista.

415. [Dos cuentos tomados de Week-end en Guatemala], Svétová lite. vatura, 4 (Praga, 1960), pp. 44-99 [traducción y presentación de Zdnek Hampl].

416. "Sobre la Armenia Soviética", La Armenia literaria, 6 (Erevan, Armenia, 1960), p. 94.

417. "Nuestro ejemplo: Cuba", Izvestia (Moscú, 2 ene. 1961).

418. "Uik-end v Gvatemale", Zbensbcbiny mira, 7 (Moscú, 1962), pp. 32-34 [fragmento].

419. "Los escritores juraton", La cultura y la vida, 9 (Moscú, 1962), p. 7 [trata del Congreso por el Desarme y la Paz].

420. "Four selections from Miguel Angel Asturias", Odyssey Review, III:1 (Nueva York, mar. 1963), pp. 62-135.

Traducción al inglés por Hardie St. Martin de "El Cadejo", "2 capítulos de El señor Presidente" y "un fragmento de Hombres de matz". Interesa notar que en esta revista se solian incluir varios autores de cada pais. Sin embargo, en esta ocasion, "The editors have chosen to represent Guatemala with Asturias only because, besides being Guatemala's greatest modern author, he is considered one of the outstand. ing writers of all Latin America who is practically unknown in the United States". 
421. "Originalità e caratteristiche del romanzo latino-americano", Terzo Programma, 4 (Roma, 1964), pp. 51-74.

422. "La novela latinoamericana es testimonio de nuestro tiempo", Inostramaia literaturn, 9 (Moscú, 1966), pp. 191-199.

423. "Las Ieyendas del volcán y de la tatuana", Slovenske pobl'ady, 11 (Praga, 1966), pp. 105-111 [traducción de Tania Kotuliaková].

424. "Con la cara a la tempestad", Gaceta Literaria (Moscú, 21 jul. 1966).

Discurso de maA en Moscá con motivo del otorgamiento del Premio Lenin.

425. "Une mise au point de l'Ambassadeur", Le Monde (París, 31 dic. 1966).

Desmiente MAA la noticia publicada en Le Monde (23-XII-66) acerca de que Guatemala estaba a punto de declarar la guerra a Cuba.

426. "La Gal'ia; Rasskaz", Ogoniek, XXXV:33 (Moscú, ag. 1957), pp. 27-30. ["La Galla"].

427. "Un poème inédit; 'moi et eux" ", Les Lettres Françatses (París, 25 oct. 1967), p. 6 [poema inédito. Traducido al francés por Claude Couffon].

428. "Un texte inédit; 'L'écrivain-metis'", Le Monde (París, 25 nct. 1967 ), p. I [suscrito en Paris, octubre 1967. Traducido al francés pot R. Sorin].

429. "El señor Presidente", Kiernnki (Varsovia, Polonia, 12 dic. 1967) [fragmento de la novela traducido al polonés por Dolatowka K.].

430. "Testigos oculares y acusadores", Inostrannaia Literattra, 7 (Moscú, 1967-1968), p. 37 [a propósito de la novela latinoamericana].

431. "C'est le moment de parler", Journal de Genève, 107 (París, 8 may. 1968 ), p. 11.

Traducción al francés del poema, "Es el caso de hablar". No se indica nombre del traductor.

432. "Le sange doré des dieux circule dans l'art guatémaltèque", Le Figaro Littéraitre (Paris, 24-30 junio, 1968), PP. $45-46$ [con motivo de la Exposición de arte maya en París].

433. "Mes ancêtres mayas", Réalités, 268 (París, may. 1968), pp. 50-52.

Afirma MAA "Chez nous l'archéologie n'est pas une science éloignée du quotidien, comme en Egypte par example. Elle touche la vie du pays. C'est dans l'archéologie que nous trouvons le commencement de notre histoire, la confirmation que nous sommes les successeurs d'une grande culture qui remonte au-delà de l'ère chrétienne". 
434. "Poesia", Humboldt, 33 (Hamburgo, 1968), pp. 16-17.

Traducción al alemán de los siguientes poemas: "Aquí donde la ori11a", "Duermo del mismo lado de tu nombre", "No altere tu candor de ala y aroma", "Te apago con los ojos..."' y "Creo en la libertad, Madre de América". Tradujeron: Curt Meyer Clason $\ngtr$ Wolfgang Promies,

435. "Legenden von teufelskut", Süddeutscbe Zeitung (Munich, 21-22 oct. 1968) [traducción al alemán por Fritz Vogelgsant].

\section{TRADUCCIONES DE ASTURIAS INCLUIDAS EN ANTOLOGIAS}

436. Arendt, Erich: Sïdamerikaniscbe Freibeitsdicbtungen. T'taducción de... Berlín, Este, Volk und Welt, 1951 [MAA, p. 44. Poesía].

437. Fal sbivye monety; Sbornik rasskazov [Moneda falsa: Colección de cuentos], Moscú, Profizdat, 1959 [MAA, p. 61. "El Bueyón"].

438. Fitts, Dudley: Anibology of Contemporary Latin-American Poetry. Norfolk, Conn., A New Directions Book, 1947. 677 pp.

MAA, pp. 156-167, "Los indios bajan de Mixco", con traducciön al inglés de D.D.W.

439. Jolás, Eugène: Transition workshop. Compilado por Eugène Jolás, Nueva York, Vanguard Press, 1949, pp. 33-37. [MAA, pp. 33-37. "Legend of the tattooed girl". Traducción de A. F. Flecher].

440. Liscano, Juan: Les 20 meillewres nouvelles de l'Amérique Latine. Selección y prólogo de... Traducciones por René Durand y otros, París, 1962 (Collection "Melior"). MAA. "Torotumbo". Posteriormente se publicó por separado en forma de libro: Torolumbo, París, Seghers, 1966.

441. Lorenz, Günter W.: Nesyo; Sonderbeft Lateinamerica. 'Traducción de... y otros. Munich Sankt Gallen, 1965. [MAA, PP. 11, 37-41. Poesía y narración].

442. Lorenz, Günter W.: Literatur in Lateinamerica. Sankt Gallen, Galerie Press, 1967 [MAA, Pp. 19, 67-69. Poesía y narración].

443. Lundgren, Arne: Latinamerikanska berättare [Cuentistas Latinoamericanos], Estocolmo, Editorial Norstedts, 1963. 425 pp.

Antologia, MAA, "Leyenda del Volcán". Véase teseña de esta obra, Sten Björild: Göteborgs Posten (Gotemburgo, 29 mar., 1963).

444. Morov, A. (Recop.) Skromnye dorogi [Senderos modestos; Antología de cuentos de escritores latinoamericanos], Moscú, Iskusstvo, 1959. 125 pp. [MAA, pp. 101-107. "El Bueyón"].

445. Neuendorff, Georg H. Der Scbatz der Mayas. Herausgegeben und übertragen von... Saarlouis, Hausen Verlag, 1933 ["Leyendas de MAA", PP. 9-17]. 
446. Neuendorff, Georg H.: Stimmen der völker; Mittelamerika. Traducción de... Gauting, 1947 [MAA, pp. 741-746. Narración].

\section{CONFERENCIAS SOBRE ASTURIAS}

\section{LIBROS, FOLLETOS Y SEPARATAS}

447. Aguilera, León: Treinta años de "El Imparcial", Diario Independiente. Guatemala, Unión Tipográfica Castañeda Avila y Cía., 1952.

MAA, pp. 68 passim. Asturias empieza a escribir en este periódico en 1924. Al año siguiente es ya colaborador del extranjero en pie de igualdad con Gómez de la Serna José Juan Tablada, etc.

448. Alegría, Fernando: Historia de la novela bispanoamericana. México, Ediciones de Andrea, 1966 [MAA, pp. 221-225].

449. Andrea, Pedro F. de: Miguel Angel Asturias en México; ensayo bibliográfico. Portada de Toño Salazar, México, 1969. 20 Pp. ("Hojas Volantes" de la CLE, 1).

Edición limitada de 200 ejemplares numerados. Contiene 217 cédulas. Nota. En la presente bibliografia he incluido sólo una parte de las fichas de mi Astzurias en México.

450. Ayala, Juan Antonio: Cifra de bumanidad. San Salvador, Ministerio de Cultura, 1955 [MAA, Pp. 119-125. "De Tirano Banderas a El señor Presidente"].

451. Bellini, Giuseppe: La protesta nel romanzo ispano-americano del novecento. Milán-Varese, Istituto Editoriale Cisalpino, 1957. 80 pp. [MAA, Pp. 50-53].

\452. Bellini, Giuseppe: La narrativa di Miguel Angel Asturias. Milán, Istituto Editoriale Cisalpino, 1966. 217 pp. [básico].

453. Benseler, F. (ed.): Georg Lukaics. Festscbrift zum 80. Geburtstag. Neuwied-Berlín, Ed. Luchterhand, 1965.

Contiene, Rafael Gutiérrez Girardot: "Das Groteske als Sozialkritic in der Literatur Lateinamerikas", MAA, pp. 68-70, passim. El señor Presidente "es el núcleo de todo el attículo".

454. Carte, Boyd G.: Historia de la literatura bispanodmericana a través de las revistas. México, Ediciones de Andrea, 1968 [MAA, p. 44$]$.

455. Castelpoggi, Atilio Jorge: Miguel Angel Asturias. Buenos Aires, Editorial La Mandrágora, 1961. 222 pp. [trabajo pionero, pero aún de indispensable consulta].

456. Codina, Iverna. América en la novela. Buenos Aires, Ediciones Cruz del Sur, 1964 [MAA, Pp. 57-60]. 
457. Corvalán, Octavio: El postmodernismo. Nueva York, Las Américas Publishing Company, 1961. 159 PP. [MAA, Pp. 81-89].

458. Couffon, Claude: Hispanoamérica en su nueva literalura. Santander, "La Isla de los Ratones", 1962. 99 Pp. [análisis de El señor Presidente, Viento fuerte y Los ojos de los enterrados].

459. Cruz, Salvador de la: La novela iberoamericana actual. México, Secretaría de Educación Pública, 1956 [MAA, Pp. 42-43].

460. Dauster, Frank N.: Historia del teatro bispanoamericano, siglos xIx y Xx. México, Ediciones de Andrea, 1966 [MAA, p. 109].

461. Dethorey, Ernesto: Miguel Angel Asturias; Premio Nobel de Literatura 1967, Breves apostillas. Estocolmo, Tiden, 1967, $16 \mathrm{pp}$. [importante para el conocimiento de la repercusión de MAA en Suecia].

462. Franco, Jean: The Modern Culture of Latin America. Society and the Artist. Londres, Pall Mall Press, 1967. 339 PP. [MAA, Pp. 111-112, 172-173, 240-242].

463. Guillén, Nicolás: Prosa de prisa. Buenos Aires, Editorial Hernández, 1968. [MAA, pp. 275-278].

464. Harss, Luis: Los nuestros. Buenos Aires, Editorial Sudamericana, 1966. $461 \mathrm{pP}$.

"Miguel Angel Asturias o la tierra florida", pp. 87-127. Hay edición en inglés: Into the Mainstream. N.Y., Harper, 1967.

465. Kuteischikova, Vera N.: Roman Latinskoi Ameriki $v$ xx veke. Moscú, Nauka, 1964. 334 pp. ["La novela de la América Latina en el siglo XX", MAA, pp. 271-276. Bien documentada obra].

466. Leal, Luis: Historia del cuento bispanoamericano. México, Ediciones de Andrea, 1966. [MAA, p. 129].

467. Leiva, Raúl: Los sentidos y el mundo. Guatemala, Editorial del Ministerio de Educación Pública, 1952. [MAA, pp. 71-79].

468. Loveluck, Juan: Diez conferencias. Concepción de Chile, 1963 ["El señor Presidente, la dictadura y sus demonios", pp. 275-286].

469. Lorand de Olazagasti, Adelaida: El indio en la narrattva guatemalteca [Barcelona], San Juan, Editorial Universitaria, Universidad de Puerto Rico, 1968. 277 PP. ["MAA y su narrativa poética mágico-realista", Pp. 85-121].

' 470. Lorenz, Günter W.: Miguel Angel Asturias; Porträt und Poesie. Neuwied und Berlin, Hermann Luchterhand Verlag Gmbh, 1968. 322 pp. Ilus.

471. Lundkvist, Artur: Utsikter Over Utländsk prosa. Estocolmo, Bonniers, 1959. $2^{\text {a }}$ ed. 1961. 260 Pp. [MAA, pp. 231-237]. 
472. Lundkvist, Artur: Fran Utsiktstornet. Estocolmo, Tidens Förlag, 1963. 228 Pp. (Colección Kronos) [MAA, pp. 180-190].

473. Menton, Seymour: Historia critica de la novela guatemalteca. Guatemala, Editorial Universitaria, 1960. 332 pp. ["Miguel Angel Asturias: Realidad y fantasía", pp. 195-241, básico].

474. Montezuma de Carvalho, J. (Ed.): Panorama das literaturas das Américas (de 1900 à actualidade). (III), Angola, Ediçao do Municipio de Nova Lisboa, 1959.

Contiene, Otto-Raúl González: "Panotama de la literatura guatemalteca" [MAA, pp. 1044-1049].

475. Navas Ruiz, Ricardo: Literatura y compromiso; ensayos sobre la novela politica bispanoamericana. Sao Paulo, Universidad de Sao Paulo [1962]. 118 pp. [MAA, pp. 71-87, 98-111].

476. Ospovat, L.: Govovit Latinskatia Amerika; o sovremennom latinoamerikanskom romane ["Habla América Latina: La novela contemporánea latinoamericana"], Moscú, Znanie, 1961. $47 \mathrm{pp}$. [MAA, PP. 22-32].

477. Pacurariu, Francisc: Introducere in literatura Americii Latine. Bucarest, Editura Pentru Literatura, Universala, 1965. 303 pp. [MAA, pp. 298-301].

478. Pacurariu, Francisc: Scrittori Latino-Americani. Bucarest, Editura Pentru Literatura, Universala, 1966. 317 pp. [Miguel Angel Asturias; Sau Magia realitatii", pp. 272-317].

479. Pevtsov, Yuri: Migel" Ankhel' Asturiar; biobibliograficbeskii ukazatel'. Moscú, Vses, kn Palata, 1960. 28 pp.

Indice biobibliográfico. Contiene introducción, pp. 5-12, tabla biográfica, titulos de obras asturianas en español, un registro de las traduc. ciones al ruso y bibliografía pasiva. Obra pionera pero todavía muy útil.

480. Reyes, Alfonso: Obras completar. (X), México, Fondo de Cultura Económica, 1959 [MAA, p. 279. Véanse también fichas 187 y 189 de mi Asturias en México].

481. Sánchez, Luis Alberto: La tierra del quetzdl. Santiago, Ercilla, 1950. 217 PP. [MAA, Pp. 186-191].

482. Sánchez, Luis Alberto: Proceso y contenido de la novela bispanoamericana. Madrid, Gredos, 1953. [MAA, Pp. 295-297].

483. Saz, Agustin del: Teatro social hispanoamericano. Barcelona, Editorial Labor, S. A. 1967 [MAA, Pp. 147-149].

484. Solórzano, Carlos: El teatro latinoamericano en el siglo XX. México, Editorial Pormaca, S. A. de C. V. 1964. (Colección Pormaca, 10) [MAA, PP. 174-175]. 
485. Torres-Ríoseco, Atturo: Aspects of Spanish American Literature. Seattle, University of Washington Press, 1963. 95 pp. [MAA, p. 76].

486. Trigueros de León, Ricardo: Perfil en el aire. San Salvador, Ministerio de Cultura, 1955 [MAA, pp. 115-131].

487. Valle, Rafael Heliodoro: Historia de las ideas contemporáneas en Centroamérica. México, Fondo de Cultura Económica, 1960 [MAA, Pp. 279-281].

488. Vela, Arqueles: Una anécdota de Miguel Angel Asturias (México, 25 nor. 1968), 2 pp. Mecanografiadas.

Trabajo inédito, escrito expresamente para esta bibliografía. Un sucedido en Guatemala en el lapso de los años 1916 a 1918. Respuesta ingeniosa de MAA a un dómine impertinente, que causó toda una polémica.

489. Verzasconi, Ray A.: "Bibliografía de y sobre Miguel Angel Asturias", Corvallis, Oregon State University, 1968.

Manuscrito. Envío del autor y gentil amigo. Una valiosa recopilación de 400 y tantas fichas sobre MAA. Contiene además unas 85 cédulas adicionales sobre bibliografia general (literatura, historia y cultura) útiles para consulta ancilar.

490. Zum Felde, Alberto: Indice crítico de la literatura hispanoamericana. La narrativa. México, Distr. Studium, 1959 [MAA, pp. 371$373]$.

\section{TESIS}

491. Albízures Palma, Francisco: "Algunos elementos fundamentales en la novelística de Miguel Angel Asturias". Madrid, Universidad Central de Madrid, 1965 [véase Repertorio Centroamericano,? (San Salvador, 1968) ].

492. Alvarez, Carmen H.: "Las imágenes en El señor Presidente de Miguel Angel Asturias". Princeton, Princeton University, 1968 [tesis de grado, inédita].

493. Andreasson, Yvonne: "El porqué y el cómo de El señor Presidente de Miguel Angel Asturias", Malmö, Suecia, 1963 [tesis inédita].

494. Asturias Amado, Miguel Angel: "El problema indígena en nuestra realidad social". Guatemala, 1958.

Tesis inédita de su hijo en la cual alude a algunos problemas desarrollados por MAA en su disertación; El problema social del indio, 1923.

495. Asturias, Rodrigo: "La novelística americana exponente de nuestros problemas". Guatemala, tesis inédita, 1956. 75 pp.

En esta disertación - de su hijo mayor- se estudian varios escritores;

M. A. Asturias, C. Alegría, M. Azuela, J. Icaza y R. Gallegos. 
496. Avila, Eneida: "Las compañías bananeras en la novelística centroamericana". Nueva Orleans, Tulane University, 1959 [tesis inédita, MAA, pp. 103-133, passim].

497. Callan, Richard Jerome: "Fecundity in Two Novels of Miguel Angel Asturias". Saint Louis, University of Saint Louis, 19641965 [tesis doctoral inédita. Véase Dissertation Abstracts, XXVI, 4653].

498. Ciruti, Joan: "The Guatemalan Novel; A Critical Bibliography", Nueva Orleans, Tulane University, 1959 [tesis de grado, inédita].

499. Connolly, M. Killian: "The Narrative Prose of Miguel Angel Asturias". New Haven, Yale University, 1967 [tesis de grado, inédita].

500. Donahue, Francis James: "Miguel Angel Asturias: escritor comprometido". Los Angeles, University of Southern California, 406 pP. [tesis doctoral. Véase Dissertation Abstracts, XXVI, 1965, 2208].

501. Dumas, Jean-Louis: "Le Guatémala dans l'oeuvre de M. A. Asturias". Bordeaux, Estudios Superiores del Instituto Iberoamericano de la Universidad de Bordeaux, 1961 [tesis inédita].

502. Georgescu, Paul Alexandru: "Arte narrativa a lui Miguel Angel Asturias", Bucarest, 1964 [tesis doctoral, Universidad de Bucarest].

503. Hampares, Katherine J.: "The Image of the Yankee: the North American Business Man in the Contemporary Novel of Spanish America". Nueva York, Universidad de Columbia, 1968. 234 pp. [tesis doctoral, inédita, MAA, pp. 94-131 passim].

504. Kennedy, James H.: "El indio en la novela guatemalteca contemporánea". Washington, D. C., Howard University, 1968 [tesis de grado, inédita. Se ocupa ampliamente de MAA].

505. Mégued, Najum: "La obra de Miguel Angel Asturias; combinación de elementos mitológicos y problemas económico-sociales". Jerusalem, Universidad Hebrea Ttesis de maestría en preparación. Quizá esté terminada. Dato en Zona franca, 57 (Caracas, may. 1968)].

506. Navarro, Carlos: "The Destruction of Reality in El señor Presjdente". Pittsburgh, University of Pittsburgh, 1967. 174 pp. [tesis doctoral, inédita].

507. Nichols, Grace: "National Elements in the Poetry of Guatemala". Albuquerque, The University of New Mexico, 1951. 312 pP. [tesis doctoral, inédita]. 
508. Orellana, Riera: "Miguel Angel Asturias: El señor Presidente y otras obras". Santiago, Universidad de Chile, 1954 [tesis de grado].

509. Santizo, Mario: "A Study of Miguel Angel Asturias; La mulata de tal". Saint Louis, University of Saint Louis, Mo. Ltesis en preparación. Posiblemente esté terminada].

510. Serena, Whitman Rachels: "Miguel Angel Asturias and his World". Nueva York, Columbia University [1967?] 197 FP. [tesis de maestría, inédita].

511. Saborit, André: "Miguel Angel Asturias y sus hombres", Universidad de Toulouse, Francia. 1965.

512. Thompson, Miriam Henrietta: "Twentieth Century Yanqui Imperialism in the Prose Fiction of Middle America". Nueva Orleans, Universidad de Tulane, 1955 [tesis doctoral, inédita].

513. Verdugo, Iber: El carácter de la literatura bispanoamericana y la novelistica de Miguel Angel Asturias. Guatemala, Editorial Universitaria de Guatemala, 1968?

514. Verzasconi, Raymond: "Miguel Angel Asturias; A Critical Perspective of $\mathrm{El}$ señor Presidente". Seattle, Universidad de Washington, 1962 [tesis de maestria, inédita].

515. Verzasconi, Ray, A.: "Magical Realism and the Literary World of Miguel Angel Asturias". Seattle, Universidad de Washington, 1965 [tesis doctoral, inédita].

\section{ALGUNOS HOMENAJES}

516. Asomante, XXIV:3, Homenaje a MAA (San Juan, P. R., sep. 1968).

Trabajos de L. de Arrigoitia, A. C. de Gaztambide, C. Meléndez, A. L. Morales, $A$. Lorand de Olazagasti. Un conjunto de valiosos es-
tudios.

517. Culiura, 46, Homenaje a MAA (San Salvador, oct.-dic. 1967). Colaboracionts de: A. Orantes, A. E. Barrientos, A. Quijada Urias. Se reproducen varios escritos de Asturias. Ilus.

518. Diario de Centroamérica, 26136, Homenaje a MAA (Guatemala, 9 dic. 1967).

Artículos de L. A. Jiménez, C. Martínez Durán, M. Sánchez Guerra, R. Díaz Rodríguez, F. Hetrera, F. Zelaya, G. Bellini y otros. Ilus.

519. Diario de Centroamérica. Suplemento de Arte y Literatura, V:231, Homenaje a MAA (Guatemala, 9 dic. 1967).

Textos de Asturias. Articulos de D. Gardella, R. Cordón Batteira, R. Estrada, P. Valéry, A. Díaz Lozano. Ilus. 
520. Dirección General de Cultura de Bellas Artes, Homenaje a MAA. Folleto (Guatemala, 1967), 4 pp. [contiene un ensayo de G. Bellini, un poema de MAA, etc.].

521. Europe, Revue Mensuelle, 473, número dedicado a Guatemala. (Contiene un "Hommage à Asturias" (París, sep. 1968).

Trabajos dedicados a la cultura guatemalteca en general y cnsayos so. bre MAA en particular. Se recogen las conferencias leídas en el homenaje de la Universidad de París. Véanse fichas correspondientes, en la sección de referencias hemerográficas scbre maA. Ilus.

522. El Gráfico, Suplemento especial, Homenaje a MAA (Guatemala, $\sin$ fecha [11 nov. 1967]). 15 pp.

Textos de J. L. Cifuentes, P. Valery, M. Brion, A. E. Barrietos, E. Quintana, F. Soler y Pérez, G. Baquero, R. Estrada, etc. Escritos de MAs. Profusamente ilus.

523. El Imparcial. Homenaje a MAA (Guatemala, 9 dic. 1967), pp. 17, 23-24.

Aportaciones de C. Martínez Durán, V. Soto de Avila, H. Cortés Ruiz, etc. Se reproduce licencia de bautizo de Asturias.

524. El Maestro, 13, Homenaje a MAA (Guatemala, ene.-mar. 1968), pp. 91-114.

Se reproducen escritos de MAA. Ensayos de M. Sánchez Guerra de Garza y A. E. Barrientos.

525. La Pájara Pinta, 27, Homenaje a MAA (San Salvador, mar. 1968) [transcripciones de escritos asturianos].

526. Repertorio [Centroamericano], 9, Homenaje a MAA (San Salvador, abr. 1968). 31 pp.

Un capítulo de los Nuestros de Luis Harrs y trabajos de R. Estrada y F. Albizures Palma. Ilus.

527. Revisia A. P. G., 27, Homenaje a MAA (Guatemala, dic. 1967). Colaboraciones de: J. C. Anzueto, L. Castellano Carrillo, L. Paz y Paz, A. H. Solguero, etc. Poemas inéditos de Asturias. Ilus.

528. Revista Conservadora del Pensamiento Centroamericano. 89, Homenaje a MAA (Managua, feb. 1968) [ensayos de B. Carrión, R. Estrada, A. E. Barrientos],

529. Revista de Guatemala, XVIII:2, Homenaje a MAA (Guatemala, ene.-dic. 1960).

Excelente entrega. Estudios, poemas e iconografía. Colaboraciones de A. Foppa, R. Leiva, F. Méndez, L. Cardcza y Aragón, O. R. González, M. Monteforte Toledo, C. Illescas, etc.

1530. Université de Paris: Hommage de l'Université a MaA (París, 9 feb. 1968) [en el Amphithéâtre Richelieu, 17 rue de la Sorbonne].

Conferencias de P. Verdevoye, C. V. Aubrun, P. Darmangeat, M. Bataillon, Jean Cassou. MAA leyó algunas páginas de sus obras. Véase revista Europe, 473 (París, sept., 1968). 


\section{ALGUNAS CONFERENCIAS}

531. Carlos, Alberto J.: "El infierno dantesco en $E l$ señor Presidente". Poneazcia, leida en al XIII Congreso ( $2^{\circ}$ reunión) del Instituto Internacional de Literatura Iberoamericana, Caracas, Universidad Central de Venezuela (Ciudad Universitaria. Sala " $\mathrm{C}$ " de la Biblioteca. 5 agos., 1967). Véase Revista Nacional de Cultura, 180 (Caracas, abr.-jun., 1967), pp. 132-133.

532. Cassou, Jean: "Miguel Angel Asturias et la réalité indienne". Conferencia, en la Sorbonne, Amphithéâtre Richelieu (París, 9 feb., 1968) [no se publicó en la revista Europe, 473].

533. Estrada, Ricardo: "Ubicación de Miguel Angel Asturias en el movimiento literario mundial".

Conferencia, sustentada en el Salón Mayor, Facultad de Derecho. Universidad de San Carlos (Guatemala, 9 dic., 1967). Véase Prensa Libre (Guatemala, 11 dic., 1967), p. 18.

534. Lorenz, Günter W.: "Das exemplarische Leben des Miguel Angel Asturias". "La vida ejemplar de MAA".

Conferencia radiada por la estación Sudwestfunk (Baden-Baden, 14 dic., 1967) [dato, cortesía del conferencistal].

535. Morales, Angel Luis: "Miguel Angel Asturias, Premio Nobel 1967".

Conferencia leida en el Anfiteatro de Estudios Generales de la Universidad de Puerto Rico (San Juan, P. R., 23 abr., 1968). Véase Asomante, 3 (San Juan, P.R., jul.-sept., 1968), p. 21.

536. Pieczara, Stefan: "M. A. Asturias".

Conferencia. Círculo de la Scciedad de Romanistas, Universidad de Poznam (Poznam, Polonia, 20 oct., 1967).

537. Pieczara, Stefan: "Asturias, novelista comprometido de la América Latina: su lucha por la justicia social".

Conferencia. Sociedad de los Hispanistas de la Universidad de Poznam (Poznani, Polonia, 4 nov., 1967).

538. Pieczara, Stefan: "Premio Nobel al gran escritor guatema'teco, Asturias".

Canferencia. Sociedad de los Amigos de las Ciencias, Academia de Poznam (Poznam, Polonia, 27 mar., 1968) [datos, cortesía del conferencista].

539. Vela, David: "Motivación del mito indigena en su obra literaria". Conferencia, sustentada en el Salón Mayor, Facultad de Derecho. Universidad de San Carlos (Guatemala, 9 dic., 1967). Véase Prensa Libre (Guatemala, 11 dic., 1967), p. 75.

540. Velásquez, Alberto: "Riqueza idiomática y estilo de su obra". Conferencia, sustentada en el Salón Mayor, Facultad de Derecho. Universidad de San Carlos (Guatemala, 9 dic., 1967). Véase, Prensa Libre (Guatemala, 11 dic, 1967), pp. 18 y 75. 
541. Zea Ruano, Rafael: "Trascendencia del premio otorgado, ante la conciencia internacional".

Conferencia, sustentada en el Salón Mayor, Facultad de Derecho. Universidad de San Carlos (Guatemala, 9 dic., 1967). Véase Prensa Libre (Guatemala, 11 dic., 1967), p. 75.

\section{REFERENCIAS: HEMEROGRAFIA SIN FIRMA}

542. "La cena en homenaje a la prensa diaria", Nuestro diario (Guatemala, 11 dic. 1942), p. 4.

En el convite M. A. Asturias "sacó algunos pensamientos que tenía a flor de expresión". Se glosan sus palabras.

543. "Una gran novela latinoamericana", Suma bibliográfica, I:5 (México, dic. 1946), p. 219.

Sobre El señor Presidente 1" ed., "Una de las más notables novelas latinoamericanas de los últimos tiempos"... lo mejor y lo más apa. sionante, pertenece a un realismo singular, donde los elementos se combinan en forma fantástica presionando desde el subconsciente de los personajes". Una de las primeras reseñas de El señor Preidente.

544. "Letras de Guatemala en la Argentina; Leyendas de Guatemala de Miguel Angel Asturias", Saker-Ti, II:5 y 6 (Guatemala, may.ag. 1948), pp. 42 y 43.

Reseña de la edición argentina, "Pleamar". "Todo el sentido de lo vital de la vida americana, como simple juego, sabiduría o adivinación se halla en sus páginas..."

545. "Hombres de maíz", Repertorio Americano (San José, C. R., 1 mar. 1950), p. 83 [reseña].

546. "Homenaje a Miguel Angel Asturias", Repertorio Americano, XLVI:6 (San José, C. R., 7 mar. 1950), Pp. 81-83.

547. "Miguel Angel Asturias", Sexto Continente, 7-8. (Buenos Aires, nov-dic. 1950), p. 142 [breve nota. "Una formidable resonancia telúrica"].

548. "Viento fuerte", Noticias Gráficas (Buenos Aires, 27 mar. 1951). Reseña. "El empleo de localismos en Viento fuerte nos lieva al problema de la necesaria unidad del castellano, pero también al de la naturalidad de la expresión. Miguel Angel Asturias equilibra los dos términos en su misma calidad literaria..."

549. "Un premio para El señor Presidente", Marcha, XIII (Montevideo, 1952).

550. "Miguel Angel Asturias", Franc-Tireur (París, 24 dic. 1953).

Reseña impresionista de la edición francesa de Hombres de maiz. "Delirio de la angustia humana en el universo extraño en el que la razón capitula frente a los poderes sobrenaturales del mal". 
551. "Un écrivain célèbre de l'Amérique Latine; Légendes du Guatémala par Miguel Angel Asturias", Arts, 447 (París, 21-27 ene. 1954).

Reseña de la edición francesa de Leyendas de Guatemala. "M. A. Asturias nous entraine dans un univers étrange fantastique et tertifié".

552. "Partida", Sintesis, I:6 (San Salvador, sep. 1954), p. 151 [su salida de San Salvador y homenaje].

553. "Teatro de Miguel Angel Asturias", El Nacional (Caracas, 23 feb. 1956).

554. "Colaboran en este número; 'Asturias"", Revista Nacional de Cultura, 116 (Caracas, may.-jun. 1956), Pp. 227-228.

Sucinta noticia biobibliográfica en la sección de los colaboradores. La revista contiene el poema miguelino "Meditaciones del pie descalzo".

555. "Un nuevo libro de Asturias", El Nacional (Caracas, 10 ene. 1957).

556. "Brújula quieta", Brecba, I:6 (San José, C. R., feb. 1957), p. 27 [referencia al proyecto de filmación de El señor Presidente].

557. "Asturias no Brasil", Jomal de letras, IX:100 (Río, nov, 1957), P. 12.

558. "Le miroir de Lida Sal....", Le Figaro Littératire, 612 (Paris, 11 ene. 1968).

559. "El señor Presidenle", Gazzetta di Milano (Milán, 18 oct. 1958) [reseña de la versión italiana de El señor Presidente].

560. "Encuesta literaria: ¿Cuáles son los libros que usted considera como verdaderas obras de arte?", Negro sobre blanco, 8 (Buenos Aires, nov. 1958), pp. 31 y 107.

En su respuesta, el novelista paraguayo, Augusto Roa Bastos, incluye a El señor Presidente junto con Marbeth, Hamlet, El Quijote, el Fausto, Moby Dick, La condicion bumana, El canto general, etc. En su preferencia, posiblemente aflore un trasfondo afin. Registro el dato. Puede ser de utilidad al comparatista.

561. "Miguel Angel Asturias", Negro sobre blanco, 8 (Buenos Aires, nov. 1958), p. 61.

Breve nota biobibliográfica y caracteristicas de su obra. "Pintura de la naturaleza americana y ...fidelísima cuanto artística transcripción de los modos de sentir, de obrar y de hablar de los habitantes del Caribe".

562. "Weck-end au Guatemala", L'Humanité (París, 22 may. 1959) [reseña].

563. "Week-end au Guatemala", France Ohrorvateur (París, 20 ag. 1959) [reseña]. 
564. "México condecoró a Miguel Angel Asturias", Excélsior (México, 3 ag. 1960).

Medalla como recompensa por su valiosa cooperación en su calidad de jurado en el Primer Certamen Continental de Novela convocado por el INBA de México. Cabe apuntar que MAA es invitado, con mucha frecuencia, a participar en jurados de certámenes literarios y fílmicos.

565. "Miguel Angel Asturias", Negro sobre blanco, 15 (Buenos Aires, oct. 1960), p. 7.

566. "Miguel Angel Asturias: Leyendas de Guntemala", Negro sobre blanco, 16 (Buenos Aires, 1960). [reseña].

567. "Bibliografía de MAA". Revista de Guatemala, XVIII:2 (Guatemala, ene.-dic. 1960), pp. 109-111 [algunas fichas bibliográficas incompletas].

568. "O novom romane Asturiasa", Inostranndia literatura, 12 (Moscú, dic. 1960), p. 256 [reseña de Los ojos de los enterrados].

569. "Miguel Angel Asturias, Los ojos de los enterrados", Negro sobre blanco, 16 (Buenos Aires, dic. 1960), p. 9.

Reseña: "En los ojos de los enterrados... encontramos balanceados los dos elementos que caracterizan a este autor guatemalteco: Io poćtico y lo social, no como mensaje, sino como amalgama de los sillares, realidad y ficción, en que Miguel Angel Asturias asienta sts concepciones".

570. "La audiencia de los confines el próximo mes", El Imparcial, 27 (Guatemala, 18 ag. 1961), p. 8.

Noticia adelantada del estreno - Première Mundial"- - del drama asturiano.

571. "En La audiencia de los confines; Manuel Lizandro Chávez encarna a fray Bartolomé de las Casas", El Imparcial (Guatemala, 26 ag. 1961), p. 16.

Comentarios acerca de la representación de esta pieza teatral en el Conservatorio Nacional. M. L. Chávez actuó en el papel principal.

572. "Week-end au Guatemala", Revue des Deux Mondes (París, 1 oct. 1961) [reseña].

573. "El Albajadito", La Nación, supl. (Brenos Aires, 14 ene. 1962), p. 4.

Reseña. "Un estilo que, conservando la frescura virginal de su mundo de origen, exhibe las huellas y el aite de lo que ha conocido el rigor ejemplar de las reglas más arduas, para florecer en relatos singularmente vigorosos".

574. "Hispanoamérica en busca de su novela", Visión, XXIV:3 (México, 30 nov. 1962), p. 49.

575. " $\Lambda$ Paris depuis hier; Miguel Angel Asturias poursuit en Europe le 'voyage de ses droits d'auteur" ", Combat (Paris, 15 nov. 1962). Entrevista. Declara que, "L'Italie et l'Espagne m'ont reçu. Au moins, pour une fois, je ne perds pas au change... même si l'Europe n'est pas disposés à mouvrir toutes ses portes. Celle d'Angleterre par exam. ple". 
576. "Les yeux des enterrés", L'Express (París, 17 enc. 1963) [reseña].

577. "Fidel Castro som idol", Dagens Nybeter (Estocolmo, 28 ene. 1963) [entrevista con MAA].

578. "Mulata de tal", Negro sobre blanco, 30 (Bucnos Aires, oct. 1963), p. 8.

Breve reseña. "Un descenso a las raíces del hombre centroamericano $y$, también, una experiencia literatia incomparable".

579. "New Fiction; Miguel Angel Asturias: The President", The Times (Londres, 10 oct. 1963).

Reseña de la traducción al inglés de El sefior Presidente. Sentencia el critico "it is frankly an exercise in political propaganda".

580. "Hated Tyranny; Miguel Angel Asturias, The President", The Times Literary Supplement (Londres, 18 oct. 1963).

Equilibrada reseña de la versión inglesa de $E l$ señor Presidente. "The theme is quite unusual and it is this which raises the book above mere propaganda... The author darts from scene to scene, skilfully conveys colour and sound and switches from reality to symbolism, dreams, nightmates and delirium... Its interest lies not so much in the political message, which is familiar, as in the originality and efectiveness of the style".

581. "A Miguel Angel Asturias en Buenos Aires", La Hora Dominical, $\mathrm{V}: 811$ (Guatemala, 15 dic. 1963), p. 13 [se evoca a MAA en Buenos Aires y se exalta su personalidad literaria].

582. "Los Jibros, los planes y los temas", Inostrannaia literatura (Moscú, 1964), pp. 234-235 [entrevista].

583. "Colección gran teatro del mundo", Negro sobre blanco, 35.36 (Buenos Aires, nov.-dic. 1964), p. 15.

Reseña de su Teatro. "Las dos vertientes... de Asturias (su sentido de las raíces indigenas de nuestra América y la conciencia del. desequilibrio social en que se debaten sus habitantes actuales) se entrelazan en forma sutil y diversa en las cuatro piezas aquí reunidas".

584. "Au royaume de tous les monstres", L'Express (Paris, 23-29 ag. $1965)$, p. 41.

Reseña de la versión francesa de Malata de tal. "Commencé d'une manière très réaliste par une histoire de braguette mal fermée, le roman tourne vite au fantastique".

585. "Beifallsstütme für Asturias", Berliner Zeitung (Berlín, Este, 24 sep. 1965) [breve comentario acerca de su visita a la Universidad de Rostock].

586. "L'Amérique du Sud favorite par le Nobel", Le Figaro Littéraire, 1016 (París, 7 oct. 1965), p. 2 [se menciona a MAA].

587. "Sholokhov wins Nobel Literature Prize", The News (Nueva York, 16 oct. 1965).

"Choice was not unanimous... Swedish Academy... divided between Sholokhov and... Miguel Angel Asturias". 
588. "Fünf Lenin-Fricdenspreise", Berliner Zeilung (Berlín, Este, 1 may. 1966) [fechado en Moscú. Noticia de la concesión del Premio Lenin a MAA].

589. "Miguel Angel Asturias gana el Premio 'Lenin' de la Paz", diatio El Gráfico, III:843 (Guatemala, 1 may. 1966).

590. "Un prince guatémaltèque", La Quinzaine Listéraire, 9 (París, 15 jul. 1966).

591. "M. A. Asturias, Premio Lenin", Novedades de Moscú, 31 (Moscú, jul. 1966), pp. 5-6.

592. "Selón un journal de Guatémala, Miguel Angel Asturias pourrait être nommé ambassadeur en France", Le Monde (París, 8 jul. 1966) [se recoge una noticia de El Imparcial de Guatemala].

593. "El Premio Lenin por la Paz", Izvestia (Moscú, 20 jul. 1966) [entrevista].

594. 'L'écrivain Miguel Angel Asturias est nommé ambassadeur du Guatémala en France", Le Monde (París, 4 ag. 1966) [se comenta el anuncio oficial del gobierno guatemalteco].

595. "Miguel Angel Asturias enjuiciado por la juventud", El Imparcial (Guatemala, 3 sep. 1966), pp. 15 y 21.

596. "Miguel Angel Asturias con admirativa acogida", El Imparcial (Guatemala, 3 sep. 1966), pp. 1 y 4.

597. "Obras escogidas", "La Cultura en México", supl. de Siempre! 242 (México, 5 oct. 1966), p. XVII [reseña].

598. "Asturias for forste gang pa norsk ihost", Aftenposten (Oslo, 10 oct. 1966).

599. "Indice de colaboradores; Asturias", Margen, 1 (París, oct.-nov. 1966), p. 143.

Se señala que "se escriben 33 tesis sobre su obra en diversos puntos del planeta".

600. "Flor de pascua en la cintura de América", Alerta (Guatemala, nov. 1967), pp. 1 y 9 [insidioso artículo en el cual se ataca a MAA].

601. "Prix Nobel", Le Bulletin du Livre, 150 (París, 1967). p. 5 [breve nota biobibliográfica].

602. "Réquisitoires sur le Vietnam", L'Express, 816 (París, 6-12 feb. 1967).

Protesta de intelectuales contra la guerra de Vietnam. MAA aparece entre los firmantes.

603. "¿Por qué no el diálogo latinoamericano si lo hay entre ingleses, 
franceses y rusos?, replica Miguel Angel Asturias", El Di (México, 17 mar. 1967), p. 9 [entrevista].

604. "Nuevas publicaciones", Mundo Nuevo, 10 (París, abr. 1967), Pp. 88-89.

MAA, p. 89. Comentarios acerca de El albajadito. "La novela de Asturias es una de las que ha tenido más lenta y morosa redacción de toda su obra: iniciada en la década del veinte no se completa hasta la del cincuenta... una aventura fabulosa a través de las formas amenazantes o favorables de Ia naturaleza tropical, de los simbolos, los presagios y los encantamientos que son la memoria latente y no dominada de su raza".

605. "Parle de la littérature hispano-américaine", Le Figaro Littéraire, 1097 (París, 24 abr. 1967), p. 16 [entrevista con MAA].

606. "Le miroir de Lida Sal", L'Humanité (París, 20 jun. 1967) [reseña].

607. "Sextante, México; Congreso de Escritores", Mundo Nuevo, 13 (París, jul. 1967), pp. 76-79.

MAA, p. 77. Asturias, "abogó por la creación de la Comunidad siguiendo el ejemplo de la Comunidad Europea, en la que participan los soviéticos, los escritores del Este y los de los paises capitalistas".

608. "Miguel Angel Asturias; poeta y novelista de América", Bayoán, 25 (Río Piedras, P. R., jul.-sep. 1967) [presenta a MAA].

609. "Miguel's novels", Evening News (Londres, 20 sep. 1967). Se anuncia que se publicará en Inglaterra, Mulata de tal y la "trilogía bananera".

610. "Magic Moments", The Times Literary Supplement (Londres, 28 sep. 1967).

Reseña de la traducción al inglés de Mulata de tal y Viento fuerte. "The Mulatia... is a very rich and subtle book, even too rich too kaleidoscopic. Certainly, its insights into the sources of fear and desire are not explored or developed, and can not be, for magic has implicit limits". El crítico tiende a soslayar lo positivo de la novela y a detenerse en lo que él considera fallas.

611. "El espejo de Lida Sal", Boletín de información interna, Secretaría de Comunicaciones y Transportes (México, oct. 1967).

"Lo contemporáneo lleva la sobrecarga emocional de cuanto acaeció, lo mismo en la época colonial que en tránsito de lo colonial a los momentos del presente", sintetiza el crítico.

612. "Miguel Angel Asturias", Politica, VIII:176 (México, oct. 1967), pp. 48-49.

613. "Asturias defendió siempre con vigor a la clase pobre y oprimida de su patria", Ultima Hora (La Paz, Bolivia, 19 oct. 1967), p. 1. Una semblanza de MAA. "Este escritor comprometido... ha escrito una prosa ética y colorista".

614. "Asturias; Strijdbaar auteur met liefde voor de Indianen", N. $V$. Dagblad De Telegraaf (Amsterdam, 19 oct. 1967). Noticia del Premio Nobel 1967 e información general sobre la personalidad literaria de MAA. 
615. "Declaró Miguel Angel Asturias; 'Un gran estímulo, no sólo para mí sino para toda la América Latina" ", Ovdciones (México, 19 oct. 1967).

616. "Galardón a Guatemala; Miguel Angel Asturias, Premio Nobel. Lo motiva su labor enraizada en lo nacional y tradición indígena", El Imparcial (Guatemala, 19 oct. 1967), pp. 1 y 12 [nota informativa desde Estocolmo: "Gran regalo de cumpleaños" declaró MAA].

617. "Guatemala Envoy Wins Nobel Literature Award", Detroit News (Detroit, 19 oct. 1967), p. 15 [noticia cablegráfica anunciando a MAA como Premio Nobel; breves notas biobibliográficas].

618. "Guatemala Writer Wins Nobel Award", Boston Herald Traveler (Boston, 19 oct. 1967).

Cable del "Globe Wire Service" en el cual se da la noticia del Premio Nobel 1967. Se reiteran los datos conocidos.

619. "Guatemala diplomat wins Nobel Prize for Literature", Toronto Star (Toronto, 19 oct. 1967) [suscrito en Estocolmo. Breves comentarios].

620. "Miguel Angel Asturias; El Premio Nobel de Literatura 1967", Ultima Hora (La Paz, Bolivia, 19 oct. 1967), p. 1 [se reproduce un cable de París y una entrevista con MAA].

621. "Para el guatemalteco Miguel Angel Asturias fue el Premio Nobel de Literatura de 1967", Universal Gráfico (México, 19 de oct. 1967) [notícula].

622. "Premio Nobel de Literatura ganó Miguel Angel Asturias", La Hord (Guatemala, 19 oct. 1967), Pp. 1-2 [comentarios generales].

623. "Agradece el galardón el escritor guatemalteco", Ultimas Noticias (México, 20 oct. 1967).

624. "Apoteose", Correio da Manbã (Río, 20 oct. 1967) [Guatemala recibió con júbilo la noticia del Premio Nobel].

625. [Asturias], Al-Abram (El Cairo, Egipto, 20 oct. 1967) [breve nota informativa].

626. "Asturias de Guatemala; Nobel de Literatura", El Sol de México (México, 20 oct. 1967) [breve nota].

627. "Asturias-diplomaten som helst av allt vill syssla med litteratur", Göteborgs-Posten (Gotemburgo, 20 oct. 1967), p. 10 [semblanza biobibliográfica].

628. "Asturias ethöll litteratur-priset pa födelsedagen", Göteborgs Posten (Gotemburgo, 20 oct. 1967) [comentario general sobre su vida $y$ obra]. 
629. "Asturias ja suomi", Helsingin Sanomat, 265 (Helsinki, Finlandia, 20 oct. 1967), p. 15.

630. "Asturias; Guatemalan Poet Wins Nobel Prize", Cbicago SunTimes (Chicago, 20 oct. 1967) [reiteración de datos biobibliográficos básicos].

631. "Asturias obtuvo el Nobel de Literatura; es la segunda vez que un latinoamericano logra ese galardón", Excélsior (México, 20 oct. 1967), pp. 1, 10 y 11.

632. "Ocurrió lo que era justo", Ultimas Noticias (México, 20 oct. 1967) [cable de Madrid en el cual se señala la justicia del premio].

633. "Palabras del escritor", Ultimas Noticias (México, 20 oct. 1967) ["El novelista debe ser testigo de su tiempo", MAA].

634. "Asturias, poeta e politico", Jomal do Brasil (Rio, 20 oct. 1967), p. 10.

"Asturias está incluido entre los 'grandes mágicos da linguagem' na América Latina, citado ao lado de Borges e Neruda. Mas inclui-se também entre os pensadores das crises políticas e sociais latino-americanas".

635. "Asturias, Premio Nobel", Correio da Manbã (Río, 20 oct. 1967). Naticia del Premio Nobel a MAA. "As obras de Asturias são uma vibrante ilustração e defesa do povo guatemalteco. Este diplomata cuja cortesia e proverbial, soube também ser um escritor violento".

636. "Asturias, Premio Nobel", Ultimas Noticias (Río, 20 oct. 1967). Trayectoria de su vida y obra. "No feroz e magnifico T'orotumbo, censura a ação de algumas fraçóes da Igreja e a atividade oculta dos comitès anticomunistas, aos quais chamou de nova inquisição, em benefício dos ditadores".

637. "Asturias, Premio Nobel literario", Ultimas Noticias (México, 20 oct. 1967).

638. "Asturias -Premio Nobel de Literatura 1967", El Heraldo (México, 20 oct. 1967).

639. "Asturias pris en stor hāndelse för Guatemala", Dagens Nybeter (Estocolmo, 20 oct. 1967).

640. "Declaraciones", El Nacional (México, 20 oct. 1967), p. 7 [declaraciones de MAA al ganar el Nobel].

641. "Diplomat und Dichter", Berliner Morgenpost (Berlín, 20 oct. 1967) [notícula].

642. "Escritor canta a luta de seu pais", Jornal do Brassl (Río, 20 oct. 1967) [se pone especial énfasis en la vertiente revolucionaria de MAA].

643. "Nõberu bungakushõ wa Astsuriasushi ni; Guatemara no Chufutsu 
taishi; Kenryoku no kõgi suru seijishõsetsuka", Mainichi Shimbun (Tokio, 20 oct. 1967), p. 15. Edición de la mañana.

"El Premio Nobel de Literatura al Sr. Asturias, Embajador de Guatemala en París. Novelista político que protesta contra la tirania".

644. "Galardón a Guatemala; Miguel Angel Asturias, Premio Nobel", El Imparcial (Guatemala, 20 oct. 1967).

645. "Guatemalan Envoy Gets Nobel Prize". The Japan Times (Tokio, 20 oct. 1967).

Se reproducen algunas declaraciones suyas al recibir la noticia del Premio.

646. "Guatemalan novelist arvarded Noble Prize", The Mainicbi Daily News (Tokio, 20 oct. 1967) [dos cables: uno de Estocolmo y otro de París. Breves notas informativas].

647. "Homenaje de escritores franceses", El Dia (México, 20 oct. 1967), p. 6.

Opiniones de Marcel Brion y Georges Pillement sobre Asturias.

648. "Indianättlingar folkmajoritet i Asturias land", Dagens Nybeter (Estocolmo, 20 oct. 1967).

649. "Kirjailijan tulee olla oman aikansa todistaja", Helsingin Sanomat, 265 (Helsinki, Finlandia, 20 oct. 1967), p. 15 [fechado París. Entrevista con MAA].

650. "Kirjallisuuden Nobel syntymäpäivälahjaksi Miguel Asturiasille", Helsingin Sanomat (Helsinki, Finlandia, 20 oct. 1967) [noticia general sobre MAA ganador del Premio Nobel].

651. "Kultur im tagesgeschehen; Literatur-Nobelpreis geht nach Guatemala", Berner Tagblatt (Berna, Suiza, 20 oct. 1967), p. 2 [comentarios biobibliográficos].

652. "L'ambassadeur du Guatémala a París, Prix Nobel de Littérature; le jour de ses 68 ans", France-Soir (Paris, 20 oct. 1967), p. 1 [con grandes capitulares se anuncia el Premio Nobel. Fotografía en formato mayor].

653. "Ambassadeur à Paris; Asturias Prix Nobel a fait de la prison au Guatémala pour un livre contre la dictature", France-Soir (París, 20 oct. 1967) [breves notas comentando sus nexos con Francia].

654. "La obra de Asturias es la epopeya de la lucha de su pueblo contra su opresión", El Gráfico (Guatemala, 20 oct. 1967) [en Suecia se le recuerda con cariño].

655. "Latin-Amerikas fjerde Nobelpris", Aftenposten (Oslo, Noruega, 20 oct. 1967) [noticia del otorgamiento del Premio Nobel a MAA con datos biobibliográficos]. 
656. "Lenin Prize Writer, Wins Nobel Award", Morning Star (Iondres, 20 oct. 1967) [semblanza literaria].

657. "Le Nobel à Asturias", Journal de Genève, 245 (Ginebra, 20 oct. 1967), p. 5.

Presentación general de su obra, "Même dans ses romans-pamphlets, il teste un écrivain de haute race, dont les images, les cadences 'passent' à travers les traductions..."

658. "Literary Nobel to a critic of Yankee Big Biz", The News (Nucva York, 20 oct. 1967) [sobrio comentario].

659. "Maanpakolaisuuden jälkeen maansa suurlähettilääksi", Helsingin Sanomat, 265 (Helsinki, Finlandia, 20 oct. 1967), p. 15 [artículo biobibliográfico].

660. "Marco Antonio Asturias (hermano de Miguel Angel Asturias) en entrevista exclusiva al diario El Gráfico", El Gráfico (Guatemala, 20 oct. 1967) [de cómo, MAA, recibió "en forma confidencial" la noticia del Premio Nobel].

661. "Miguel Angel Asturias ambassadeur du Guatémala en France; prix Nobel de Littérature", Le Parisien Liberé (París, 20 oct. 1967) [perfil de su vida y obra].

662. "Miguel Angel Asturias", Die Welt (Hamburgo, 20 oct. 1967) [la obra de MAA es un "ingente bloque monolítico"].

663. "Miguel Angel el primer centroamericano y el segundo latinoamericano que recibe el Premio Nobel de Literatura", El Gráfico (Guatemala, 20 oct. 1967) [boceto de su personalidad].

664. "Miguel Angel Asturias", Frankfurter Allgemeine Zeitung (Francfort, 20 oct. 1967) ["Alto contenido colorístico... así como un "don poético, mágico, extraño y enorme" "].

665. "Miguel A. Asturias, ganó el Nobel de Literatura", El Debate (Los Mochis, Méx., 20 oct. 1967), p. 13.

Se transcribe el discurso del académico sueco Anders Oisterling: "Asturias se ha liberado totalmente de la rutina de la técnica narmativa tradicional... marca claramente la afinidad con el surrealismo francés... sin embargo, es de observar que el material ha sido siempre sacado de su expetiencia personal".

666. "Miguel Angel Asturias", General-Anzeiger (Bonn, 20 oct. 1967). "Asturias aboga decididamente por una literatura comprometida que refleje las realidades modernas..."

667. "Miguel Angel Asturias, Nobel de Literatura", El Correo (Medellín, Colombia, 20 oct. 1967) [fotografía].

668. "Miguel Angel Asturias, Nobel de Literatura", El Heraldo (México, 20 oct. 1967). 
669. "Miguel A. Asturias; Nobel Winner", Boston Herald Traveler (Boston, 20 oct. 1967) [cable: Breve noticia sobre MAA].

670. "Miguel Angel Asturias; Premio Nobel de Literatura, titán de las letras de Hispanoamérica", El Gráfico (Guatemala, 20 oct. 1967) [como lo indica el título se trata de una nota laudatoria].

671. "Miguel Angel Asturias, Premio Nobel de Literatura", El Grífico (Guatemala, 20 oct. 1967), pp. 6 y 39.

672. "Miguel Angel Asturias recibió el Premio Nobel de Literatura", El Dia (México, 20 oct. 1967), pp. 1 y 6.

673. "Miguel Angel Asturias; Wins the Nobel Prize", The Globe and Mail (Toronto, 20 oct. 1967) [comentarios generales].

674. "Modern aus indianischer tradition", Hannoverscbe Allgemeine Zeitung (Hannover, 20 oct. 1967) [apuntes sobre su producción literaria].

675. "Nobel Winner's Work not in English", Toranto Star (Toronto, 20 oct. 1967).

Reportaje. "When asked whether his poetry had brought him much in the way of cash reward,

"Money?" he said. "If you want to make money from books these days you have to write sexy things - in English".

676. "Nobel — Diplomatie", Die Welt (Hamburgo, 20 oct. 1967) [breve exposición de su obra].

677. "Nobelpreis für Asturias", Berliner Zeitung (Berlín, Este, 20 oct. 1967) [simples referencias].

678. "Nobelprijs voor literatuur naar Zuidamerikaan", De Volkskrant (Amsterdam, 20 oct. 1967) [esbozo de su personalidad literaria].

679. "Nobel Prize for Guatemalan Crusading Author-Envoy", The Times (Londres, 20 oct. 1967).

Ncta informativa. "Señor Asturias is the prototype of the politically committed writer... tirelessly drawing attention to the problems of Latin America".

680. "Onnitteluja virtaa Miguel Asturiasille", Ilta-Sanomat (Helsinki, Finlandia, 20 oct. 1967) [corta exposición biobibliográfica].

681. "Pensa em deixar a diplomacia", $O$ Globo (Río, 20 oct. 1967) [entrevista con MaA suscrita en París].

682. "Premio Nobel ganó M. A. Asturias", La Hora (Guatemala, 20 oct. 1967).

Andrés Osterling expone: "En Clarivigilia primaver al Asturias trata la génesis misma de las artes y la creación poética en una forma que parece tomada del radiante plumaje del pájaro quetzal". 
683. "El Premio Nobel al más grande escritor guatemalteco", El Gráfico (Guatemala, 20 oct. 1967), p. 13.

684. "Premio Nobel de Literatura 1967", El Díd (México, 20 oct. 1967), p. 6.

685. "Premio Nobel de Literatura, Asturias", Jomal do Brasil (Río, 20 oct. 1967) [apreciaciones generales].

686. "Premio Nobel à Miguel Angel Asturias", $O$ Globo (Río, 20 oct. 1967) [cable anunciando el otorgamiento del Premio].

687. "Premio Nobel; Miguel Angel Asturias", O Jornal (Río, 20 oct. 1967).

"Conquanto panfletário, em alguns livros, Asturias é considerado um verdadeiro estilista, sua linguagem resistindo ás inúmeras traduçōes".

688. “QQué es el Premio Nobel?”, El Gráfico (Guatemala, 20 oct. 1967).

689. "Repercusión", El Nacional (México, 20 oct. 1967), p. 7. Júbilo en Guatemala al conockr la noticia del Nobel. "Las emisoras de radio interrumpieron sus programas" para difundir la información.

690. "Un écrivain engagé", Gazette de Lausanne (Lausana, Suiza, 20 oct. 1967), p. 16.

"Son action en a fait un défenseur des opprimés; son oeuvre, un ténovateur de la mythologie des Mayas".

691. "Un escritor comprometido; Asturias Premio Nobel de Literatura", Esto (México, 20 oct. 1967) [breve semblanza].

692. "Verjaardagagesche voor Asturias; Nobelprijs!", N. V. Dagblad De Telegradf (Amsterdam, 20 oct. 1967) [perfil literario].

693. "Violencia y aliento poético en la obra de Asturias", $A B C$ (Madrid, 20 oct. 1967), p. 80.

Reportaje. Se recuerdan hitos de su obra. Se intentan comparaciones. "Como narrador se le ha señalado entronque a Miguel Angel Asturias con Alfonso Reyes... El idioma que maneja Asturias, como el que manejó Reyes, es de una gran plasticidad, con un barroquismo deliberado... Su pintura hablada podría compararse con la de los lienzos de nuestro José Gutiérrez Solana..."

694. "Writer Asturias gets Nobel Prize", Excélsior (México, 20 oct. 1967), P. 22 [sección en inglés].

695. "Glüchwunsch für Asturias", Berliner Zeitung (Berlín, Este, 21 oct. 1967). [noticia general].

696. "Llueven a M. A. Asturias, las felicitaciones", Novedades (México, 21 oct. 1967) ["Los más entusiastas fueron los guatemaltecos residentes en París].

697. "M. A. Asturias, Laureatern literackiej Nagrody Nobla" [M. A. 
Asturias, Ganador del Premio Nobel de Literatura]. Express Wieczorny (Varsovia, 21 oct. 1967) [breve noticia].

698. "Mensajes del Canciller y del Cabildo. Presidente congratula a Miguel Angel Asturias", El Imparcial (Guatemala, 21 oct. 1967) [se reproduce el texto].

699. "Miguel Angel Asturias", Sïddeutscbe Zeitung, 252 (Munich, 21 oct. 1967) [corta información].

700. "Prix Nobel de Littérature; Asturias (Ambassadeur du Guatémala à Paris) a connu les prisons de son pays", France-Soir (París, 21 oct. 1967) [notícula biobibliográfica].

701. "Asturias innostuksen kohteens N. liitossa", Helsingin Sanomat (Helsinki, Finlandia, 22 oct. 1967) [en Moscú se recogen repercusiones de MAA].

702. "Asturias le surréaliste engagé", L'Express (París, 23-29 oct. 1967), pp. 125-126.

Valoración general de su obra. "Asturias est l'un des très rares ècrivains qui soit parvenu, jusqu'ici, à concilier ce que Sartre et Breton, chacun à leur manière, ont manqué: les exigences proprement littéraires de 'l'écriture' et de l'art engagé'. A tous égards, un bon Nobel".

703. "Poco entusiasmo en Cuba por el Premio a Miguel Angel Asturias", El Día (México, 23 oct. 1967), p. 7.

"La reserva en dichos medios se debe, al parecer, no a los méritos de Asturias, que nadie discute, sino a su calidad de embajador del gobierno guatemalteco".

704. "Asturias un Premio Nobel completo", El Gráfico (Guatemala, 24 oct. 1967), pp. 11 y 31.

Telegrama fechado en Río de Janeiro. Se consigna que las obras asturianas están "desprovistas de sectarismos políticos".

705. "Miguel Angel Asturias; Premio Nobel 1967 y la proyección humana y social de su obra", Diario de Centroamérica (Guatemala, 24 oct. 1967), p. 1.

706. "Sello postal con efigie de Miguel Angel Asturias piden", La Hora (Guatemala, 24 oct. 1967), pp. 1 y 2.

La "Asociación de Autores y Amigos del Libro Nacional" solicitan al Gobierno "la emisión de un sello postal con la efigie de MAs.

707. "Guatemala baño de oro para el totem", Primera Plana, 252 (Buenos Aires, 24 oct. 1967), pp. 31-32.

"Borges fastidia a las izquierdas, Neruda a las derechas, Asturias en cambio... habia alcanzado la respectabilidad".

708. "Orgullo y júbilo de Guatemala: por la adjudicación del Premio Nobel", El Imparcial (Guatemala, 24 oct. 1967), p. 3.

"Esta concesión de un galardón tan ambicionado... incluyendo disidencias, críticas y regateos inevitables no podia recibirse en su patria sino con agrado y orgullo". 
709. "El realismo mágico de Miguel Angel Asturias", Guatemala en Matrba, I:7 (Guatemala, 24 oct. 1967), p. 11 [reseña de Mulata de tal $]$.

710. "Mi gran maestro es Quevedo, dice Miguel Angel Asturias", El Imparcial (Guatemala, 28 oct. 1967), p. 17.

Entrevista de Josefina Carabías. Dice MAA, "Soy español por mis. antepasados e indio por mis antepasados".

711. "Sobre El espejo de Lida Sal", Mañana (México, 28 oct. 1967). "Lo que verdaderamente importa es el aliento poético el esplendor de la expresión", subrkya el comentarista.

712. "Points from publishers", The Bookseller (Londres, 28 oct. 1967), p. 13.

"Victor Gollancz are the publishers of The President ... It is available at 25s., but in view of the number of orders received in the few hours since the award was announced they have decided to reprint the book".

713. "Premio Nobel; premio político", Alerta (Guatemala, 29 oct. 1967), pp. 1 y 12.

Pontifica el articulista que últimamente el galardón se ha convertido en premio por "desplantes políticos".

714. "Miguel Angel Asturias: Premio Nobel de Literatura 1967", Papel literario, El Nacional (Caracas, 29 oct. 1967), p. 2.

715. "El escritor y sus raíces", Tiempo, 1330 (México, 30 oct. 1967), p. 61 [breves apreciaciones sobre la obra de Asturias].

716. "Miguel Angel Asturias: dos veces Premio Nobel", Cultura, 46 (San Salvador, oct.-dic. 1967), pp. 71-72.

En la madrugada del 17 de oct. 1965 se anunció que MAA había ganado el Premio Nobel. Más tarde el cable transmitió la noticia que Sholojov era el vencedor. "El director del diario Tribuna Libre de Guatemala - Humberto Ibarra-, no se desanimó, sino que ....editorializó al día siguiente sobre la obra indiscutible y la sólida personalidad de Asturias, señalando valores y adelantando juicios que ahora el mundo entero corrobora.-Mediante ese editorial ...se anticipó en dos años, concediendo a Miguel Angel Asturias, el galardón que hoy la Academia le ha entregado por derecho".

717. "El espejo de Lida Sal", El Libro, 222-224 (Buenos Aires, oct.dic. 1967), p. 7 [reseña].

718. "Universal consagración de Miguel Angel Asturias", Novedades (México, 21 oct. 1967), p. 4.

719. "Un segundo Premio Nobel", El Sol (México, 21 oct. 1967), p. 5.

720. "Vanidad insustancial", Polítict, VIIl:179-180 (México, nov. 1967), p. 61 [reseñd de El espejo de Lida Sal]. 
721. "Le Prix Nobel de Littérature sculpté á Paris", Frante Soir (París, 8 nov. 1967).

Narra el escultor francés Coutelle: "Ce qui m'a frappé le plus quand je reproduisais sa tête dans le granit ...c.était sa faculté d'absence ou de présence".

722. "Miguel Angel Asturias; poeta, diplomático, novelista y etnólogo", Diario de Centroamérica (Guatemala, 10 nov. 1967), pp. 3 y 6.

723. "El $Y a$ de Madrid editorializa... otro Nobel al idioma castellano", supl. homenaje a MAA dol diario El Gráfiro (Guatemala, 11 nov. 1967), p. 10.

"No es el momento de discutirle la ideologia" ...resplandece "como escritor de garra" y subraya que Miguel Angel Asturias no es un espontáneo; es artista reflexivo".

724. "Clarivigilia primaveral", Clarin (Buenos Aires, 11 nov. 1967) [reseña].

725. "Guatemala rinde homenaje a Asturias", El Día (México, 16 nov. 1967), p. 1 [homenaje del Congreso de Guatemala].

726. "Héroe romántico llama Asturias al Che Guevara en una entrevista", Excélsior (México, 22 nov. 1967), p. 29A.

Entrevista publicada anteriormente en el perí́dico $l l$ Messaggero de Roma.

727. "Mulattkvinnan", Göteborgs Handels ocb Sjofart-Tidning (Gotemburgo, 23 nov. 1967) [breve reseña de la versión sueca de Mulata de tal].

728. "Miguel Angel Asturias y el Premio Nobel", Horizonte, XIII: 87-88 (Guatemala, nov.-dic. 1967), pp. 5-6.

Es creador poético de múltiples recursos "desde la brillante e imaginativa exactitud de su soneto 'Ulises', pasando por su místico canto 'A la Virgen', el épico y revolucionario 'Credo a Bolívar', hasta sus coruscantes metáforas del sonoro poema a 'Tecún Umán'..."

729. "Asturias; 'Mito y realidad", Portal, 6 (Santiago, Chile, dic. 1967), p. 4.

"A muchos escritores chilenos les causó desilusión el nuevo Premio Nobel de Literatura. En ningún caso desconocen los méritos de Miguel Angel Asturias, pero esperaban que el agraciado fuera Pablo Neruda..."

730. "Balcón", La Gaceta, XIV:160 (México, dic. 1967), p. 5, col. 3 [trata del Premio Nobel].

731. "Miguel Angel Asturias en Estocolmo", Diario de Centroamérica (Guatemala, 7 dic. 1967), p. 1 [véase Svenska Dagbladet (Estocolmo, 7 dic. 1967)]. 
732. "Lujoso estilo para un vasto fresco de Guatemala", Clarin (Buenos Aires, 7 dic. 1967), p. 3.

Reseña de El espejo de Lida Sal. Se publica esta obra al mismo tiempo "en seis idiomas: español, ftancés, inglés, alemán, italiano y sueco. ¿Un best-seller mundial fundado en la magia con que reviste el Premio Nobel a sus destinatarios?"

733. "Asturias aktiviteter", Aftonbladbet (Estocolmo, 8 dic. 1967).

734. "Miguel Angel Asturias declarado guatemalteco insigne mediante Decreto del Congreso", El Imparial (Guatemala, 8 dic. 1967), pp. 1 y 10 [se recalca la recia personalidad del homenajeado].

735. "Miguel Angel Asturias declarado guatemalteco insigne", Diario de Centroamérica (Guatemala, 8 dic. 1967), p. 1 [véase cédula anterior]:

736. "Informa la revista Visión; El segundo Premio Nobel de Literatura", Diario de Centroamérica, LXXXVII:26136 (Guatemala, 9 dic. 1967), pp. 1-2.

"Los novelistas latinoamericanos lentamente están rompiendo las barreras del idioma y comienzan a ser más apreciados en Eutopa".

737. "Hoy recibirá Miguel Angel Asturias en la capital de Suecia el Premio Nobel de Literatura", El Gráfico (Guatemala, 10 dic. 1967), p. 6.

738. "Asturias Hedrades Därhemma", Sydsvenska Dagbladet (Malmö, 10 dic. 1967).

739. "En fest med pompa och snille", Dagens Nybeter (Estocolmo, 10 dic. 1967) [banquete en honor a MAA].

740. "El rey sueco entregó los Nobel; hermoso discurso pronunció el laureado Miguel Angel Asturias", Excélsior (México, 11 dic. 1967), Pp. 1A y 15A.

741. "Sobre El espejo de Lida Sal", Sucesos para todos (México, 11 dic. 1967).

"Libro poético y mágico... intención política y social", señala el comentarista.

742. "La novela auténtica debe ser leal a los puños de los obreros, afirma Asturias", El Día (México, 12 dic. 1967), p. 6.

743. "Asturias habla de la novela; cita antecedentes entre los aztecas, mayas y quechuas", Novedades (México, 12 dic. 1967), p. 2.

744. "Miguel Angel Asturias recibió el Premio Nobel de Literatura", El Gráfico (Guatemala, 12 dic. 1967), p. 5.

745. "Miguel Angel Asturias definió lo que debe entenderse por novela", El Nacional (México, 12 dic. 1967), p. 2. 
746. "Guatemala; paréntesis", Tiempo, 1338 (México, 25 dic. 1967), p. 32 [sobre Asturias].

747. "Miguel Angel Asturias", Literární listy, 15 (Praga, 1968), p. 11 [entrevista].

748. "Legendaria Guatemala de Miguel Angel Asturias", Clarin (Buenos Aires, 4 ene. 1968).

749. "El espejo de Lida Sal", La Nación (Buenos Aires, 7 ene. 1968). "En un estilo más depurado - tal vez menos barroco-, Asturias vuelve a los temas reposados, gratos a su fantasía, que habia abandonado para incorporarse a la más cruda corriente realista de la literatura hispanoamericana..."

750. "Premio Nobel para Latinoamérica", Alcor, 46 (Asunción, ene.feb. 1968), pp. 19-20.

Breve pero certera síntesis de la significación de la obra asturiana. "Ha protagonizado una interesantísima aventura literatia. Partiendo de una actitud renovadora tanto en el plano formal como en el temático elaboró sus obras utilizando una vasta gama de recursos literarios entre los cuales muchos dependian de una formidable y personalisima intuición:".

751. "Al pie de la letra", Casa de las Américas, 46 (La Habana, ene.feb. 1968), pp. 207-208.

Una glosa del artículo de Emmanuel Carballo, publicado en Excélsior (México, 29 oct., 1967), pp. 3 y 5 [véase ficha núm. 904].

752. "El espejo de Lida Sal", Insula, 255 (Madrid, feb. 1968), p. 18 [reseña].

753. "Libros que más se han vendido en la semana del 26 de enero al 2 de febrero", Tiempo, 1344 (México, 5 feb. 1968), p. 43.

El señor Presidente es clasificado en primer lugar durante varias semanas.

754. "Miguel Angel Asturias opina sobre la actual novela latınoamericana", Clarin, supl. lit. (Buenos Aires, 8 feb. 1968).

MAA hace hincapié en que su prosa "es un poco barroca, está muy vestida. Pero se lo debo yo indudablemente un poco a la tradición maya". Los mayas temían el vacio y sus grandes monumentos: "los llenaban de figuras y así nos pasa a los escritores con esta ascendencia: buscamos mucha palabra".

755. "Nota editorial", La pájara pinla, III:27 (San Salvador, mar. 1968), p. 1.

"Autor de novelas que reflejan vicios y miserias de la América Central; cuentista barroco con mucho de brujo maya... poeta de gran valía. Asturias está demostrando al mundo que América Latina sí tiene ya una literatura propia".

756. "Rechten van mens centraal op Wereldthe: awereldtheaterdag", de Volkskrant (Amsterdam, 23 mar. 1968). 
757. "Nota editorial", Repertorio [Centroamericano] IV:9 (San José, C. R., abr. 1968), p. 4.

" "Centroamérica, como región cultural delimitada a principios de siglo por el genio de Rubén Dario, no vuelve a sutgir en dimensión universal sino hasta la aparición de El señor Presidente, la primera gran novela que afronta nuestra realidad y que toma como escenario la gran noche feudal de las dictaduras tropicales".

758. "La Universidad de Jerusalem rinde homenaje a Miguel Angel Asturias", El Imparcial (Guatemala, 4 abr. 1968), pp. 11 y 15. Velada en honor a MAA. Hizo la exégesis el Prof. Moshé Lazar.

759. "Publican en España ensayos de Miguel Angel Asturias", Excélsior (México, 6 abr. 1968), p. 3 [reseña de Torotumbo; La audiencia de los confines, mensajes indios, Barcelona, 1967].

760. "Mulata", United Church Herdld (St. Louis, Mo., may. 1968). Notícula sobre la traducción al inglés de Mulata de tal "Witchraft and mythology".

761. "Asturias: Obras completas", Insula, 258 (Madrid, may. 1968), p. 18.

Reseña. "Las direcciones mágicas o de protesta social de su narrativa pueden apreciarse mejor ahora en que aparecen juntas, facilitando consulta y comparaciones".

762. "Carta de Jerusalén; homenaje a Miguel Angel Asturias", Zona Franca, IV:57 (Caracas, may. 1968), p. 45.

Homenaje efectuado en la Univ. de Jerusalén rindiendo tributo a MAA. Disertó el Prof. Moshé Lazar. "Visicnatio y acusador, poeta y fiscal, portavoz de la hetida cultura maya, testigo fiel de los sufrimientos de los campesinos..." así caracterizó a MAA el catedrático israelí:

763. "New books at library", Bassett Journal (Bassett, Va., 9 may. 1968).

Breve reseña de la traducción al inglés de Mulata de tal. "Leading off the list of new fiction is a novel dealing with Indian life in South America..."

764. "Letras; Asturias, un clásico", SP. (Madrid, 12-18 may. 1968), p. 51 [amplia y elogiosa reseña de las Obras completas].

765. "Sextante", Mundo Nuevo, 1 (Paris, jul. 1968), pp. 79-84. MAA. pp. 79-80. Opiniones de Alain Bosquet y Claude Couffon respecto a la traducción francesa de Clarivigilia primaveral.

766. "Entrevista con Miguel Angel Asturias", Pregón, 308 (México, jul. 1968), pp. 8-9.

Extracto de un trabajo publicado en la revista española, Cuadernos para el diálogo.

767. "Homenaje a Miguel Angel Asturias en el festival hispano", Novedades (México, 13 jul. 1968), p. 6, tercera sección.

En el Concurso Internacional de Cine de San Sebastián, se proyectó la película Soltunt, de Marcos Madanés, inspirada en la obra de Asturias. Su "figura literaria fue exaltada antes de la proyección del mencionado filme". 
768. "Miguel Angel Asturias en el mundo", El Imparcial (Guatemala, 5 ag. 1968) [se refiere a la revista alemana Informa 44, que contiene comentarios sobre MAA].

769. "Mulata", Watsonville Register-Pajaronian (Watsonville, Calif., 7 oct. 1968).

Noticula sobre la traducción al inglés de Mulata de tal. "Exotic, a little difficult to read, but a valuable orientation to the Indian mind-set of Latin America Nobel Prize-Winner".

770. "Asturias y Senghor estudiarán la realidad afro-latinoamericana", El Día (México, 16 feb. 1969), p. 7.

Basándose en la premisa de que hay "cierta similitud entre las cuestiones... del continente africano" y las de indo-latinoamérica, el Presidente del Senegal ha invitado a MAA para que "cambien impresiones" en Dakar, durante 15 días.

\section{REFERENCIAS: HEMEROGRAFIA SOBRE ASTURIAS}

(Estudios, artículos, reseñas, etc.)

771. A. B.: "Monsieur le President par Miguel Angel Asturias", Les Nouvelles Littéraires (París, 3 abr. 1952), p. 3 [reseña].

772. Abraham, Rosario: "Miguel Angel Asturias", Acción (Montevideo, 1er. domingo de diciembre 1967).

Entrevista y comentarios criticando a MAA por su actuación como diplomático del gobierno de Julio César Méndez Montenegro.

773. Abreu Gómez, Ermilo: "Poeta de Guatemala", Américas, II:8 (Washington, jul. 1950), pp. 37-38.

774. Acevedo, Hugo: "Poesía precolombina", Ficción, 33-34 (Buenos Aires, sep.-dic. 1961), p. 197 [reseña de la "Selección", hecha por MAA].

775. Acoca, Miguel: "Un maya en París habla de su obra", Life en español, XXX:12 (Nueva York, 4 dic. 1967), pp. 65-66.

Entrevista. "Asturias... es un gran artifice del español de la América Latina. Ha desquiciado la lengua castellana y le ha inyectado nuevos ritmos y significados propios, sin caer en la trampa del preciosismo puro... Mulata de tal, una obra dificilísima, en lenguaje que describe como 'español que deja de ser español, siendo español"'.

776. Adán: "Verdiente Ehrung M", Berliner Zeitung (Berlín, Este, 22 oct. 1967) [breve nota biobibliográfica].

777. Aguilera, León y Carlos Samayoa Aguilar: "Un poema y un libro", Boletin de la Biblioteca Nacional, IV (Guatemala, 1935), Pp. 666-667 [reseña de Emulo Lipolidón]. 
778. Aguilera, León: "Miguel Angel Asturias en el Olimpo del Nobel", El Imparcial (Guatemala, 24 oct. 1967), p. 3.

Emocionada exaltación "y si observamos su trayectoria... los mitos indígenas se han convertido en la tonalidad de sus creaciones, en la guatemalidad universalizada".

779. Ahrweiler, A.: "Miguel Angel Asturias; romancier du Guatémala", Les Lettres Françaises, 659 (París, 21-27 feb. 1957), pp. 1 y 5 .

780. Alarcón Folgar, Romelia: "La ticrra de Ilom", El Imparcial (Guatemala, 9 dic. 1967), p. 17 [poema dedicado a MAA].

781. Alba, Ma. Teresa: "Miguel Angel Asturias, su obra y su mundo", "Revista de la Semana", de El Universal (México, 11 ago. 1968), Pp. 6-7.

782. Alegría, Ciro: "Hombres de maiz de Miguel Angel Asturias", Asomante, VI:2 (San Juan, P. R., abr.jun. 1950), pp. 92-94 [reseña].

783. Alegría, Fernando: "Retrato y autorretrato; la novela hispanoamericana frente a la sociedad", Aportes, 8 (París, abr. 1968), p. 24 passim.

"Miguel Angel Asturias es un pozo sin fondo. Rásquelo Ud. y sale, no el Popol $V u b$ que es un libro, salen los muertos de su lago, los coyotes de sus muertos, los conejos de sus coyotes, los brujos de sus conejos. Sin decir nada de los coroneles de sus chacales y los chacales de sus gringos".

784. Alegría, Fernando: "Miguel Angel Asturias, novelista del viejo y del nuevo mundo". La literatura del Caribe y otros temas. Memoria del Octavo Congreso del Instituto Internacional de Literatura Iberoamericana (México, 1961), Pp. 131-141 [medular valoración. De indispensable consulta].

785. Alvarado, Humberto: "La realidad guatemalteca en la obra de Asturias", Revista de Gtuatemala, XVIII:2 (Guatemala, ene.-dic. 1960), pp. 46-65.

Exaltación. "Antes de Astutias ningún escritor del país pudo darnos una imagen mejor del hombre guatemalteco... Asturias incursiona en el espiritu guatemalteco, en sus características externas e internas; en su vocabulario, en su manera de ser, en su psicologia..."

786. Alvarado, José: "Intenciones y crónicas bajo el Premio Nobel", Excélsior (México, 26 oct. 1966), p. 7A [menciona entre otros, a Asturias].

787. Albízures Palma, Francisco: "Lo social en dos novelas de Miguel Angel Asturias", El Imparcial (Guatemala, 3 sep. 1966), pp. 13-20.

788. Albízures Palma, Francisco: "Bibliografía de Miguel Angel Asturias", Repertorio Centroamericano, IV:9 (El Salvador, abr. 1968), pp. 30-31 [algunas fichas de sus publicaciones]. 
789. Albízures Palma, Francisco: "Miguel Angel Asturias: Señor de las letras", El Imparcial (Guatema'a, 4 nov. 1967), p. 9.

790. Anderson Imbert, Enrique: "Análisis de El señor Presidente", Testigo, 4 (Buenos Aires, oct.-dic. 1966, pp. 1-7).

Análisis desde el punto de vista estético y no "como documento histórico". Anderson Imbert, contrario a varios críticcs, considera El señor Presidente, su "mejor novela".

791. Andrés, Alfredo: "Miguel Angel Asturias; nota y reportaje", El escarabajo de oro (Buenos Aires, nov.-dic. 1961), [sobre El albajadito].

792. Anea: "Ett Förlosande Skratt inledde Nobelfesten...", Svenska Dagbladet (Estocolmo, 11 dic. 1967), pp. 1 y 9.

793. Antúnez, Rodrigo: "Literatura y sociedad: una relación problemática", Imagen, 24 (Caracas, 1-15 may. 1968), pp. 6-7.

Al estudiar la visión dialéctica de la crítica literaria -crítica interpretativa e inmanente-, se detiene en el ensayo de Yepes Boscán sobre Asturias, publicado en la revista Aportes, 8 (París, 1968).

794. Anzueto, Julio César: "Miguel Angel Asturias habla de su retorno", Prensa. Libre (Guatemala, 29 jun. 1966), p. 7.

795. Anzueto, Julio César: "Miguel Angel Asturias habla del Premio Nobel de Literatura", Prensa Libre (Guatemala, 1? jul. 1966), p. 12.

Entrevista con maA en Paris. Se abordan varios temas: la repatriación de Gómez Carrillo, Sartre, la comunidad de escritores latinoamericanus, el periodismo, etc.

796. Anzueto, Julio César: "Comunistas de Suecia tratan de explotar el triunfo de Asturias", Prensa Libre (Guatemala, 18 dic. 1967), p. 21 .

797. Anzueto, Julio César: "Asturias en el recuerdo", Revista A.P. G. 27 (Guatemala, dic. 1967), pp. 21-23.

Un recortido evocador por los lugares de la niñez y la juventud de MAA. Esto es, por el viejo y pintoresco barrio de La Parroquia en la ciudad de Guatemala. Se acerca a la "nana" de Asturias, una viejecita de 96 años, quien revela que el niño Miguel Angel era "muy caprichoso... no quería ser cuidado".

798. Anzueto, Julio César: "La entrega del Premio Nobel", Revista A.P.G. Asociación de Periodistas de Guatemala, 28 (Guatemala, abr. 1968), pp. 23 y 56.

En Estocolmo, durante la ceremonia, "al recibir el abrazo de su hijo Miguel, sus ojos se nublaron $y$... unas lágrimas rodaron por sus mejillas".

799. Aponte, Bárbara B.: "Los falsos demonios", Insula, 262 (Madrid. sep. 1968), p. 11 [comparación de Los falsos demonios de Carlos Solórzano y El señor Presidente]. 
800. Aponte, Bárbara B.: "La imposibilidad de la inocencia", "La cultura en México", supl. de Siempre!, 356 (México, 11 dic. 1968), p. XII [resumen del ensayo anterior].

801. Aramendía, María Victoria: "Entra el Tercer Mundo en las letras universales", El Imparcial (Guatemala, 6 abr. 1968), pp. 15-21.

802. Arbenz, Jacobo: "Prefacio' a la traducción rusa de Los ojos de los enterrados, Moscú, Ediciones "Progreso", 1968.

803. Arce, Manuel José: "El exilio en la poesía centroamericana", Universidad de Honduras, II:21 (Tegucigalpa, abr. 1960), pp. 10 y 14.

MAA, p. 14. "Su novela, su teatro, su poesía siempre tiene como escenario Guatemala... el escritor se debe a su pueblo... por la patria sufre y vive el exilado".

804. Arce, Manuel José: "Asturias habla sobre el Premio Nobel", El Gráfico (Guatemala, 10 dic. 1967), pp. 8 y 31.

Entrevista. MAA subraya que el premio se otorga a la obra de un autor y no precisamente al escritor...

805. Arce, Manuel José: "Premio Nobel, 36 horas en tren con Miguel Angel Asturias", Diario de Centroamérica, LXXXVII:26 153 (Guatemala, 3 ene. 1968), pp. 1-2.

El corresponsal, junto con Günter W. Lorenz, viajó en el Expreso Paris-Copenhague con MAA. Narra los incidentes del viaje. "Las cámatas de la T.V. captando todos sus movimientos... los micrófonos registran todas sus palabras en interrogatorio agotador... en el vagón especial, 'cámara de tortura', hasta su sueño será capturado por la prensa audio-visual... sólo puede descansar en el cuarto de baño...

"'Estos fregados me tratan como si yo fuera la Brigitte Bardot', exclama MAA. '¿Serán tán ciegos que no se dan cuenta de la diferencia?' "

806. Arce, Manuel José: "De cómo Miguel Angel Asturias encendió una corona de llamas en Estocolmo", El Gráfico (Guatemala, 21 ene. 1968), pp. 18 y 31.

807. Arce, Manuel José: "Carta abierta a propósito del Premio Nobel de un guatemalteco", El Gráfico (Guatemala, 23 ene. 1968), pp. 8 y 31 [arremete contra los críticos de MAA].

808. Arciniegas, Germán: "Balance de 1967: aceptación de América Latina", Excélsior (México, 28 dic. 1967), p. 7A [sobre Asturias y otros].

809. Arciniegas, Germán: "Mirador; Lo bueno de Asturias", El Imparcial (Guatemala, 22 nov. 1967), p. 9.

Reminiscencias de su trato con MAA. Ásevera que "lo bueno de Miguel Angel Asturias es su complejidad", que va "a la iglesia" y recibe "el Premio Lenin"... "Los suecos se inclinaron del lado de Asturias... como ellos mismos son complicados, buscaron... algo que llevara a su Academia un perfume exótico".

810. Arenas Castillo, Enrique: "El señor Presidente o la concepción 
demoníaca del mundo", Antuario de filología, VI-VII:6-7 (Maracaibo, 1967-1968), pp. 231-300.

Amplio ensayo. Se estudian varios aspectos: Lo fantasmagórico y sobrenatural. La deshumanización del hombre y la humanización de las cosas. El naturalismo escatológico. El elemento onírico y algunos recursos surrealistas... Buceo psicológico, monólogo y técnica joyceana... Contrastes estilísticos... La denuncia y la sátira político-social, etc.

811. Arrigoitia, Luis de: "Leyendas de Guatemala", Asomante, XXIV: 3 (San Juan, jul.-sep. 1968), pp. 7-20.

Revisión de las Leyendas de GHatemala y El espejo de Lida Sal. Analiza con ponderación, "los recursos narrativos y estilísticos".

812. Asturias, Marco Antonio: "Miguel Angel Asturias: Premio Nobel de Literatura", El Gráfico (Guatemala, 20 oct. 1967), pp. 5 y 38.

813. Aubert, Claude: "Clairveillées de printemps", Journal de Genève (Ginebra, 28 may. 1966) [reseña de la traducción francesa de Clarivigilia primaveral].

814. Aubrun, Charles V.: "Structure interne des romans de Miguel Angel Asturias".

Conferencia, en la Sorbona, Amphithéâtre Richelieu, París, 9 feb. 1968. Se publicó después con el siguiente título "Aperçu sur la structure et la signification de Mulata de tal", en Europe, 473 (París, sep. 1968), pp. 15-20. "Lida Sal, Celestino Yumi... Ie President... Mais c'est nous, c'est nous révélés à nous-mêmes par la magie du verbe... pour nous guider dans notre éternel périple".

815. Ayala, Carlos: "Rincón literario; universalidad de Miguel Angel Asturias", Revista Aérea, VI:6 (Guatemala, 10 dic. 1967), p. 63. Defensa y exaltación de MaA. "Su universalidad lo colcca... en Ia cúspide de la creación literaria... [Por] el surrealismo mágico de su poesía y el contenido dinámico de sus populvúhicas expresiones".

816. Ayala, Juan Antonio: "Papeles al vienio; del barro de la tietra", Vida Universitaria, 361 (Monterrey, N. L., 1958).

817. Aycinena, Luis: "La antigua Guatemala según Miguel Angel Asturias", Cuademos Hispanoamericanos, 16 (Madrid, jul.-ag. 1950), Pp. $145-146$.

Reseña de Leyendas de Guatemala. "Es la cocción de dos culturas, dos religiones, dos razas, dos almas, dentro de un fondo telúrico avasallador. El fondo adonde Ilegaron hombres hechos de barro y encontraron al hombre hecho de maíz".

818. Aycinena, Luis: "Novela y dolor de Guatemala", Cuadernos Hispanoamericanos, 14 (Madrid, mar.-abr. 1950), pp. 375-378.

Reseña de El señor Presidente. "Las imágenes surgen retorcidas como los bejucos alrededor de los viejos troncos. Es el trópico en marejadas de metáforas. $\mathrm{Y}$ el argumento es igualmente de cuño americano".

819. Azaña, Manuel M. y CL. Mie: "Entrevista con Miguel Angel Asturias; Premio Nobel", Bulletin Hispanique, LXX:1-2 (Bordeaux, ene.-jun. 1968). 
820. Balcárcel Ordóñez, José Luis: "La pasión guatemalteca de Asturias", Revista de Guatemala, XVIII:2 (Guatemala, ene.-dic. 1960), p. 108.

"Para percatarse de lo propio, Miguel Angel Asturias se tomó el trabajo de escudriñar lo universal en función de lo nacional..."

821. Baldacci, Luigi: "E un grande scrittore il nuovo Premio Nobel?", Epoca, 895 (Milán, 19 nov. 1967), pp. 150-151 y 154.

Cauteloso acercamiento a MAA. ¿Por qué? ¿Animo de buscar sólo lo que el articulista cree que son defectos? ¿Turista inseguro en un mundo literario ajeno? Pero a veces le reconoce una "felice libertà d'invenzione" y una "esasperada coerenza del suo stile".

822. Baquero, Gastón: "Miguel Angel Asturias, Premio Nobel", Mundo Hispánico, 237 (Madrid, 1967), pp. 12-15.

823. Baquero, Gastón: "Se ratifica la significación literaria de Hispanoamérica", supl. homenaje a MAA de El Gráfico (Guatemala, 11 nov. 1967), p. 10.

Al confrontar El señor Presidente, con El Tirano Banderas, el articulista afirma: "Lo que en Valle es tema de exotismo, en Asturias es sufrimiento y pasión, sin descuido del magnífico idioma".

824. Barbiellini Amadei, G.: "Asturias, il volto di un idolo maya", Corriere d'Informazione (20-21 nov. 1967), p. 3.

Se reproduce este ensayo en La Hora (Guatemala, 25 ene. 1968), en traducción de Julio Varona. "Desorden en las estructuras se ha ya señalado aquí y allá en las novelas de Asturias. Pero la conciencia de un tealismo mítico, de una simbología vivida, ofrece a menudo al conjunto de la obra una estructura más vasta, en la cual las fạllas menores son como los golfos, los fjords en la extensión de las costas".

825. Barbieri, Vicente: "Hombres de maiz", Sur, 189 (Buenos Aires, jul. 1950), PP. 89-93.

El poeta argentino al reseñar esta novela, la compara con una sinfonia.

826. Bareiro-Saguier, Rubén: "Miguel Angel Asturias, romancier de l'Amérique Latine", Signes du temps (París, 12 dic. 1967), pp. 27-29.

MAA, "intègre d'emblée l'univets indien, le merveilleux mayas-quichés, les correspondances mystérieuses de la mentalité primitive, totalement absentes de la logique occidentale".

827. Bareiro-Saguier, Rubén: "Miguel Angel Asturias, Premio Nobel", supl. literario de La Tribuna (Asunción, Paraguay, 5 nov. 1967), p. 11.

828. Barnoya, José: "Estampas del presente, el Premio Nobel", La Hord (Guatemala, 24 oct. 1967).

Narra cómo recibió la noticia de la "conquista" del Premio Nobel 1967.

829. Barón Castro, Rodolfo: "Leyendas de Guttemala", Nosotros, I:3 (Madrid, 15 may, 1930).

Tal vez la primera reseña de las Leyendas. Elogia el doble aspecto de "la obta del escritor guatemalteco. . el de haber hecho un buen libro y el de haber hecho un libro americano". 
830. Barrera Avila, Rubén: "Un hombre de estirpe literaria conquista el Premio Nobel. ..", La Hora (Guatemala, 23 oct. 1967).

"araA tiene... dos fisonomías, el hombre como testigo de la historia y el esteta como analista de la belleza y de la vida".

831. Barrientos, Alfonso Enrique: "El cuento guatemalteco", Guatemala literaria, artística, económica... 1:5 (México, may. 1949). MAA, p. 4. "Miguel Angel Asturias traduce los sentimientos más hondos del indigena a expresiones poéticas y todo aquel mundo estético sale a relucir en un accionismo delirante".

832. Barrientos, Alfonso Enrique: "El cuento guatemalteco", El Imparcial (Guatemala, 4.jun. 1949) [MAA, p. 9].

833. Barrientos, Alfonso Enrique: "Ecos de Miguel Angel Asturias", El Colombiano Literario (Bogotá, 9 ag. 1959), pp. 1-2.

Entrevista con MAA en Buenos Aires. Entreteje su trayectoria literaria, con tecuerdos y noticias de amigos. El diálogo se interrumpe con la "llegada" de Eduardo Mallca.

834. Barrientos, Alfonso Enrique: "Ecos de Miguel Angel Asturias", Nivel, 9 (México, 25 sep. 1959), p. 4.

835. Barrientos, Alfonso Enrique: "Aproximaciones a Miguel Angel Asturias", El Imparcial (Guatemala, 28 oct. 1967), PP. 17 y 23. Evocación de sus encuentros y reencuentros con MaA a través de los años $\mathrm{y}$ en diferentes paises.

836. Barrientos, Alfonso Enrique: "Un año del Premio Nobel; aproximaciones a Miguel Angel Asturias", La Hora Dominical, I:1017 (Guatemala, 29 oct. 1967), pp. 31-34.

837. Barrientos, Alfonso Enrique: "Año del Premio Nobel; aproximaciones a Miguel Angel Astutias", El Maestro, 13 (Guatemala, ene.-mar. 1968), PP. 91-98.

838. Barrientos, Alfonso Enrique: "Guatemala en el mundo; el Nobel para Asturias", La Hora Dominical, I:1017 (Guatemala, 29 oct. 1967), pp. 29 y 46 [glosa al comentario de A. Osterling].

839. Barrientos, Alfonso Enrique: "La poesía de Miguel Angel Asturias", Cultura, 46 (San Salvador, oct.-dic. 1967), pp. 19-28.

"La poesia de Miguel Angel Asturias ha sido cada vez un paso... en la evolución de la palabra y de la imagen; ha ido de lo natural a lo sobrenatuml, pero asentando los pies desnudos en la sustancia del sueño".

840. Barrientos, Alfonso Enrique: "La poesía de Miguel Angel Asturias", supl. homenaje a MAA del diario El Gráfico (Guatemala, 11 nov. 1967), Pp. 6 y 15.

841. Barrientos, Alfonso Enrique: "La poesía de Miguel Angel Asturias", Revista conservadora del pensamiento centroamericano, 89 (Managua, feb. 1968), pp. 14-17. 
842. Barrios Archila, Jaime: "Miguel Angel Asturias, el iluminado", Revista A.P.G. 27 (Guatemala, dic. 1967), pp. 31-50.

Reproducción parcial del discurso que mas pronunció al recibir el Premio Lenin de la Paz: "Yo soy el personero de un mundo literario que de México a la Argentina... está volcando en sus obras, creadas a base de sustento popular, la dimensión latinoamericana del hombre, hecha de fábula, de complejos instintos y atávicas llamadas, en la que lo primitivo se funda en lo moderno..."

843. Blanco, César Augusto: "Miguel Angel Asturias, gran chimán de las letras", La Hora (Guatemala, 15 dic. 1967) [divagantes notas].

844. Bastide, Roger: "L'Amérique Latine dans le miroir de la littérature", Annales, 1 (París, 1958) [estudia las contribuciones indígenas mediante los mitos y leyendas en MAA].

845. Bataillon, Marcel: "Miguel Angel Asturias et Bartolomé de las Casas".

Conferencia en la Sorbona. Amphithéâtre Richelieu (París, 9 feb, 1968). Se publicó posteriormente en Europe, 473 (París, sep. 1968), pp. 6-10. "Asturias tisse reminiscences et souvenits de figure historique avec une liberté insouciese de chronologie qui est celle de la mémoire populaire".

846. Batis, Huberto: "Los libros", El Heraldo cultural, 47 (México, 2 oct. 1966), p. 14.

"Comentario al tercer tomo de las Obras escogidas y Clarivigilia...", esta última es señalada como "obra sincopada".

847. Bauer, Walter A. "Anwalt der armen und Unterdruckten", Kölniscbe Rtındschau (Colonia, 20 oct. 1967) [semblanza biobibliográfica y análisis del realismo mágico en Asturias].

848. Bay, Andrés: "Literaturas hispanoamericanas", Opera (París, 12 18 mar. 1952).

Reseña de varios libros hispanoameticanos: Ficciones, de Borges, Doña Bárbard, de Gallegos y El señor Presidente. "El señor Presidente nos introduce en un universo que por ser barroco y absurdo, es menos realista y lógico. Es una especie de pórtico de los milagros, de extravagante monumento azteca, erigido con carne y pasta de miseria humana".

849. Becirovic, Komnen: "Entretien Asturias: 'Engagé'? Non. Responsable!", La Quinzaine litteraire, 43 (París, 15/31 ene. 1968), pp. 6-7.

Entrevista. Versa sobre "L'irrationel et Valéry", "Le double héritage Espagnol et Maya" de MAA, etc.

850. Beltranena Sinibaldi, Luis: "Breve historia y significación del Premio Nobel".

Conferencia, sustentada en los canales 3 y 7 de televisión. (Guatemala, 10 dic. 1967). Se refiere a MAA. Véase Prensa Libre (Guatemala, 10 dic. 1967), p. 75.

851. Bellini, Giuseppe: "Escritores latinoamericanos en italiano; Mi- 
guel Angel Asturias", Asomante, XXII:1 (San Juan, P. R. 1966), Pp. 68-71.

852. Bellini, Giuseppe: "La poesía de Miguel Angel Asturias", Revista Nacional de Cultura, 180 (Caracas, abr.-jun. 1967), pp. 125127.

"Su poesia es esencialmente diálogo reencontrado con las cosas y el hombre, auscultación atenta de su secreto latido, revelación continua de la humanidad, que de esta manera se construye y encuentra la fuerza para resistir el mal, superar el desgaste del tiempo y creer en el 'dia de luz' que Asturias pregona".

853. Bellini, Giuseppe: "La fama de Asturias", Diario de Centroamérica, LXXXVII; 26136 (Guatemala, 9 dic. 1967), pP. 5 y 7.

854. Bertino, Cledy M.: "Miguel Angel Asturias y el simbolismo mítico de Hombres de matz", Universidad [revista de la Universidad Nacional del Litoral], 68 (Santa Fe, Argentina, jul.-sep. 1966), pp. 233-266.

"Gaspar Ilóm y la Piojosa Grande se transforman en la réplica fun. cional del dúo cosmo-teogónico maya-quiché, cuyo sentido de permanencia está dado en la inmortalidad del semen creador y en su proyección a través del tiempo y el espacio en la fertilidad del cosmos que reviviendo siempre, no muere jamás".

855. Bergenstein, O. Stigbjoern: "Neruda y Miguel Asturias candidatos al Premio Nobel 1966", El Imparcial (Guatemala, 18 oct. 1966), pp. 1 y 4.

856. Bernal, Ligia: "La andiencia de los confines", El Imparcial (Guatemala, 22 sep. 1961), Pp. 11 y 13 [reseña].

857. Bernert, Philippe: "Nouveau Prix Nobel", L'Aurore (París, 20 oct. 1967).

Bosquejo informativo con ribetes de sensacionalismo: "Cette Amérique Latine à l'ordre du jour, avec ses guerrilleros, ses Guevara et ses Debray, a désormais aussi son Ptix Nobel".

858. Bertocci, S.: "Un poeta guatemalteco", Il Popolo (Roma, 18 jul. 1965), P. 5.

859. Bjorneberg Anne: "Premio Nobel de Asturias una gloria para el pais", Prensa Libre (Guatemala, 23 oct. 1967), p. 59.

860. Blanco, Ramón: "Galera referente a Miguel" Angel Asturias", El Imparcial (Guatemala, 20 nov. 1967), p. 2.

861. Blanzat, Jean: "Week-end au Guatemala", Le Figaro Littéraire (París, 7 feb. 1959), p. 10 [reseña].

862. Blanzat, Jean: "Hommes de maïs", Le Figaro Littéraire, 407 (París, 6 feb. 1954), p. 9 [reseña].

863. Blanzat, Jean: "L'Ouragan de Miguel Angel Asturias", Le Figaro 
Littéraire, 490 (París, 10 sep. 1955), p. 9 [reseña de Viento fuerte].

864. Blöcker, Günter: "Zwischen legende und Aufklärung", Sïddettsche Zeitung, 12 (Munich, 13 ene. 1968) [reseña de la versión alemana de Viento fuerte].

865. Bodini, Vittorio: "Asturias y Sábato", Ulisse, IX (Roma, abr. 1968).

866. Bosquet, Alain: "Claireveillée de Printemps", Le Monde (París, 23 abr. 1966) [reseña].

867. Bosquet, Alain: "L'expressionnisme tropical de Miguel Angel Asturias", Combat (París, 27 dic. 1962).

"Une oeuvre qui est toute d'élan irresistible et de voyance, dans l'accepticn à la fois que pourraient lui donner Rimbaud et Zola".

868. Bosquet, Alain: "Le miroir de Lida Sal", Combat (París, 20 jul. 1967) [reseña].

869. Bosquet, Alain: "Lettre ouverte aux comités Nobel", Combat (Paris, 3 oct. 1967).

Solicita que el Premio Nobel sea otorgado a MAA y así reconocer el aporte de todo un continente "aux possibilités spirituelles innombrables".

870. Bourcier, Paul: "La obra de Asturias", Ultima Hora (La Paz, Bolivia, 19 oct. 1967), p. 1.

Panorámico derrotero de su vida y obra. "Este diplomático cuya cortesía es proverbial, ha sabido ser asimismo un escritor violento... con violencia... ha denunciado la complicidad de ciertos funcionarios $y$ ciertos arribistas ion los propietarios de latifundios".

871. Bourcier, Paul: "Asturias y su obra", El Nacional (México, 20 oct. 1967), p. 7 [laudes a su obra socio-política].

872. Bourcier, Paul: "Premio Nobel de Literatura, 1967; pasión por Guatemala, repudio a la dictadura, odio a las intervenciones del extranjero", El Dia (México, 20 oct. 1967), p. 6.

873. Brehm, C. Mauricio: "El señor Presidente de Miguel Angel Asturias, novela de contraste", "Revista de la Semana", supl. de El Universal (México, 3 mar. 1968), pp. 2 y 6.

874. Brent, Albert: "Viento fuerte", Books Abroad, XXVI (Norman, 1952), p. 384 [reseña].

875. Brion, Marcel: "Lectures étrangères; Miguel Angel Asturias", Le Monde (Paris, 22 ene. 1954).

Reseña de Hombres de maiz y Leyendas de Guatemala, "La prodigieuse féerie que déploient devant notre sprit assourdi, ébloui, ces légendes antiques, n'a pas de communes mesures avec nos mythes propres... langage chatoyant et hérissé, dont les images ont en espagnol une couleur et un relief extraordinaires..." 
876. Brion, Marcel: "Dans la ligne de Tolstoi; Miguel Angel Asturias et Les yeux des enterrés", Le Monde (París, 1 dic. 1962).

Autor de reveladores estudios sobre maA, el académico francés lleva a cabo lúcida reseña de Los ojos de los enterrados.

877. Brion, Marcel: "Miguel Angel Asturias et La flaque du mendiant", Le Monde (París, 3 sep. 1966).

Opina Brion que MAA en esta obra - El albutjadito, traducido al francés por Alaíde Foppa y Dominique Elouard-, "abandona la literatura de lucha social y el folklore legendario para dejarse llevat por la fantasía, más allá de los mismos paises legendarios".

878. Brion, Marcel: "Un homme a l'image de la forêt", Le Monde (París, 20 oct. 1967), p. 24.

Para el académico francés, MAA es la imagen misma de la naturaleza de su país. Hay en su aspecto físico, en su voz, una especie de intensidad vegetal, como si las fuerzas de la selva centroamericana "le traversaient et s'épanouissaient en lui".

879. Brion, Marcel: "Ha espresso nella sua opera splendori e miserie del Guatemala", La Siampa (Turín, Italia, 20 oct. 1967) [traducción al italiano del artículo de Le Monde, 20 oct. 1967].

880. Brion, Marcel: "Está al nivel de los volcanes", Revista de América (México, 11 nov. 1967) [traducción del attículo aparecido en $L e$ Monde].

881. Brion, Marcel: "Un hombre con la imagen de la selva", supl. homenaje a MAA del diario El Gráfico (Guatemala, 11 nov. 1967), PP. 4 y 15 [este artículo apareció anteriormente en Le Monde].

882. Brushwood: John S.: "Miguel Angel Asturias entre sus contemporáneos", supl. cultural de El Nacional, 5a época: 25 (México, 8 sep. 1968$)$, p. 10.

"Es una generación - señala J. S. Brushwood- que descubre los nexos entre arte y compromiso. Sus maestrcs maduran tarde... se trata de una generación tclescopiada".

883. Brushwood, John S.: "The Nobel Prize Winner has a Fine Sataniz Wit", Kansas City Star (Kansas City, 29 oct. 1967).

Perspicaz reseña de la versión inglesa de Mulata de tal: "his work is more than just a protest; it is an exploration into why men ate what they are... For him, myth is not an antiquarian's delight, it is living, breathing reality".

884. Brushwood, John S.: "Tyrants and Exploiters Stung by his Words", Kansas City Star (Kansas City, 4 may. 1968), página editorial [revisión de su novelística].

885. Buttitta, Pietro A.: "Un vento forte dal Guatemala", Avinti (Milán, 10 feb. 1966), p. 3 [reseña]. 
886. Callan, Richard Jerome: "El albajadito", Books Abroad, XXXV:4́ (Norman, Otoño, 1962), pp. 411-412.

Reseña. "It recreates the imaginary adventures, the wide-awake dreams of a solitary little boy, dreams of a mind drenched in the magic and folklore of two cultures, Mayan and Spanish".

887. C[allan] R[ichard] J[erome]: "Los ojos de los enterrados", Books Abroad, XXXVI:4 (Norman, Otoño, 1962), p. 417.

Reseña. "Asturias"s novelistic genius, his boundless mastery of words and language, his poetic style and imagination make this book and the entire trilogy a remarkable artistic creation".

888. Callan, Richard Jerome: "Mulata de tal", Hispania, XIVIII:949 (Appleton, 1965), pp. 949.

Reseña. "He attaches tremendous significance to sex, in its splendor as well as in its degradation. Here, in Mulata de tal, it has become one of his main themes: the mystery of sex as creator or devourer of mankind, according to its use".

889. Callan, Richard Jerome: "El tema del amor y de la fertilidad en El señor Presidente", Cuadernos Hispanoamericanos, 214 (Madrid, 1967), pp. 194-205.

890. Callan, Richard Jerome: "Babylonian Mythology in El señor Presidente", Hispania, L:3 (Appleton, sep. 1967), PP. 417-424 [sugestivo paralelo].

891. Callan, Richard Jerome: "The Quest Myth in Miguel Angel Asturias' Hombres de maiz", Hispanic Review, XXXV:3 (Filadelfia, jul. 1968), pP. 249-261.

"It has struck me that under the surface plot of some sections of Hombres de mazz, another level can be discerned wherein some of the standard myths of antiquity are acted out, giving parallel versions of one of the novel's major topics, fertility".

892. C. R.: "Asturias; Poesia", Sur, 179 (Buenos Aires, sep. 1949), Pp. $79-83$.

"Sólo un reparo cabría formular a esta antología: el exceso acumulativo, que redunda en detrimento de la cohesión y la calidad intrínsecas de cada una de las partes que la integran. Un criterio más riguroso en la selección de los pcemas hubiese permitido omitir aquellos que no representan de modo cabal la personalidad car:cterística del autor".

893. Campos, Jorge: "Charlas en Insula; Miguel Angel Asturias", Insula, 133 (Madrid, dic. 1957), p. 4.

Jorge Campos se distingue como uno de los críticos más constantes de la obra asturiana. Sus sólidas reseñas publicadas en Insula, son de frecuente consulta y por ende muy conocidas.

894. Campos, Jorge: "Letras de América; la flor y la calavera, poesía de los pueblos precolombinos", Instula, 174 (Madrid, may. 1961), p. 11 [reseña de Poesia precolombina].

895. Campos, Jorge: "Letras de América; tanta realidad en tanto sue- 
ño de Miguel Angel Asturias", Insula, 181 (Madrid, dic. 1961), p. 15 [reseña de El albajadito].

896. Campos, Jorge: "Letras de América; nuevas novelas de viejos conocidos", Insula, 212-213 (Madrid, jul.-ag. 1964), p. 20 [reseña de Mulata de tal].

897. Campos, Jorge: "Letras de América; lenguaje, mito y realidad cn Miguel Angel Asturias", Insula, 253 (Madrid, dic. 1967), pp. 11 y 13 [con este ensayo Insula "quiere recordar el conjunto de su obra"].

898. Campos, Jorge: "Letras de América; las nuevas leyendas de Miguel Angel Asturias", Insula, 254 (Madrid, ene. 1968), pp. 11 y 14 [reseña de El espejo de Lida Sal].

899. Cancegui, Walter: "Asturias", Confirmado (Buenos Aires, 7 dic. 1967), p. 70.

Carta en la cual este lector de Confirmado, ventila su discrepancia. No está de acuerdo con el juicio del crítico de este periódico sobre $E l$ espejo de Lida Sal, y defiende a MAA.

900. Cantón, W. L.: "Las letras mexicanas durante 1946", Suma bibliográfica, II:6 (México, ene.-feb. 1947), p. 14.

En el apéndice se señala que $E l$ señor Presidente la "sensacional novela de Miguel Angel Asturias, fue el mejor libro latinoamericano editado en México".

901. Cañas, Salvador: "Con Miguel Angel Asturias en Montevideo", Marcba (Montevideo, 11 feb. 1950).

902. Carabias, Josefina: "Mi gran maestro es Quevedo, dice Miguel Angel Asturias", El Imparial (Guatemala, 28 oct. 1967), p. 17.

Entrevista con maA y su esposa Doña Blanca Mora y Araujo de Asturias. Tomada del Ya de Madrid. Cuenta MAA, que en 1930 llegó a Madrid y conoció los "grandes contemporáneos": Unamuno, Valle Inclán, Azorín, Baroja... Señala que su gran maestro fue Quevedo "...y que se interesa mucho por los jóvenes: "Sastre, Celaya, Conde, Matute, Delibes, Buero Vallejo". Durante un intermedio la esposa de MAA narra con donaire, cómo conoció al novelista.

903. Caracciolo Trejo, Enrique: "El lenguaje en El señor Presidente", "Hojas de Crítica", 3, supl. de la Revista de la Universidad de México, XXII:12 (México, ago. 1968), Pp. 5-7.

904. Carballo, Emmanuel: "Miguel Angel Asturias o la dicha y desdicha de Guatemala", "La cu!tura en México", supl. de Siempre!, 3 (México, 7 mar. 1962), p. XIV.

905. Carballo, Emmanuel: "Miguel Angel Asturias, si y no", "Diorama de la Cultura", supl. de Excélsior (México, 29 oct. 1967), Pp. 3 y 5.

"El Premio Nabel - subraya Carballo- al mismo tiempo que nos llenı de satisfacción, ya que se trata de uno de los más ilustres escritores de Iberoamérica, no deja de alarmarme por las circunstancias que. rodean la elección". Sigue un excelente resumen crítico de la ncvelística de Asturias. 
906. Cardona Peña, Alfredo: "La noticia del Premio Nobel en México", El Imparcial (Guatemala, 27 oct. 1967), p. 13.

Cardona Peña relata emocionado cómo recibió la noticia del nuevo Premio Nobel 1967.

907. Cartión, Benjamin: "La novela en América Latina; encuesta", El Día (México, 10 mar. 1965), p. 4.

Para mí [Asturias es] el primer novelista latinoameticano "en ejercicio". Nos ofrece un sólido "faenar balzaciano".

908. Carrión, Benjamín: "El realismo mágico", Ateneo, 227-228 (San Salvador, enc.-jun. 1961), pp. 55-56 [reseña de Los ojos de los entertados].

909. Carrión, Benjamín: "El realismo mágico", El Nacional (Caracas, 10 jun. 1961).

910. Carrión, Benjamín: "Miguel Angel Asturias, Premio Nobel de Literatura", Letras del Ecuador, 134 (Quito, nov. 1967), pp. 10 11 y 18.

Reminiscencias y exégesis de la cbra asturiana: "Vestido de cucurucho, en las procesiones de Semana Santa en Guatemala, Miguel Angel, este admirador de Lenin, era un modelo de devoción y piedad, que nuestras madres nos presentaban para que siguićramos sus pasos edificantes... El binomio de Toynbee: incitación-respuesta, se cumple como en pocos escritores latinoamericłnos, en Asțurias... no desentona, no se queda retrasado, como algunos han dicho, ante la novísima no. vela latinoamericana".

911. Cartión, Benjamín: "Miguel Angel Asturias: Premio Nobel de Literatura", Revisth conservadora del pensamiento centroamericano, XVIII:89 (Managua, feb. 1968), Pp. 2-6 [véase artículo anterior].

912. Carrión, Benjamín: "Miguel Angel Asturias; escritor universal", El Imparcial (Guatemala, 18 jun. 1966), pp. 15 y 21 [ensayo escrito en ocasión del Premio Lenin].

913. Cassou, Jean: "Le message des lettres hispano-américaines", Preutves (París, ene. 1954), Pp. 67-71.

914. Castañeda, M. Salvador: "Licencia de bautismo", El Imparcial (Guatemala, 9 dic. 1967), p. 17.

Reproducción: "En la Parroquia Rectoral del Sagrario a veintinueve de octubre de mil ochocientos noventa y nueve el Sr. Pbro. don Alberto Rubio y Piloña con mi lícencia bautizó solemnemente a Miguel Angel, que nació el dieciocho del corriente, hijo legítimo del Ldo. Ernesto Asturias y Dña. María Rosales. Fue su padrino el Ldo. Pedro Rubio Pilona".

915. Castelpoggi, Atilio Jorge: "Los ojos de los enterrados", Comentario, VII:26 (Buenos Aircs, 1960), pp. 85-86 [reseña].

916. Castellanos, Rosario: "Miguel Angel Asturias, iluminado por la luz del verbo", Excélsior (México, 28 oct. 1967), pp. 6 y 10. 
917. Castellanos-Carrillo, Leopoldo: "Homenaje del señor Presidente a Miguel Angel Asturias", La Hora (Guatemala, 19 y 4, 5 y 6 mar. 1968) [cuatro artículos].

918. Castelli, S.: "Miguel Angel Asturias e la responsabilita dell'artista", La Fiera Letteraria (Roma, 19 dic. 1965), Pp. 1-2.

919. Castelli, S.: "Vento forte di Miguel Angel Asturias", Avanti (Milán, 30 nov. 1965), p. 3 [reseña].

920. Castiglione, Luigi: "Miguel Angel Asturias", Il Giornale di Bres* cia (Brescia, 28 feb. 1968).

Una exposición general de su vida y obra. Pese a algunos errores de detalle -afirma que MAA, rehusó el Premio Lenin por la Paz-, esta valorización es interesante.

921. Castillo, Othón: "Desde la Argentina; la hora de la novelística iberoamericana", Diario de Yucatán (Mérida, Yucatán, 5 ene. 1969), p. 3.

Entrevista con Ernesto Sábato en la cual, Castillo recoge "ciertas alusiones a MAA, achacadas a Jorge Luis Borges, en torno al Premio Nobel... y Säbato nos corta: 'Asturias es un magnífico escritor y se merece muy bien el premio', agregando que hay cuatro o cinco que bien podrían haberlo aspirado".

922. Castro, Josué de: "Asturias, regionalismo que se universaliza", Excélsior (México, 12 nov. 1967), P. 7.

923. Castro-Viejo, Concha: "Miguel Angel Asturias, su posición literaria", La Nación (Santiago de Chile, 14 abr. 1963).

924. Cervoni, Albert: "M. A. Asturias prix Nobel", France Nouvelle, 1149 (París, 25 oct. 1967).

"Asturias est notre ami et cela évidemment a pesé dans la joie éprouvée. Mais cette amitié, cette joie ne sont pas, n'étaient pas complaisantes. Les mérites d'Asturias sont patents".

925. Cifuentes, José Luis: "Páginas de adolescencia; Miguel Angel As" turias", supl. homenaje a MAA del diatio El Gráfico (Guatemala, 11 nov. 1967), pp. 2 y 15.

Cifuentes le llama; "Poeta amamantado por el trópico... tiene la brujeria ancestral de fabricar muñecos... oscila entre la poesia y la leyenda".

926. Cirici-Ventalló, Domingo: "Panorama literario de Guatemala", Cuadernos Hispanoamericanos, XV:42 (Madrid, jun. 1953). MAA, p. 404. Breves y leves comentatios sobre Leyendas de Guatemala y El seinor Presidente.

927. Clemente, Ocanto J.: "El Papa verde", El Nacional (Caracas, 4 ag. 1955) [reseña].

928. Coleman, Alexander: "Why Asturias?", The New York Times Book Review (Nueva York, 19 nov. 1967), pp. 1-2, 89.

Uno de los artículos más sonados en torno al Nobel. Coleman sopesa los múltiples factores que entran en juego al otorgar el galardón. Ba- 
rajea varios nombres latinoamericanos: Neruda, Borges, Carpentier. Según Coleman ganó Asturias "because the human commitment of his work most fittingly reflects the Nobel thinking about literature".

929. Coleman, A.: "Why Asturias?", Revue svetovej literattry, 2 (Praga, 1968), pp. 160-161.

Adaptación del ensayo que apareció en el New York Times Book Re. view (Nueva York, 19 nov., 1967), pp. 1-2 y 89.

930. J[uan] C[ollantes] de T[erán]: "Miguel Angel Asturias desde Buenos Aires", Estudios Americanos, XIX:101 (Sevilla, mar.-abr. 1960), pp. 177-178.

Glosa de la entrevista que Alfonso Enrique Barrientos publicó en Nivel, 9 (México, 25 sept., 1959).

931. Condal, Elías: "Nobel, el Premio y su requisito", Siempre!, 750 (México, 8 nov. 1967), pp. 25 y 70 [crítica política adversa].

932. Conte, Rafael: "Las leyendas de Miguel Angel Asturias", Información (Madrid, dic. 1967).

Reseña de $E l$ espejo de Lida Sal. "Desde la primera página, se impone la especial ambientación retórica de Asturias... una muestra muy significativa de su literatura de conocimiento inexcusable".

933. Conte, Rafael: "Más allá de la literatura; el pensamiento vivo de Miguel Angel Asturias", Información (Madrid, 6 abr. 1968), p. 4. Reseña de Latitzoamérica y otros ensayos. "La obra de Asturias, aun. que posee un significado político evidente, es sobre todo, literaria". El mismo escritor lo confiesa en su entrevista con Guillermo Medina, ya citada. "No somos agitadores políticos", dice refiriéndose a los actuales escritores iberoamericanos. "Si hay un compromiso del escritor, es con la libertad y la justicia".

934. Cordón Barreira, René: "Miguel Angel Asturias; poeta", Diario de Centroamérica, supl. de Arte y Literatura, V:231 (Guatemala, 9 dic. 1967), p. 5.

"Las imágenes saltan inconteniblemente del papel... cantan la labor mística de aquellos constructores de templos, ciudades y pirámides y la hierática soledad de sus abrumados e irredentos descendientes".

935. Cormorán, Diego: "Italia: pasión y literatura de América Latina", La Gaceik, tercera época, XV:3 (México, may. 1968) [pp. 16-18, sobre Asturias y otros].

936. Cortez Ruiz, Hernán: "De un maestro de las nuevas generaciones; el diez de diciembre debe ser declarado día de júbilo nacional", El Imparial (Guatemala, 9 dic. 1967), pp. 17-23 [exaltación; subraya el significado del Nobel para Guatemala].

937. Corrales Egea, José: "Tres escritores hispanoamericanos en París; II. Miguel Angel Asturias", Insula, 197 (Madrid, abr. 1963), p. 12.

Entrevista con motivo de la edición francesa de Los ojos de los ente. rrados, pero el diálogo se extiende a otros asuntos literarios. 
938. Corrales Egea, José: "Carta de París; una charla con Miguel Angel Asturias", Instula, 99 (Madrid, 15 sep. 1953), pp. 2 y 4.

"Los grandes escritores norteamericanos, han tenido una gran reper. cusión en nuestros países, como en todas partes; aquellos, sobre todo, que plantean en sus obras problemas similares a los existentes en el resto de América", afirma MAA.

939. Correa, Gustavo: "El espíritu del mal en Guatemala; ensayo de semántica cultural", Middle American Research Institute, Tulane University Publication, 19 (Nueva Orleans, 1955), pp. 37-104. MAA, pp. 62 y 70 . Analiza dos leyendas: "El cadejo" y "El monje".

940. Contreras Vélez, Alvaro: "Dignidad y altura para el homenaje a Asturias", Prensa Libre (Guatemala, 7 dic. 1967).

El critico R. Paz Paz, a través de esta columna, hace un llamado a los "hompnajeantes", para que usen de ponderación y compostura en los tributos a MAA.

941. Cordero V. Rafael: "Diálogo romano", Papel literario. El Nacional (Caracas, 29 oct. 1967), p. 3 [extensa e incitante entrevista verificada en Roma, 1966, con MAA].

942. Couffon, Claude: "Monsieur le President", Le Figaro Litséraire, 562 (París, 26 ene. 1957), p. 9 [reseña].

943. Couffon, Claude: "Week-end att Guatemala", Lettres Nouvelles (París, 11 mar. 1959) [reseña].

944. Couffon, Claude: "Miguel Angel Asturias et le réalisme magique", Les Lettres Françaises (Paris, 6 dic. 1962), pp. 1-4.

Entrevista con motivo de la publicación en francés de Los ojos de los enterrados. Pero se amplia sobre otras obras de MAA y la situación sociopolítica Iatinoamericana.

945. Couffon, Claude: "Miguel Angel Asturias y el realismo mágico", Alcor, xxiii-xxiv (Asunción, Paraguay, mar-jun. 1963), p. 2 [véase ficha anterior].

946. Couffon, Claude: "La Flaque du mendiant", La Quinzaine Litlévaive (París, 15 jul. 1966) [reseña de El albajadito].

947. Couffon, Clandc: "Un merveillcux Nobel; Migucl Angel Astutias", Lettres Françaises (París, 25 oct. 1967), pp. 3-5 y 7.

"Ce n'est pas Monsieur l'Ambassadeur qui a reçu le prix Nobel, c'est Miguel Angel Asturias. C'est le tomancier colossal de l'Amérique Latine, c'est le poète telurique et le conteur insolite, c'est le lutteur et le défenseur des "hommes de mais" ... y después C. $C$. recuenta ampliamente la vida $y$ aquilata la obra asturiana.

948. Coulthard, G. R.: "EI mito indigena en la literatura hispanoamericana contemporánea", Cuadernos Americanos, XXVII:1 (México, ene.-feb. 1968), Asturias, pp. 164-165.

949. Covantes, Hugo: "Asturias habla a París sobre el diablo", "Mé- 
xico en la Cultura", supl. de Novedades, 867 (México, 31 oct. 1965), pp. 3 y 5 .

Una entrevista de Claude Couffon con Asturias, tomada de Lettres Françaises con traducción y notas de Hugo Covantes. La plática gira alrededor de la Mulata de tal, cuyo punto de partida -explica Asturias - es una vieja leyenda de Guatemala.

950. Cremoux López, Raúl: "Asturias, manantial que habla", Excélsior (México, 24 nov. 1967), 1A y 11A.

951. Cremoux López, Raúl: "Asturias, manantial que habla", Impacto 2510 (Guatemala, 16 dic. 1967), pp. 2 y 20 [véase ficha anterior].

952. Crusat, P.: "Asturias; Torotumbo y la audiencia de los confines, Insula, XXIII:263 (Madrid, oct. 1968), p. 9 [reseña].

953. Cuadra, Pablo Antonio: "Miguel Angel Asturias", Revista de la Facultad de Derecho y Ciencias Sociales, V:19 (Buenos Aires, 1950), p. 667.

954. Curley, Thomas: "Confraternity of the Dunghill", New York Times Book Review (Nueva York, 2 feb. 1964), p. 35 [reseña la versión inglesa de $E l$ señor Presidente].

955. Chadeau, Danielle: "Miguel Angel Asturias; le Tolstoi de l'Amérique Latine", Democratie (París, 13 dic. 1962).

Análisis de sus obras, especialmente de la traducción en francés de Los ojos de los enterrados. El crítico, con ojo avizor, vaticina que recibirá una consagración internacional, "fresque a la Tolstoi, a l'irrésistible mouvement dramatique, mais aussi oeuvre de visionnaire et de poète, Les yeux des enterrés est un livre auquel on ne peut pas rester indifférent. Nous ne serions pas surpris si son auteur recevait un jour une consécration internationale que d'autres moins dignes que lui, ont à ce jour obtenue".

956. Chalon, Jean: "Trois sud-américaines a Paris", Le Figaro Littéraire (París, 15 abr. 1965), p. 4 [acerca de Mulata de tal].

957. Chalon, Jean: "Nommé Ambassadeur du Guatémale a Paris", Le Figaro Litiéraire (París, 11 ag. 1966), p. 2 [trata de El alhajadito].

958. Chalon, Jean: "Miguel Angel Asturias nombrado embajador de Guatemala en Francia", La Hora (Guatemala, 22 ag. 1966), pp. 4 y 6 [véase ficha anterior].

959. Chalon, Jean: "Asturias, Prix Nobel de Littérature", Le Figaro Littéraire (París, 23 oct. 1967), p. 30.

Comentarios acerca de su trilogía: Viento fuerte, El Papa verde y Los ojos de los enterrados.

960. Chalon, Jean: "Asturias, Premio Nobel de Literatura", Horizonte, XIII:87-88 (Guatemala, nov.-dic. 1967), pp. 7-10.

Tomado de Le Figaro Littéraire: "Al anuncio de su premio, su embajada ha sido alegrémente saqueada por los periodistas y sus amigos. Sólo él guardaba su calma, su sontisa". 
961. Chapman, Arnold: "Asturias; Bolivar"; Handbook of Latin American Studies, 20 (Gainesville, 1958), p. 249.

"A minor production of a major writer. Sumptuously gotten up as a book, this short (14-page) poem is a paean of praise to the Liberator, in his meaning as a man and as a patriotic myth".

962. Daix, P.: "Week-end at Guatemala", Lettres Françatses (París, 5 dic. 1959) [reseña].

963. Darmangeat, Pierre: "Aspects poétiques de l'oeuvre ' de Miguel Angel Asturias".

Conferencia en la Sorbona, Amphithéâtre Richelieu (París, 9 feb., 1968). Se publicó posteriormente en Europe, 473 (París, sept., 1968), pp. 3-6. Sus novelas; "Plus que paroles ils sont images".

964. Dashkevich, Yuri: "Migel 'Ankhel' Asturias", Inostrannaia literatura, 12 (Moscú, dic. 1962), pp. 232-234 [diálogos con MAA sobre sus obras].

965. Dashkevich, Yuri: "Miguel Angel Asturias, cantor de Guatemala", Literatura Soviética, 9 (Moscú, 1966), pp. 161-164.

Exposición de su obra en ocasión de serle otorgado el Premio Internacional Lenin de la Paz. "Hay... algo volcánico en la creación de Asturias. Su talento es insólitamente poderoso y polícromo", afirma el traductor de varias obras asturianas al ruso.

966. Dashkevich, Yuri: "El embajador de Guatemala", Inostrannaia literatura, 17 (Moscú, 1966), pp. 262-264 [entrevista].

967. Dauster, Frank: "Asturias: Soluna", Handbook of Latin American Studies, 21 (Gainesville, 1969), p. 226.

MAA, p. 226. "This first play of a distinguished novelist is hampered by the clouded implications of Indian myth and by excessive narration of antecedent. Nevertheless, it is a serious and imaginative attempt at making dramatic use of folklore".

968. Dávalos, Baica: "Miguel Angel Asturias; la magia y el mito", Imagen, 11 (Caracas, 15-30 oct. 1967), p. 24.

Confrontación de Hombres de maiz de Asturias, El reino de este muntdo, de Carpentier y La Serpiente emplumada de Lawrence: "en grados de irracionalidad podria establecerse una escala profundizante que vaya desde Lawrence a Asturias pasando por Carpentier".

969. Dávila G., Ramiro: "Mulata de tal, de Miguel Angel Asturias", Agora, 7 (Quito, abr. 1967), pp. 70-74.

Reseña. Doble fuente de la novela: a) tradiciones centroamericanas y b) siglos de literatura española.

1970. Dessau, Adalbert: "Mythus und Wirklichkeit in Miguel Angel Asturias' bananentrilogie"' [Mito y realidad en la trilogía bananera de Miguel Angel Asturias], Lateinamerika (Rostock, Primavera, 1966), PP. 7-51.

El Prof. Dessau examina detalladamente las relaciones entre el mito y la realidad. "El análisis - nos dice- revela que a partir de Viento fuerte y a través de El Papa verde hasta Los ojos de los enterrados, el autor recorre un largo camino cognoscitivo, que lo induce a modi- 
ficar profundamente la concepción original de la 'trilogía'. En este proceso, Ia relación entre mito y realidad, juega un papel importante... El problema central es la superación de la conciencia mágica por una conciencia racional que crea una de las condiciones para resolver los problemas sociales..."

971. Dessau, Adalberto: "Mito y realidad en la trilogía bananera de Miguel Angel Asturias", Islas, IX:3 (Santa Clara, Cuba, jul.sep. 1967), pp. 389-408.

"Miguel Angel Asturias presenta, con Alejo Carpentier, la variedad más avanzada o importante de este 'realismo mágico' o, como dice Carpentier, de la concepción de lo 'real maravilloso'". Pese al mismo título, este ensayo no es igual al anterior.

972. Dethorey, Ernesto: "Asturias fran Guatemala", Göteborgs Handels-och Sjöfarts-Tidning (Gotemburgo, 9 oct. 1964).

Este artículo, cuyo primer título eta "Kanske en nobelpristagare?" (¿Tal vez un Premio Nobel?), comienza así: "El único Premio Nobel de literatura latinoamericano es... la poetisa chilena Gabriela Mistral... ¿Por qué no el Premio Nobel a un novelista en vez de_a otro poeta?... por ejemplo, Miguel Angel Asturias". Véase Dethotey: Miguel Angel Asturias... Estocolmo, 1967, p. 12.

973. Dethorey, Ernesto: "Fran Flykting til ambassador", Göteborgs Handels-och Sjöfarts-Tidning (Gotemburgo, 20 sep. 1966).

974. Díaz Castillo, Roberto: "Reencuentro con Miguel Angel Asturias", Revista de Guatemala, XVIII:2 (Guatemala, ene.-dic. 1960), pP. 106-107 [bocetos de reminiscencias].

975. Díaz, José Manuel: "Las biblias americanas", El Día (México, 9 jun. 1967), P. 9 [sobre Asturias].

976. Díaz, José Manuel: "Miguel Angel Asturias en México", El Día (México, 6 oct. 1966), p. 9 [trata de El señor Presidente y Hombres de Matz].

977. Díaz, José Manuel: "Entrevista con Miguel Angel Asturias", El Gallo Ilustrado, supl. de El Dia (México, 23 oct. 1966), p. 1.

978. Díaz Lastra, A.: "Entrevista con Miguel Angel Asturias", "La cultura en México", supl. de Siempre!, 246 (México, 12 nov. 1966), pp. II y III.

979. Díaz Lastra, Alberto: "En provesten for kommende digtergenerationer", Berlingske Tidende (Copenhague, Dinamarca, 23 oct. 1967).

980. Díaz Lastra, Alberto: "Miguel Angel Asturias al teléfono", "La cultura en México", supl. de Siempre!, 301 (México, 22 nov. 1967), pp. IX y X.

981. Díaz Lozano, Argentina: "Aquí... Premio Nobel 1967", Diario de Centroamérica, supl. de Arte y Literatura, V:231 (Guatemala, 9 dic. 1967), p. 8. 
La autora aborda el porqué del Premio Nobel 1967. El "genio de MAA... vuelve plástica el alma de los mayas".

982. Díaz Plaja, Guillermo: "Torotumbo", El Imparcial (Guatemala, 24 feb. 1967), pp. 13 y 15.

Reseña del libro publicado por la Editorial Plaza y Janés (Barc., 1967).

983. Díaz Plaja, Guillermo: "Nuevo libro de Miguel Angel Asturias; tres aspectos de su obra", Diario de Yucatán (Mérida, 3 mar. 1968), p. $1,2^{\text {s }} \mathrm{sec}$.

984. Díaz Rozzoto, Jaime: "El realismo mágico de Miguel Angel Asturias", Revista de Guatemala, XVIII:2 (Guatemala, ene.-dic. 1960), pp. 66-78.

“...metáforas, imágenes, epretes, sinécdoqucs, metonimias, antítesis, hiperbatones maya-quichés, maneja diestro y majestuoso las herramientas del floricultor del mito reverdecido".

985. Diaz Rozzoto, Jaime: "Origenes et originalité de la littérature guatémaltèque", Europe, 473 (París, sep. 1968), pp. 27-46.

MAA, pp. 41-44. "En edifiant la charpente de son roman, Asturias sc sert du cubisme et il multiplie le tythme des séquences. Il use savoureusement des procédés de l'impressionnisme... Aliénation de force humaine luttent pour se frayer un passage vers une vie meilleure".

986. Díaz Seijas, Pedro: "La novela en cinco países americanos", "Diorama de la cultura", supl. de Excélsior (México, 1 oct. 1967) [Asturias, pp. 3 y 6].

987. Diego, Getardo de: "Asturias y Guatemala", $A B C$ (Madrid, 16 nov. 1967) [edición aérea].

988. Diego, Gerardo de: "Comentario español; Asturias y Guatemala", El Imparial (Guatemala, 21 nov. 1967), pp. 11 y 15.

Divagador ensayo: "Entre el poeta de las 'Odas' y el Popol-Vuh, en. tre Quevedo y Neruda, Miguel Angel Asturias ha encontrado ancho campo para asimilar sugestiones y desplegar talento. $Y$ sobre todo la lección de su tierra".

989. Dolatowka, K: "Asturias; prosista, hombre y escritor guatemalteco, Premio Nobel 1967", Kierunki (Varsovia, 12 dic. 1967), p. 5.

990. Domínguez Aragonés, Edmundo: "Esta nuestra Latinoamérica", "El Gallo Ilustrado", supl. de El Día, 288 (México, 31 dic. 1967), p. 3 [sobre Asturias y otros].

991. Donahue, Francis James: "Miguel Angel Asturias: su trayectoria literaria", Cuadernos Hispanoamericanos, LXII:186 (Madrid, jun. 1965), pp. 507-527.

Exposición de su vida y obra. Opina el profesor Donahue que a MA le "queda sólo por escribir la cbra maestra de indole social que un.versalice el problema principal de su país, La apatición de tal obra maestra depende de la habilidad de Astutias de cootdinar todàs sus fuerzas creadoras en una novela capital". 
992. Donoso Pareja, Miguel: "Sobre El espejo de Lida Sal", El Día (México, 8 ene. 1968).

993. Donoso Pareja, Miguel: "Sobre El espejo de Lida Sal", El cuento, 28 (México, feb. 1968), p. 245.

994. Dumur, Ruy: "Les yetix des enterrés", France Observateur (París, 1 feb. 1968) [reseña].

995. Dumur, Guy: "L'ambassadeur rebelle", Le Nouvel Observateur (Paris, 25 oct. 1967).

"Tantôt, il peint - Le Pape vert-, l'agent quasi mythique de I' -United Fruit-, tantôt ces révolutionnaires qui, aujourd'hui encore, et plus qu'en Bolivie, tiennent le maquis, et tantốt ces forçes obscures, magiques, d'un pays en proie aux peurs - anciennes et... modernes".

996. "Editorial del periódico Sydsvenska Dagbladet" (Malmö, 20 oct. 1967).

997. "Editorial del periódico Dagens Nyheter" (Estocolmo, 20 oct. 1967).

998. Editorial: "El Premio Nobel de Miguel Angel Asturias", Presencia (La Paz, Bolivia, 21 oct. 1967) [el Premio Nobel a MAA es un acto de justicia].

999. Editorial: "Universal consagración de Miguel Angel Astutias", Novedades (México, 21 oct. 1967).

1000. Editorial: "Un segundo Premio Nobel", El Sol (México, 21 oct. 1967) [sobre Asturias, p. 5].

1001. Editorial: "Se hace justicia a Miguel Angel Asturias", El Día (México, 23 oct. 1967), p. 5.

1002. Editorial: "Los premios Nobel y la política", La Prensa (Buenos Aires, 25 oct. 1967).

Se editorializa sobre las implicaciones políticas del Premio, refirién. dose no sólo a MAA, sino también a los "casos" Pasternak, Sartre y Sholojov.

1003. Editorial: "Miguel Angel Asturias, Premio Nobel de Literatura", Plana, OEI, 121 (Madrid, nov.-dic. 1967), pp. 1 y 3. Anécdota relativa a la aparición de la $1^{\text {na }}$ edición de Leyendas de Guatemala.

1004. Editorial: "Trascendencia del triunfo de Miguel Angel Asturias", Diario de Centroamérica, LXXXVII:26136 (Guatemala, 9 dic. 1967), p. 3.

Editorial. Exaltación de MAA. "En adelante, será el faro, el guía, la estrella tutelar de nuestras generaciones futuras".

1005. Editoriales: "Miguel Angel Asturias", El Caribe (Santo Domingo, R. D., 13 dic. 1967). 
1006. Editorial: "Miguel Angel Asturias, Premio Nobel 1967", La Hora (Guatemala, 6 nov. 1967).

"Cabría... considerar a Asturias como un escritor comprometido, si se pone de relieve que el contacto con una realidad humana y social incandescente quita al compromiso de los escritores sudamericanos el empaque sacerdotal que casi siempre encontramos en Europa".

1007. Editorial: "Miguel Angel Asturias Premio Savagny", El Imparcial (Guatemala, 21 dic. 1931).

1008. Fditorial: "Miguel Angel Asturias; Premio Nobel", Papeles, 5 (Caracas, nov.-ene. 1967-1968), pp. 5-7.

1009. Editorial: "El momento culminante de Miguel Angel Asturias", Prensa Libre, XVII:5020 (Guatemala, 11 dic. 1967), p. 10.

El editorialista se lamenta que los honores que maA recibe de tierra extraña, contrastan con la indiferencia y frialdad con que se le recibe en su patria.

1010. Editorial: "La A. P. G. arriba pujante a su mayoría de edad", $R e$ vista A. P. G., 28 (Guatemala, abr. 1968), p. 1.

Trata de la creación del Premio "Quetzal de Jade Maya" que será entregado a Miguel Angel Asturias, en París.

1011. Ekner, Reidar: "Bröd och frihet", Göteborgs Handels och SjëfartTidning. (Gotemburgo, 20 dic. 1967) [reseña de la versión sueca de Hombres de maiz].

1012. E. M. B. C.: "Asturias; leyendas de Guatemala", El Día (La Plata, 20 ene. 1968), p. 12 [reseña de El espejo de Lida Sal].

1013. Espinosa Altamirano, Horacio: "La poesía, raíz de la grandeza de Miguel Angel Asturias", El Heraldo cultural, 107 (México, 26 nov. 1967), p. 10.

El crítico señala que MAA, se preocupa tanto por la prosa como por el verso.

1014. Estensoro B., Hugo: "Asturias Premio Nobel", El Imparcial (24 oct. 1967), pp. 3 y 9.

Tomado de Excélsior. Véase mi Asturias en México, ficha 117.

1015. Esther de Miguel, María: "Los ojos 'de los enterrados", Criterio, XXXIII (Buenos Aires, 1961), p. 77 [reseña].

1016. Ertze Garamendi, Ramón: "Asturias, Premio Nobel", Excélsior (20 oct. 1967), p. editorial.

1017. Estrada, Ricardo: "Estilo y magia del Popol-Vub en Hombres de maiz de Miguel Angel Asturias", Humanidades, III:2 (Guatemala, sep. 1961), 15 pp.

Análisis comparativo pormenorizado. "Al sumergirnos en la lectura de Hombres de maiz, tenemos, al igual que cuando leemos el Popol.Vub, la sensación de penetrar en la semioscuridad de un 'viejo relato', donde asoma cierta "habla' clásica de los aniepasados". 
1018. Estrada, Ricardo: "La prosa de Miguel Angel Asturias", Revista conservadora del pensamiento centroamertino, 89 (Managua, feb. 1968), pp. 7-13.

Reproducción de su "Estilo y magia". Humanidades, sept., 1961. También en Repertorio Centroamericano, 9, 1968.

1019. Estrada, Ricardo: "Creador de la palabra por arte mágico", El Imparcitl (Guatemala, 19 oct. 1966), Pp. 15 y 20.

MAA, es el "joyero... el escultor... el platero de la poesía $y$ del relato" guatemalteco. En seguida, Estrada nos da algunas muestras de esta creación.

1020. Fabré, Eugene: "Les yeux des euterrés", Journal de Genève (Ginebra, 29 ene. 1963) [reseña de la traducción francesa de Los ojos de los enterrados].

1021. Falla, Orlando, y L. Sears: "Miguel Angel Asturias; El señor Presidente", Caminos, IV (Guatemala, abr. 1963), pp. 18-19 [reseña].

1022. Fell, Claude: "Le miroir de Lida Sal", Le Monde (París, 14 jun. 1967), p. VII.

Reseña. "Une longue procession hiératique qui laisse de ce Guatémala de MAA, situé au-delà de vaines querelles des hommes, une image palpitante et hallucinée:-

1023. Fell, Claude: "El último libro de Asturias", Mundo Nuevo, 17 (París, nov. 1967), pp. 84-85 [traducción de la reseña registrada en la cédula anterior].

1024. Fernández, Miguel: "Miguel Angel Premio Nobel", La Hora (Guatemala, 13 ene. 1968) [breve recorrido por las "dimensiones de su talento"].

1025. Ferreiro, Fabra: [Tirano Banderas y El señor Presidente], Estafeta literaria (Madrid, 27 ene. 1968) ["Dos inmensos retablos de exuberante barroquismo"].

1026. Figueira, Gastón: "Sobre Poesía, Sien de Alondra", Revista Iberoamericana, XV:30 (México, ag-ene. 1949-1950), pp. 297-298.

1027. Figueira, Gastón: "Viento fuerte", La Mañana (Montevideo, 24 may. 1951).

Reseña. "Asturias en Viento fuerte, tecobra aquella fuerza vitalisima de las páginas más hondas de El señor Presidente".

1028. Fonquerne, Yves René: "Nota de felicitación a MAA", Caravelle 9 (Toulouse, 1967), pp. 180-181.

1029. Fonquerne, Yves René: "Miguel Angel Asturias", Les Langues Néo-Latines, III-IV:170-171 (Paris, sep.-dic. 1964), pp. 68-69. Reseña de Mulata de tal. "Tout l'envoûtement de la nature, toute la hantise ancestrale des forces cosmiques et des mythes telluriques se retrouvent dans l'ouvrage de $M$. A. Asturias; mais ces puissances, omniprésentes, nous apparaissent en pleine activité, douées d'une extraordinaire force vitale". 
1030. Foppa, Alaíde: "La poesía en la prosa de Miguel Angel Asturias", Revista de Guatemalat, XVIII:2 (Guatemala, ene.-dic. 1960), Pp. 9-12.

1031. Foppa, Alaíde: "Exposición de Miguel Angel", El Imparcial (Guatemala, 14 ag. 1964), p. 15.

1032. Foppa, Alaíde: "Poesía hispanoamericana en edición bilingüe", El Dia (México, 14 oct. 1966), p. 9.

Rescña de la edición bilingüe española-francesa de Claireveillée de Printemps, de Asturias.

1033. Foppa, Alaíde: "Miguel Angel Asturias, Premio Nobel, (I). El premio", El Día (México, 27 oct. 1967), p. 16.

El primero de seis artículos en los cuales se estudian las varias facetas de la obra de maA.

1034. Foppa, Alaide: "Miguel Angel Asturias, Premio Nobel, (II). La poesía", El Día (México, 28 oct. 1967), p. 13.

"La poesia de Miguel Angel Asturias es esencialmente épica... plenamente americana, en la que se mezclan barrocamente lo prehispánico y lo cristiano, lo legendario y lo social, to perdido y lo presente".

1035. Foppa, Alaíde: "Miguel Angel Asturias, (III). Antiguas y nuevas leyendas", El Dia (México, 31 oct. 1967), p. 9.

"Recuerdos de infancia, los cuentos de las viejas criadas, las historias de los arrieros... la brujería..."

1036. Foppa, Alaide: "Miguel Angel Asturias, (IV). El señor Presidente", El Dia (México, 1 nov. 1967), p. 11.

1037. Foppa, Alaide: "Miguel Angel Asturias, (V). La trilogía del banano", El Día (México, 6 nov. 1967), p. 9.

1038. Foppa, Alaide: "Miguel Angel Asturias, (VI). La magiat en la novela", El Día (México, 7 nov. 1967), p. 9.

"Creo que Miguel Angel Asturias es el único novelista hispanoamericano que haya hecho de la magia, no sólo fondo o condimento, sino tema de sus novelas".

1039. Foppa, Alaíde: "Realidad e irrealidad en la obra de Miguel Angel Asturias", Cuademos Americanos, XXVII:1 (México, ene.feb. 1968), pp. 53-69.

1040. Foppa, Alaíde: "Primavera maya de Miguel Angel Asturias", El Día (México, 2 jul. 1966), p. 11 [sobre Clarivigilia primaveral].

1041. Fouchet, Max-Paul: "Les livres étrangers", Carrefour (París, 20 ene. 1954).

Analiza varios libros de mas. "Un hombre de su tierra, pero que habla a todos los hombies de la tierra".

1042. F. R.: "Eine Ehre für Latein-Amerika; Miguel Angel Asturias ethielt Nobelpreis", Berliner Morgenpost (Berlín, 20 oct. 1967) [comentarios generales]. 
1043. Franklin, Richard L.: "Observations on El señor Presidenie", Hispania, XLIV:4 (Appleton, dic. 1961), pp: 683-685.

1044. Fresero, Máximo: "Miguel Angel Asturias, Premio Nobel 1967", Ateneo, XXI:43 (Lanús, Arg. 1967?)

"Asturias es un escritor comprometido como lo es todo auténtico creador..."

1045. Fuentes, Carlos: "La nueva novela latinoamericana", "La cultura en México", supl. de Siempre!, 128 (México, 28 jul. 1964).

Asturias, p. IV. "En América Latina son dos escritores en apariencia tan distintos como M. A. Asturias y J. L. Borges quienes abren la ruta de la mítificación y la personalización. Asturias se enfrenta al mismo mundo fatal e impenetrable de la novela tradicional, pero lejos de detenerse en el documento opaco, encuentra la transparercia en el mito y el lenguaje", consigna Carlos Fuentes.

1046. Fuentes, Carlos y Emir Rodríguez Monegal: "Situación del escritor en América Latina", Mundo Nuevo (París, jul. 1968), Pp. $5 \cdot 21$.

MAA, p. 20. Rodriguez Monegal afirma que, "ese sentido mítico suyo hace que el lenguaje sea precisamente el cauce por el que se derrama toda esa realidad mítica viva de Amética, que no es simplemente cuestión de especialistas en antropología, de museos y congresos indigenistas, sino que es la realidad actual de toda una zona de América".

1047. GA: "Literatur-nobelpreisträger 1967; Miguel Ảngel Asturias", General-Anzeiger, Bonner Siadt (Bonn, 20 oct. 1967).

"Asturias aboga decididamente por una literatura comprometida que refleje las realidades modernas y que no se refugie en la torre de marfii de los poetas. Todos los libros del nuevo Premio Nobel tienden inequívocamente a este reflejo de la realidad".

1048. Gaffory, L. [Seud. de A. Cervoni]: "A propos de La flaque dn mendiant; entretien avec Miguel Angel Asturias", France Nouvelle, 1081 (París, 6 jul. 1966), pp. 17-18.

Entrevista con motivo de la aparición en francés de El albajadito. Asturias explica cómo escribió esta novela.

1049. Gaffory, Louis [Seud. de A. Cervoni]: "Les miroirs de M. A. Asturias", France Nouvelle, 1130 (París, 14 jun. 1967).

Reseña de la edición francesa de El espejo de Lida Sal. "Continue l'itinéraire que parcourt M. A. Asturias entre le réel immediat et le fantastique, l'itinéraire du 'réalisme magique" ".

1050. Gaillard, Robert: "Miguel Angel Asturias; Hombres de maiz", Nice-Matin (Niza, 1 ene. 1954).

Reseña encomiástica. "La nobleza y grandiosidad de sus temas... la excepcional calidad de su estrlo lleno de sabor... nuevo; todo eso ha. ce, sin duda alguna, de Asturias uno de los más grandes escritores vivientes".

1051. Galaos, José Antonio: "Los dos ejes de la novelística de Miguel Angel Asturias", Cuadernos Hispanoamericanos, LII:154: (Madrid, nov.-dic. 1962). 
1052. Gallagher, David: "Fiction of the Week; Miguel Angel Asturias", The Times Literary Suplement (Londres, 28 sep. 1967).

Reseña de las traducciones al inglés de Mulata de tal y Viento fuerte. De la primera afirma que es: "a curious mixture of straightforward shamanism and surrealistic eroticism" y que Viento fuerte "is an exotic, sensual novel... the excessive exoticism of the language tends to undermine the novel's social urgency".

1053. Gallegos, Valdés, Luis: "El Papa verde", Sintesis, I:4 (San Salvador, jul. 1954), PP. 23-28 [reseña].

1054. Gamarra, Pierre: "Miguel Angel Asturias; Week-end en Guatemala", Europe, 350 (París, abr. 1959), pp. 145-146 [reseña].

1055. Garavito, Julián: "Clarivigilic primaveral", Espiral, 99 (Bogotá, jun. 1966), Pp. 68-79.

Reseña de la edición bilingüe, "su lectura no es fácil, no por lo hermético, su significado es claro, sino porque por primera vez, un poeta trata de cantar lo nuestro, lo autóctono americano, con titmos con vo. cablos, con evocaciones, con vuelos nuestros, genuinos, esto es, precolombinos".

1056. Garavito, Julián: "Lo nuestro en Europa", Espiral, 105 (Bogotá, mar. 1968), Pp. 65-67 [nota biobibliográfica de MAA].

1057. Garavito, Julián: "Dos manifestaciones culturales en Paris", $R a$ zón y Fábula, 8 (Bogotá, jul.-ag. 1968), pp. 130-131 [crónica del homenaje a MAA en la Sorbona].

1058. Garavito, Julián: "Du Popol-Vub a M. A. Asturias", Europe, 473 (París, sep. 1968), pp. 48-57.

1059. Gamboa, Lore de: "El albajadito", Critovio, XXXIV (Buenos Aires, 1962), PP. 76-77 [reseña].

1060. Garcés Larrea, Cristóbal: "Premio Nobel 1967, Miguel Angel Asturias", Cuadernos del Guayas, 24-25 (Guayaquil, abr. 1968), pp. 5 y 28 [contiene una introducción seguida del cuento "Ocelotle $\left.33^{\prime \prime}\right]$.

1061. Gardella, Doménico: "El realismo mágico de Asturias", Diario de Centroamérica, supl. de Arte y Literatura, V:231 (Guatemala, 9 dic. 1967), p. 3.

El señor Presidente, le hace pensar al crítico, en algunos aspectos, en Giovanni Verga. Para ambos, una obra es "al mismo tiempo una conquista de verdad poética y de seriedad moral".

1062. Gaztambide, Agustina F. de: "El señor Presidente", Asomante, XXIV:3 (San Juan, jul.-sep. 1968), Pp. 21-29.

Examen pormenorizado. "El señor Presidente, obra de arte, no documento".

1063. Gennaro, Giuseppe de: "Il sentimento tragico della vita nell' 
opera di M. A. Asturias", Letture, 5 (Milán, may. 1968), pp. $1+20$.

Enjundioso examen de la obra asturiana. Se estudia el narrador, el poeta, el Asturias intimo. Enfoca una dimensión poco estudiada de MAA: su religiosidad; "Denota un vero contatto personale con Dio e soprattutto con Cristo, il Figlio del Padre fattosi uomo". Y concluye "Asturias ci permette di supporre che la tragicità del suo sentimento è anche più cristiana di ciò che può apparire a prima vista. Nel tendere, infatti, verso la pienezza della dimensione individuale, sociale e cosmica, la libertà dell'uomo non appare sola, perché non si rifiuta di aptirsi all'azione di un'altra libertà, quella divina. che determina in modo predominante la compiutezza di ogni essere".

1064. Gennaro, Giuseppe de: "I felici tropici di Miguel Angel Asturias narratore", La Civiltà Cattolica, I:2822 (Roma, 1968), pp. 148157.

Un resumen del ensayo anterior. El arte y el pensamiento de MAA, "raggiunge la piena maturità solo in quelle pagine dove l'ispirazione mitica e quella storica, i felici tropici di Asturias, riescono a trovare la congiunzione e l'equilibrio nella luce dell'arte".

1065. Georgescu, Paul Alexandru: "Un mare romancier al americii latine", Revista de Filologie Romanicá di Germanicá, I (Bucarest, 1961) ["Un gran novelista de la América Latina". Sobre Asturias].

1066. Georgescu, Paul Alexandru: "Premiul Nobel pentru literaturá 1967; Miguel Angel Asturias", Scinteis (Bucarest, 27 oct. 1967) [El Premio Nobel de Literatura i967; MAA].

1067. Ghiano, Juan Carlos: "El señor Presidente, de Miguel Angel Asturias", Realidad, 6 (Buenos Aires, 16 jul.-ag. 1949), Pp. 116-119.

Reseña. "Novela tecargada de material humano y literario, idiomáticamente desbordante y jactanciosa, ejemplo dolorido de una Amética barroca, distinta a España".

1068. Ghiano, Juan Carlos: "Week-end en Guatemala", Ficción, 7 (Buenos Aires, may.-jun. 1957), Pp. 178-179.

Reseña. "...Asturias se ha sentido responsable de esa misión, integrada en el concepto de una América hispánica sin fronteras, hecha hacia un solo destino. De ahí los aciertos como los riesgos de su literatura: Aciertos derivados de la recreación intensa y colorida de... ese mundo bullente y seguro del pueblo, riesgos de una creación que avanza sobre ciertas tesis... Ambas modalidades se reiteran en los cuentos publicados por Goyanarte".

1069. Gicovate, Bemardo: "[Prólogo de Asturias a] Juan Ramón Molina, Antología, verso y prosa", Handbook of Latin American Studies 23 (Gainesville, 1958), p. 342.

MAA, p. 342. Al referirse al prólogo de Asturias, el Prof. Bernardo Gicovate, señala: 'It hardly fits into Asturias' conception of poetic symbolism as something inherited from the ancestral Indians and carried in the blood". 
1070. Gigli, Lorenzo di: "Il dramma del Guatemala tra leggende e riti magici", Gazzetta del Popolo (Turín, 15 nov. 1967).

Revisión global de su obra. "Non manca nulla... a completare il profilo di uno scrittore polivalente che mentre annunzia $\mathrm{c}$ denunzia, con alto sentimento litico e con libera coscienza civile, una situazione esistenziale inconfondibile, esercita un mestiere strettamente collegato alle tecniche moderne più raffinate".

1071. Girard, Rafael: "Las culturas indigenas; fervor de Miguel Angel Asturias", El Imparcial (Guatemala, 16 nov. 1968), pp. 15 y 20. Apreciaciones personales sobre la obra ašturiana en la cual encuentra que se suma "el novelista, el narrador, el folklorista, el poeta, el indigenista, el etnógrafo y el historiador".

1072. Goldsborough, James: "A novelist of the people", Herald Tribune (París, 20 oct. 1967). También en El Gráfico (11 nov. 1967).

"No writer could be more representative of his people... His plots weave in and out of all the great issues and problems of two hemispheres and nearly 180 million people".

1073. González León, Adriano: "Week-end en Guatemala", Culura Universitdria, 59 (Caracas, 1957), PP. 144-146 [rescña].

1074. González de Mendoza, J. M.: "Una gran novela de Miguel Angel Asturias; El señor Presidente", El Imparcial (Guatemala, 24 feb. 1947), p. 3 [reseña].

1075. González de Mendoza, J. M.: "Guatemala y las leyendas de Miguel Angel Asturias", Revista de Revistas, 1142 (México, 3 abr. 1932).

1076. González, Otto Raúl: "El señor Presidente", Revista de Guatemala, II:3 (Guatemala, ene.-mar. 1947), pp. 157-159.

Reseña. "La materia prima... proviene de la tierra americana... la forma es un tanto europeizante".

1077. González, Otto Raúl: "Miguel Angel Asturias viene de Xibalba", Revista de Guatemala, XVIII:2 (Guatemala, ene.-dic. 1960), pp. 85-86 [reseña de Hombres de maiz].

1078. González-Rodas, Publio: "Miguel Angel Asturias; El espejo de Lida Sal", Revista Iberoamericana, 66 (México, jul.-dic. 1968), pp. 371-373 [reseña].

1079. Grall, Xavier: "Portrait: Un Maya nommé Asturias", TC (París, 14 dic. 1967), P. 24.

Breve ensayo de interpretación. "Asturias n'est pas le militant engagé que quelques-uns voudraient voir en lui. Asturias est d'abotd un créateur et non un prosélyte".

1080. Grignon Dumoulin, Jacques: "Il faut que la voix de nos peuples se fasse entendre, déclare le romancier", Le Monde (París, 1 dic. 1962) [entrevista. Situación de la novela hispanoamericana]. 
1081. Grindea, Miron: "The Nobel Prize; The Road to Tomorrow's Ceremony", The Times Saturday Review (Londres, 9 dic. 1967), p. 20.

Las peripecias de los Premios Nobel y entrevista con MaA.. Se detienen los dos, frente a la máquina de escribir de don Miguel Angel. Exclama Asturias "We are all poor devils in front of this machine, enough to keep us in a constant state of fear and humility... slaving at each word, for words cover all objects, all inferences".

1082. Guandique, José Salvador: "Valle Inclán y Asturias; de Tirano Banderas a El señor Presidente", El Imparcial (Guatemala, 12 mar. 1968), p. 3 [glosa de un ensayo del crítico español Fabra Barreiro].

1083. Guandique, José Salvador: "Pro y contra...; Asturias en juicios divergentes", El Imparcial (Guatemala, 27 abr. 1968), p. 15.

Recoge conceptos críticos divergentes de Anderson Imbert, Alfonso Reyes, Diaz Plaja, etc, sobre la obra asturiana.

1084. Guandique, José Salvador: "Vargas Llosa entrevista a Asturias", Impacto (Guatemala, 7 feb. 1969), p. 9.

Glosa el artículo de Vargas Llosa: "Un hechicero maya en Londres", Imagen (Caracas, 10 a 15 jun., 1967).

1085. Guardia, Miguel: "Asturias en México, el señor escritor", Excélsior (México, 17 oct. 1966), pP. 6A y 8A.

"Miguel A. Asturias... tras veinte años de ausencia... ha vuelto a su México... bienvenido pues.

Estoy seguro de que ahora que estuvo usted en Guatemala comió pipián de indio choji, pulique, tamales colorados, oreja de coche revolcado de cabeza, pepescas de Amatitlán y rellenitos de plátano".

1086. Guerra Borges, Alfredo: "El señor Presidente de Miguel Angel Asturias", Cuadernos de Guayas, VI:11 (Guayaquil, 1955), pp. 1719 [reseña].

1087. Guibentif, Edouard: "Wne certaine mulâtresse", Joumal de Genève (Ginebra, 15 dic. 1965) [reseña de la traducción francesa de $M u$ lata de tal].

1088. Guillarte, Cecilia G.: "Miguel Angel Asturias entre los soviéticos y los alemanes", "México en la cultura", supl. de Novedades, 1013 (México, 18 ago. 1968), p. 3.

1089. Guillén, Fedro: "Miguel Angel Asturias", Novedades (México, 21 oct. 1967 ), p. 5.

"Su perfil lo hubiera esculpido con deleite algún orfebre maya. Alto, grueso, voz de bajo, propicia a resaltar en un coro de teatro griego, Miguel Angel Astutias ha entrado de rondón a esa inasible frontera de la historia..."

1090. Guillén, Fedro: "Una gota sentimental de Miguel Angel Asturias", El Nacional (México, 8 mar. 1968), p. 4.

Miguel Angel Asturias... recuerda bien a su "nana" y le ha puesto unas líneas pidiéndole perdón por las diabluras que todos hacemos a 
cierta edad... y eso nos parece amable y sentimental, como una flor llegada de París a las manos de una anciana que la habrá recibido llorosa con sus 97 años..."

1091. Guillén, Fedro: "Antologia de Miguel Angel Asturias", "México en la cultura", supl. de Novedades, 1037 (México, 2 feb. 1969), p. 5 [reseña de MAA: Antologia, México, Costa Amic, 1968].

1092. Guillén, Fedro: "Miguel Angel Asturias y el Nobel", El Imparcial (Guatemala, 11 dic. 1964), p. 15 [véanse artículos adicionales de F. Guillén, en mi Asturias en México, fichas núms. 138, 139 y 140 ].

1093. Guillẻn, Nicolás: "Suplicio de Miguel Angel Asturias", Hoy (La Habana, 3 feb. 1960).

Durante su visita a Cuba, "cuatro panelistas" le dispararon muchas preguntas. Contestó - concluye Guillén- "que hay una literatura social americana". - ¿Habrá ya un lenguaje americano? - Asturias dijo que sí.

1094. Guimaraes, Silvio: "Entrevista con Miguel Angel Asturias", Para Todos, 37 (Rio, nov. 1957).

1095. Guitard-Auviste, Ginette: "Torotumbo", Les Nouvelles Littéraires (París, 8 mar. 1967).

Reseña. Estudiosa asidua de MAA, Ginette Guitard-Auviste, sugiere que: "Cette longue nouvelle pourra servir d'initiation au lecteur qui ignore encore l'oeuvre du guatémaltèque MAA, un des plus puissants écrivains de ce temps".

1096. Guitard-Auviste, Ginette: "Miguel Angel Asturias; la bourse ou la vie", Les Nouvelles Littéraires (París, 29 dic. 1962), p. 7 [entrevista].

1097. Guitard-Auviste, Ginette: "Miguel Angel Asturias et le subconscient indien", Le Monde (París, 10 abr. 1965) [entrevista].

1098. Guitard-Auviste, Ginette: "Une vie et une oeuvre", Le Monde (París, 20 oct. 1967) [revisión de su trayectoria literaria].

1099. Gutiérrez Girardot, Rafael: "La realidad en la literatura hispanoamericana", "Lecturas dominicales", de El Tiempo (Bogotá, 23 ago. 1963).

Interptetación de la obra asturiana "como giro de la literatura social. crítica latinoamericana. No más Icaza, sino expresionismo y protesta: no más panfleto ni folklore, sino compromiso y arte".

1100. Haavardsholm, Av Espen: "En opera i tropene?", Dagbladet (Oslo, Noruega, 30 oct. 1968) [reseña de la versión noruega de Viento fuerte].

1101. Haedens, Kleber: "Les légendes du Guatémala", Paris Presse (París, 3-4 ene. 1954).

Reseña. Este crítico francés ha seguido de cerca los pasos de aras. He aquí su más antigua reseña. Critica impresionista. 
1102. Haedens, Kleber: "W'eek-end au Guatémala", Paris Presse (París, 31 ene. 1959).

Reseña. "Ses huit récits causent une forte impression par leurs violences".

1103. Haedens, Kleber: "Une certaine mulâtresse", Nonveau Candide, 208 (París, 19 abr. 1965) [reseña de la edición francesa de Mulata de $t a l]$.

1104. Haedens, Kleber: "Guatemala en Europa en Mulata de tal", El Imparcial (Guatemala, 24 jul. 1965), p. 15 [traducción de la reseña anterior].

1105. Haedens, Kleber: "La flaque du mendiant; Une opération magique comme il s'en produit parfois dans les songes", Paris Presse ( $\mathrm{Pa}$ rís, 28 may. 1966) [reseña de la versión francesa de El albajadito].

1106. Haedens, Kleber: "Et sur le lac, le corps de la jolie fille flotte sous la lune", Paris Presse (París, 16 sep. 1967) [reseña de El espejo de Lida Sal].

1107. Haiek, Olga B, y María Isabel de Gregorio de Mac: "El surrealismo en Asturias", Critica, 66:V:14 (Rosario, Arg., ago. 1966), pp. 31-42.

1108. Hampl, Zdenek: "Me enamoré de Praga y de los praguenses", Kultura, 39 (Praga, 1957), p. 2 [descripción del encuentro de MAA con escritores checoslovacos].

1109. Hecht, Yvon: "Miguel Angel Asturias; ambassadeur du Guatémala a Paris et combattant de la liberté", Paris-Normandie (París, 20 oct. 1967) [trayectoria de su vida. Se recalca su lucha por la libertad].

1110. Hermes Villordo, Oscar: "Poesia precolombina", Sur, 273 (Buenos Aires, nov.-dic. 1961), p. 72 [reseña].

1111. Hernández, Arturo: "El abrazo de los obretos y los campesinos", Revista de Guatemala, XVIII:2 (Guatemala, ene.-dic. 1960), Pp. 96-97 [exaltación con motivo de sus 60 años].

1112. Hernández, Oscar F.: "El mundo cósmico del Popol-Vub en dos novelas de Miguel Angel Asturias", El Imparcial (Guatemala, 11 nov. 1967).

1113. Hernández, Raúl: "Premio Nobel de Literatura, 1967, 'Estaba seguro", dice Rodrigo, hijo de Miguel Angel Asturias", Diario de la Tarde (México, 20 oct. 1967) [entrevista].

1114. Hernández Sánchez Barba, Mario: "Miguel Angel Asturias, Pre- 
mio Nobel de Literatura", Atlántida, VI:31 (Madrid, ene.-feb. 1968), pp. 85-88.

Firme interpretación de la narrativa asturiana. "El tiempo existencial constituye en la obra de Miguel Angel Asturias un elemento creador tan apto para penetrar las complejisimas estructuras míticas como para recoger desde puntos de vista subjetivos la radical circunstancia 50cial y política a las más flagrantes realidades económicas de su país".

1115. Hiriart, Hugo: "El bosque y las letras", El Imparcial (Guatemala, 24 oct. 1967), pp. 3 y 9 [tomado de Excélsior de México. Véase, Asturias en México, ficha 144].

1116. Hodousek, Eduard: [Ensayo sobre Asturias]. Calendario cultural (Ed. Orbis, Praga, 1969) [valoración global de su vida y obra].

1117. Hogan, William: "The 'Unknown' Nobel Laureate", Sin Francisco Cbronicle (San Francisco, 23 oct. 1967).

Reportaje en que se subraya el desconocimiento del novelista en los Estados Unidos, mientras que "Asturias is highly regarded in Europe, especially France, where his work has been compared with Faulkner, Kafka and Joyce".

1118. Hoijer, Bjorn F.: "Asturias, Neruda, Carpentier entre los aspirantes al Nobel hoy", El Imparcial (Guatemala, 18 oct. 1967), pp. 1 y 2.

El reportero escandinavo barajea los posibles candidatos americanos y europeos. Además de los mencionados, tiene en mente, Borges, MaIraux, Graham Greene, Beckett, Bacchelli y Moravia.

1119. Hoijer, Bjorn F.: "Miguel Angel Asturias, Nobel de Literatura", El Nacional (México, 20 oct. 1967), PP. 2 y 7 [reportaje general. También en $E l$ Sol de México].

1120. Huntford, Roland: "Began with Sartre; Asturias' award shows politics in Nobel Prize", The Goble and Mail (Toronto, 24 oct. 1967).

Proclama que el Nobel se ha convertido desde Sartre, en un instrumento político. Huntford opina que la Academia sueca premió a MAs, para congraciarse con la izquierda internacional. Concadena el comien. zo de la candidatura de Asturias, con el proceso de Debray.

1121. Illescas, Carlos: "Asturias crece hacia arriba", Revista de Guatemala, XVIII:2. (Guatemala, ene.-dic. 1960), p. 105.

"La abra de Miguel Angel Asturias es la conciencia literaria de un pais que ha sufrido graves males".

1122. Illescas, Carlos: "Miguel Angel Asturias ante el Premio Nobel", El Imparcial (Guatemala, 5 dic. 1964), pp. 17 y 25.

1123. Irve, Bent: "Nobelprisen til litteraei ambassador", Berlingske Tidente (Copenhague, Dinamarca, 20 oct. 1967) [noticia bibliográfica].

1124. Irving, T. B.: "Stifled protest in the City", Revista Interamericana de Bibliografia, XV:2 (México, abr.-jun. 1965), pp. 127-140 [ensayo sobre $E l$ señor Presidente]. 
1125. Isaacson, José: "El albajadito", Comentario, VIII:30 (Buenos Aires, 1961), pp. 94-96 [reseña].

1126. Jaimes-Freyre, Mireya: "Juan Girador", Revista Hispánica Moderna, XXXII:1-2 (Nueva York, 1966), pp. 107-108 [reseña].

1127. Jardin, Claudine: "Miguel Angel Asturias, Prix Nobel de Littérature", Le Figaro (París, 20 oct. 1967).

Entrevista:

C.J. - La France vous a-t-elle aidé?

MAA. - Infiniment. La France a été un pont admirable entute notre littérature et le monde:

c.J. - Vous n'avez jamais été tenté d'écrire directement en français?

MAA. - Le français est une langue qui s'est crée à travers les siècles, on ne peut plus rien inventer. Dans ma langue à moi, jai l'impression que je crée à mesure que j'écris une langue sans limites.

1128. Jiménez, Max: "Leyendas de Guatemala", Repertorio Americano, XXI (San José, C. R., 1930), p. 85 [reseña].

1129. Jiménez, Salvador: "El guatemalteco Miguel Angel Asturias, Premio Nobel de Literatura 1967", $A B C$ (Madrid, 20 oct. 1967), pp. 79-80.

Entrevista en Paris: "Habla un francés resumido y funcional, donde su expresividad queda oscurecida, porque lo suyo es manejar la palabra, el verbo, en una especie de gran retablo barroco donde la mitología maya y el espectáculo de la naturaleza componen un canto épico".

1130. Jiménez de Báez, Yvette: "El pelele; un personaje símbolo de Miguel Angel Asturias", Anuario de filología, VI-VII:6-7 (Maracaibo, 1967-1968), pp. 319-335.

Valiosa exposición: "He querido detenerme en el Pelele, figura de su primera novela. Entender este personaje-símbolo equivale a penetrar en varias constantes de la novelística asturiana".

1131. Jiménez, Luz Angélica: "La voz polémica; la obra de Asturias no ha llegado a las profundas raices del pueblo", Diario de Centroamérica, LXXXVII:26136 (Guatemala, 9 dic. 1967).

Señala la necesidad de difundir la obra asturiana en Guatemala, pues aún no se estudia como merece.

1132. J. K.: "Sydamerikas Stemme", Berlingske Tidende (Copenhague, Dinamarca, 20 oct. 1967) [semblanza].

1133. Johansson, Kjell A.: "Miguel Angel Asturias", Böckemas Värld, I:9-10 (Estocolmo, 1967), Pp. 37-38.

1134. Johansson, Kjell A.: "Skapelse och undergang", Dagens Nybeter (Estocolmo, 10 dic. 1967).

1135. Joset, Jacques: "Le Président de Miguel Angel Asturias", Marcbe Romane, XVI:2 (París, 1966), pp. 63-71.

1136. J. T.: "Nobelprisvinner Asturias' siste roman", Dagbladet (Oslo, 
Noruega, 18 dic. 1968) [reseña de la edición sueca de Mfulata de tal].

1137. Jurado, Alicia: "Leyendas de Guatemala", Sur (Bucnos Aires, dic. 1958), pp. 100-101 [reseña].

1138. Justo, Luis: "Mulata de tal", Cuadernos del Congreso por la Libertad de la Culturi, 81 (París, feb. 1964), pp. 91-92.

Reseña. "Pretendemos señalar que en Mulata de tal, aún fusionados to aborigen y lo occidental por la habilidad del natrador, en definitiva ambas aportaciones entran en conflicto en el ánimo del lector", afitma el crítico.

1139. Kalda, Alexandre: "Le petit prince du Guatemala", L'Express (París, 8 ago. 1966), p. 32.

Reseña de la versión francesa de El albajadito. "La Flaque du men. diant, le dernier roman d'Asturias publié en France, se rattache à sa veine fantastique".

1140. Kaibil: "Asturias, Premio Nobel", Revista A.P. G. 27 (Guatemala, dic. 1967), pp. 27-28 [MAA, "ha dejado su honda huella en el periodismo"].

1141. K. M.: "The Mulata and Mister Fly", The Cape Argus (Cape Town, Africa del Sur, 2 nov. 1967).

Reseña de la edición inglesa de Mulata de tal. "Sketchy plot... obscure at times, the power of Mr. Asturias' prose is such that he creates an aura of credibility, with the tensions reinforced with vivid descriptions and chaqacterizations".

1142. Kuteishchikova, Vera: "Glazami indeitsev Gvatemaly", Voprosy Literatury, VII:9 (Moscú, sep. 1963), pp. 233-236.

"A través de los ojos de los indigenas guatemaltecos". Se ocupa principalmente del libro de A. J. Castelpoggi: Miguel Angel Asturias (B. A., 1961).

1143. Kuteishchikova, Vera y Lev Ospovat: "Sud'by kriticheskogo realizma v sovremennoi literature Latinskoi Ameriki", Voprosi Literatury, 5 (Moscú, 1958), Pp. 69-85.

"La suerte del realismo critico en las letras contemporáneas de la América Latina". Contiene una sección dedicada a MAA.

1144. Kuteishchikova, Vera: "Miguel Angel Asturias en la URSS", Literatura Soviética, 2 (Moscú, 1962), Pp. 163-164.

La destacada crítica tusa de la novelistica latinoameticana, evoca la visita de MAA a la urss, en ocasión del Festival de la Juventud. "Figu. raba entre los huéspedes de honor... intervino ante los más diversos auditorios del Moscú en fiestas... hablaba... de los problemas más candentes de la actual literatura de América Latina, de los vínculos espirituales que han existido desde antaño entre Rusia y los países del Nuevo Mundo".

1145. Kuteishchikova, Vera: "Las obras de Miguel Angel Asturias en ruso", Literatura Soviética, 8 (Moscú, 1968), pp. 167-168.

Reseña de la edición rusa de Los ojos de los enterrados, Editorial Progreso. Su aparición "enriquece sustancialmente nuestras nociones 
sobre la espléndida y compleja personalidad de uno de los artistas más grandes de nuestro tiempo".

1146. Kyria, Pierre: "Asturias; 'En Amérique Latine écrire c'est combattre" ", Combat (París, $4-5$ jun. 1966), p. 7.

Entrevista que gira ptincipalmente en torno a la edición francesa de El albajadito.

1147. Labrador Ruiz, Enrique: "Miguel Angel Asturias", El Nacional (Caracas, 7 may. 1957).

1148. Labrador Ruiz, Enrique: "Asturias en Guatemala", Letras de Cuzcatlán, II:20-25 (San Salvador, jul.-dic. 1957).

1149. Lalou, René: "Le livre de la semaine: Hommes de mais", Les Nouvelles Littératires (París, 7 ene. 1954), p. 3.

Reseña de Hombres de maiz y Leyendas de Guatemala. "Nous demeurons ensorcelés, sans chercher à demêler aucun fil de ce somptueux réseâu des réalités et des symboles".

1150. Lalou, René: "Le livre de la semaine: Le Pape vert", Les Nouvelles Littéraires (París, 16 feb. 1956), p. 3 [reseña].

1151. Lalou, René: "Le livre de la semaine: Week-end at Guatemala", Les Notuvelles Littéraines (París, 19 mar. 1959), p. 3 [reseña].

1152. Lask, Thomas: "Book of the Timcs, Nobel Laureate", New York Times (Nueva York, 25 oct. 1967).

Reseña de las versiones inglesas de Mulata de tal y de El señor Presidente. Frente a las creaciones astutianas el critico - tan alejado del mundo de MAA- se encuentra petplejo, confuso. Pero se percata de "su imponencia". "El señor Presidente is a first novel, and as a work of fiction it has considerable flaws. Nevertheless, it is an impressive piece of work. Mulata is in entirely different vein... a jungle of abstruse and noncommunicative references. The names are meaningless. The situations and quick changes will baffle and confuse the reader.."

1153. Latcham, Ricardo A.: "El señor Presidente", La Nación (Santiago, 15 mar. 1949) [reseña].

1154. Laudon, Frederick: "El Rey de Suecia le entregó el máximo Premio", El Imparcial (Guatemala, 11 dic. 1967), pp. 1 y 6 [véase también mi Asturias en México, ficha 151].

1155. Lavaniegos, Manuel: "Diario del Público; el Premio Nobel de Literatura", El Universal (México, 21 nov. 1967).

"Hay en el lema de Miguel Angel Asturias una invitación a la valen. tía y civismo, al decir que dice lo que ottos no pueden o no quieren decir".

1156. Leal, Luis: "Myth and Social Realism in Miguel Angel Asturias", Comparative Literature Studies, V:3 (Urbana, 1969), Pp. 237-247.

Lúcida y rigurosa exposición de su novelística: "His best works seem to be those in which he blends motifs of both the Indian and the criollo cultures of Guatemala without giving undue emphasis to either one, as in El señor Presidente, his most successful novel". 
1157. Leiva, Raúl: "Anticipaciones; veinticinco años de letras nacionales", El Imparcial (Guatemala, 30 sep. 1943), pp. 3, 6 y 7.

MAA, p. 7. Escribia Leiva, hace más de un cuarto de siglo, "Miguel Angel Asturias... Tiene poemas admirables, escritos hace más de diez años. Sus últimos versos no nos satisfacen. Ya está volviendo al trópico otra vez... El res uno de los poetas guatemaltecos que actualmente podrían responder a la crítica americana con una obra de telieve".

1158. Leiva, Raúl: "Leyendas de Guatemala", Revista de Guatemala; X: 2 (Guatemala, oct.-dic. 1948), p. 124 [reseña].

1159. Leiva, Raúl: "Miguel Angel Asturias", Letras del Ecuador, $90-92$ (Quito, ene.-mar. 1954), p. 14.

1160. Leiva, Raúl: "Miguel Angel Asturias", El Nacional (Caracas, 29 oct. 1959).

1161. Leiva, Raúl: "Miguel Angel Asturias en Guatemala", Revista de Guatemala, XVIII:2 (Guatemala, ene.-dic. 1960), pp. 13-17.

Escribe el poeta que Hombres de maíz es la "Elucidación de fenómenos estéticos y sociales del bomo guatemalensis..."

1162. Leiva, Raúl: "Miguel Angel Asturias", Casa de las Américas, II:8 (La Habana, sep.-oct. 1961), pp. 61-69.

"A Miguel Angel Asturias algunos le han criticado porque en sus obras - dicen- no se ofrecen soluciones y porque sus finales son más o menos defrotistas. Nosotros no estamos de acuerdo con quienes así piensan; creemos que la sola denuncia de tipo social que sus novelas contienen ya es bastante..."

1163. Leiva, Raúl: "Miguel Angel Asturias en México, por Pedro F. de Andrea", "México en la cultura", supl. de Novedades, 1038 (México, 9 feb. 1969), p. 7 [breve reseña].

1164. Leiva, Raúl: "Reconocimiento mundial: Miguel Angel Asturias, Premio Nobel, 1967", "México en la cultura", supl. de Novedades, 972 (México, 5 nov. 1967), pp. 3 y 6.

"Se ha hecho justicia - señala R. L.- en lo que respecta al ámbito de Occidente... pues la otra mitad del mundo la ganó en 1965, al adjudicársele el premio Lenin de la Paz... Primero le premió el mun. do socialista, luego el mundo capitalista... Rara unanimidad. Es la primera vez que se da, y testimonia la vigencia universal del insigne autor" [para bibliografía adicional de Leiva sobre MAA, véanse las 10 siguientes cédulas: $152,153,154,155,156,157,158$ y 159 en mi Asturias en México].

1165. Lece, J. E.: "Alabanza para Miguel Angel Asturias", El Gráfico (Guatemala, 1 feb. 1968), pp. 6 y 31.

El columnista transcribe una carta en alabanza a MAA, que le llegó de Los Angeles. Una multiplicación de ditirambos.

1166. Lece, J. E.: "Guatemala gana Premio Nobel", El Gráfico (Guatemala, 20 oct. 1967), p. 7.

"La noticia procedente de Estocolmo, que la he leido y releido [confirma] que no es sueño sino tealidad, una positiva realidad... Una ráfaga de optimismo me vitaliza pensando que Guatemala no es sola. mente problemas, discordia, odios, muerte". 
1167. León, Maria Teresa: "Miguel Angel Asturias, Premio Nobel", La Palabra y el Hombre, 45 (Xalapa, Ver., ene.-mar. 1968), Pp. 5-6.

"Miguel Angel Asturias encuentra en el grupa humano donde nació el primer humus de su lenguaje poético, tan rico, tan imaginativo..."

1168. León, Victor Hugo de: "Los mayas ante los ojos del mundo", El Gráfico (Guatemala, 23 ago. 1968).

1169. L. G. "A propos de La Flaque du Mendiant; Entretien avec Miguel Angel Asturias", France-Nouvelle, 1081 (París, 6 jul. 1966), p. 17.

Entrevista. Conjunto de valiosas declaraciones que ayudan al entendimiento de El albajadito.

1170. Linder, Erick $\mathrm{Hj}_{\text {.: }}$ "Miguel Angel Asturias", Göteborgs-Posten (Gotemburgo, 20 oct. 1967).

"Si es así que el Premio Nobel tiene todavía alguna importancia, el habérselo concedido a Miguel Angel Asturias, de Guatemala, es un acontecimiento histórico" [traducción de Ennesto Dethorey].

1171. Liscano, Juan: "De Valle-Inclán à Miguel Angel Asturias", Earope, 345-346 (París, ene.-feb. 1958), pp. 180 -191 [véase otro ensayo de Liscano en mi Asturias en México, ficha 161].

1172. Loberg, Ingebriot: "Nobelprisen kom pa Asturias' 68-ars dag", Aftenposten (Oslo, Noruega, 20 oct. 1968).

Glosa una entrevista verificada en París. Versa sobre autores favoritos de MAA.

1173. Loetzcher, Hugo: "El señor Presidente", Die Weltwoche (Zurich, 15 dic. 1957) [rescña de la edición alemana de El señor Presidente].

1174. López Castro, Fulgencio: "El albajadito", El Universal (Caracas, 5 dic. 1961) [reseña].

1175. López, Matilde Elena: "Instantáneas; Miguel Angel Asturias, Premio Nobel Literario", Impacto, 2492 (Guatemala, 25 nov. 1967), Pp. 2 y 22 [reseña brevemente la obra de MAA].

1176. López Narváez, Froylán M.: "Asturias: popular y original", "Diorama de la cultura", supl. de Excélsior (México, 29 oct. 1967), pp. 3 y 5 [también en Diario de Centroamérica, 26136].

1177. López Valdizón, José Maria: "Los símbolos mayas en El espejo de Lida Sal, el reciente volumen de Miguel Angel Asturias", Revista A. P. G, 28 (Guatemala, abr. 1968), p. 47 [reseña. "Prosa conceptual... poética... característica del estilo asturiano"].

1178. López Valdizón, José: "El último libro de Asturias; El espejo de Lida Sal", El Imparcial (Guatemala, 16 nov. 1968), pp. 15 y 20 [rescก̃a]. 
'1179. Loveluck M., Juan: "Una novela de nuestro tiempo", Atenea, XVII:310 (Concepción, Chile, abr. 1951), pp. 49-63.

Amplio estudio de $E l$ señor Presidente. El profesor chileno aquilata varias facetas de la novela: estilo, ambiente, metáfotas, inventiva, etc.

1180. Lorenz, Günter W.: "Um einen ungemeuchelten Asturias bittend", Die Welt der Lileratur (Hamburgo, 28 may. 1965), p. 4 [reseña de Mulata de tal, del acucioso crítico alemán].

1181. Lorenz, Günter W.: "Miguel Angel Asturias; der unbeachtete Dichter", Die Welt, 240 (Hamburgo, 15 sep. 1965), P. 7 ["MAA; poeta desconocido"].

1182. Lorenz, Günter W.: "Wir müssen Zeugen sein", Die Welt der Literatur, supl. literario, IV:15 (Hamburgo, 20 jul. 1967), Pp. 12 y 13.

Diálogo con maA. Traducido en parte al inglés y publicado en Atlas, XIV:6 (Nueva York, dic., 1967), pp. 56.58, con el título de "Hearing the Scream".

1183. Lorenz, Günter W.: "Erbe Europas und Amerikas: Miguel Angel Asturias", Europa (Munich, ago. 1967), pp. 14-19 ["Heredero de Europa y América"].

1184. Lorenz, Günter W.: "Die Grosse Stimme Amerikas; Miguel Angel Asturias", Die Welt, 245 (Hamburgo, 20 oct. 1967), p. 5. "El gran lengua de América". Ensayo literario con motivo del Premio Nobel. Se reprodujo en numerosos periódicos alemanes, austria$\cos$ y suizos.

1185. Lorenz, Günter W.: "Hearing the Scream'; an Interview with Nobel Prize Winner Miguel Angel Asturias", Allas, XIV:6 (Nueva York, dic. 1967), pp. 56-58 [traducido parcialmente de Die Welt].

1186. Lorenz, Günter W.: "Der Magier der Wirklichkeit; Persönlichkeit und werk des Miguel Angel Asturias", Geist-Tat (Bonn, dic. 1967), pp. 4-9 ["El mago de la realidad; personalidad y obra de MAA"]. $^{\text {"I }}$

1187. Lorenz, Günter W.: "Moderne prosa aus dem Geist der Mayas; Die Bananen-trilogie von Miguel Angel Asturias", Die Welt der Literatur (Hamburgo, 1 feb. 1968), pp. 3 y 4.

"Prosa moderna escrita en espiritu maya; la trilogía bananera de MAA".

1188. Lorenz, Günter. W.: "Der Fluch der Macht oder; Der grïne Papst von Miguel Angel Asturias", Die Welt der Literatur, 25 (Hamburgo, 5 dic. 1968), p. 6 ["La blasfema de la fuerza o El Papa verde"].

1189. Lucena, Rafael María: "Miguel Angel Asturias y la literatura comprometida", "Revista Mexicana de Cultura", supl. de El $\mathrm{Na}$ - 
cional, 1624 (México, 13 nov. 1966), p. 4 [véase mi Asturias en México, ficha 166].

1190. Lundkvist, Artur: "Den Gröne Päven". Morgen-Tidningeli (Estocolmo, 29 abr. 1956) [sobre El Papa verde].

1191. Lundkvist, Artur: "De begtavdas ögon", Bonniers Litterära Magasin, XXXI (Estocolmo, sep. 1962), pP. 568-570 [sobre MAA].

1192. Lundkvist, Artur: "Langt borta, mycket nära", Dagens Nybeter (Estocolmo, 28 sep. 1966) [reseña de El albajadito].

1193. Lundkvist, Artur: "Novellister fran Latinamerika", Dagens $N y$ beter (Estocolmo, 22 abr. 1968) [reseña de El espejo de Lida Sal].

1194. Luz de Rodriguez, Blanca: "En torno a los homenajes a Miguel Angel Asturias", El Imparcial (Guatemala, 23 nov. 1967).

1195. Luzi, M.: "Il punto su Asturias", Corriere della Sera (Milán, 19 nov. 1967), p. 11.

1196. Lyon, Thomas E.: "Miguel Angel Asturias; Timeless Fantasy; The 1967 Nobel Prize for Literature", Books Abroad, XLII (Norman, Okla., Primavera, 1968), pp. 183-189.

"Linguistic interplay between archaic, popular, and newly invented words; with fertile legend and dynamic telluric forces - the timeless fantasy of his prose".

1197. Maddocks, Melvin: "Novel from a Nobel Winner", Christian Science Monitor (Nueva York, 26 oct. 1967), p. 11.

1198. Magaña Esquivel, A.: "Teoría del Premio Nobel", Novedades (México, 22 oct. 1966), p. 4.

Lamenta - AME - el olvido en que se tiene a los latinoamericanos y menciona a MAA, entre otros, como candidato al Premio. Nótese que este artículo fue escrito antes de que le fuerh otorgado el galardón en 1967.

1199. Magaña Esquivel, Antonio: "Al pie de las letras, Miguel Angel Asturias", Novedades (México, 11 feb. 1967), p. 4 [reseña el vol. III de Obras Escogidas de MaA].

1200. Maldonado Denis, Manuel: "Miguel Angel Asturias, novelista americano", Cuademos Americanos, XXII:3 (México, may.-jun. 1963), pp. 250-258.

1201. Malinow, Inés: "Un americano en París: Miguel Angel Asturias", La Nación (Buenos Aires, 29 oct. 1967), p. 3.

Pequeña estampa biográfica y transcripción de algunas declaraciones asturianas. Afirma MAA, "Mis libros se parecen a los murales de México, donde todo está mezclado: campesinos, liebres, arzobispos, aventureros'. 
1202. Mannucci, Loris: "Le dichiarazioni dello scrittore". La Stampa (Turín, 20 oct. 1967) [se reiteran los datos biobibliográficos de MAA].

1203. J[orge] M[añach]: "La arquitectura de la vida nueva", Revista de Avance IV:32 (Habana, 15 mar. 1929), p. 87.

Reseña. Asturias cumple "con esmeto en prosa de elegante sencillęz, su generoso propósito de edificación popular". Una de las primeras reseñas relativa a su obra.

1204. Marcenac, Jean: "Monsieutr le Présidcnt", Les Lettres Françatises (París, 2 may. 1952).

Reseña. "Il faut lire ce livre. Il faut le lire avec patience et passion... Il est triste et fort, scintillant et profond".

1205. Marcenac, Jean: "Un Nobel de justice", L'Humanité (París, 20 oct. 1967) [exaltación].

1206. Márquez, Velia: "Aventura de leer", Diario de la Tarde (México, 10 ene. 1967).

Reseña del libto de Giuseppe Bellini: La narrativa di Miguel Angel Asturias. "Este trabajo respecto a Asturias es uno de los más comple. tos sobre el creador de El señor Presidente. Estudia desde su iniciación literaria hasta sus últimas novelas".

1207. Martin, Gerald: "Champion of the Oppressed", The Scotsman Week-end Review (Edimburgo, Escocia, 2 dic. 1967), p. 7.

Se señalan las características de la obra asturiana y se aquilata su acogida por la prensa inglesa. Afirma que El señor Presidente "met with a cool reception" y la Mulata de tal "with decidedly muffled applause".

1208. Martínez Mar, José Luis: "El novelista, de cuerpo entero. En Latinoamérica el escritor ha jugado siempre un papel importante, por ello ha sido perseguido", El Día (México, 20 oct. 1967), p. 6 [entrevista con Asturias].

1209. Martínez Durán, Carlos: "El hombre y el artista en su trágica grandeza", El Imparial, 1 (Guatemala, 1 y 2 jul. 1964), fp. 9 y 13 [dos artículos de exégesis].

1210. Martínez Durán, Carlos: "Homenaje al poeta Miguel Angel Astutias, Premio Nobel de Literatura 1967", El Imparcial (Guatemala, 9 dic. 1967), pP. 17 y 23.

"Miguel Angel Asturias, como todos los grandes de espíritu, lleva dormidos en su intelecto, los recuerdos de la infancia, del niño que juega con el misterio, que es artista por su connubio con la libertad y la invención".

1211. Martínez Durán, Carlos: "Al ser más de su país lo es más de todo el mundo", Diario de Centroamérica, LXXXVII:26136 (Guatemala, 9 dic. 1967), pp. 2, 4 y 6 [discurso de exaltación].

1212. Martínez de la Vega, Francisco: "El gran premio condicionado", El Dia (México, 1 nov. 1967), p. 5.

Consideraciones políticas en lo referente al Premio Nóbel de Asturias. 
1213. Martorell, F.: "Miguel Angel Asturias; l'auteur du Pape Vert songe aux professeurs de morale", Les Lettres Françaises, 659 (París, 21-27 feb. 1957), p. 5.

1214. Marra-López, José R.: "Oda y elegía de Centroamérica", Insula, 175 (Madrid, jun. 1961), p. 3 [analiza la producción novelística de Miguel Angel Asturias].

1215. Marra-López, José R.: "Angustia y esperanza en la novelística de Miguel Angel Asturias", "Indice Literario" de El Universal (Caracas, 11 ago. 1960), pp. 4-5 [ponderada exposición de su narrativa].

1216. Marroquín, Rojas, Clemente: "Miguel Angel Asturias de mis recuerdos", La Hora (Guatemala, 2 nov. 1967), pp. 1 y 6 [reminiscencias, anécdotas, etc.].

1217. Marroquín Rojas, Clemente: "Y ahora hablemos de Miguel Angel Asturias", La Hora (Guatemala, 15 feb. 1967), pp. 4-5.

1218. Maubec, Paul: "Dos minutos con el Premio Nobel de Literatura 1967; el nombre de Guatemala invadió todo el ámbito de la tierra". Homenaje a MAA del diario El Grifico (Guatemala, 11 nov. 1967), Pp. 8-9.

Entrevista en la cual MAA anuncia que está trabajando en su próxima novela: "Un ladrón que no creía en el cielo".

1219. Mayora, Eduardo: "Epístola a Miguel Angel Asturias con motivo de su libro Sien de Alondra", Boletin de la Biblioteca Nacional de Guatemala, 4a época, I:1 (Guatemala, 1951), pp. 33-37.

1220. M[ead] R[obert] G.: "Asturias' El señor Presidente and U. S. Critics", Hispania, XLVII:2 (Appleton, may. 1964), pp. 410-412.

1221. Mead, Robert G.: "A Myth for Mankind", Saturday Review (Nueva York, 4 nov. 1967), p. 32.

Sagaz y sugestiva teseña de la traducción al inglés de Mulata de tal. "In Mulatat, Miguel Angel Asturias has shown his belief once more, as in several of his earlier novels, that greats myths are timeless, that they can cross geographical and cultural barriers, and that they hold forgotten or never learned truths in which contemporary man, on the brink of his own destruction, may find his salvation".

1222. Mead, Robert G.: "Miguel Angel Asturias and the Nobel Prize", Hispania, LI:2 (Appleton, may. 1968), pp. 326-331.

1223. Mead, Robert G.: "Miguel Angel Asturias y su Premio Nobel en los Estados Unidos", Cuadernos Americanos, XXVII:4 (México, jul.-ago. 1968), pp. 214-227.

En este ensayo se ponen los puntos sobre las "íes" en lo relativo a "la renuncia de los críticos a penetrar bajo la superficie y tratar de ahondarse en las raices del mundo hispano-maya que vibra en la ficción asturiana..." 
1224. Mead, Robert G.: "Nature's Cycle Slashed by Greed", Saturday Review (Nueva York, 25 ene. 1969), p. 30.

Reseña de la versión inglesa de Viento fuette. "Strong Wind is an earlier, shorter, and not so substantial or finished a novel as Mulata".

1225. Mejía González, J.: “M. A. Asturias", Artes y Letras, 4 (San José, C. R., 1966).

1226. Mejía Nieto, Arturo: "Entrevista de Filadelfo Suazo", Exira, III: 30 (Tegucigalpa, Honduras, 1968).

"La novela nueva que practican Miguel Angel Asturias, Julio Cortázar, Gabriel Garcia Márquez, Vargas Llosa y otros... por primera vez [ha] encontrado público en Europa.... A Europa siempre le interesó nuestro trigo, nuestro café, nuestras maderas, nuestras bananas, nuestro oro, pero hoy aquellos pucblos réciben la importación de nues. tro espíritu..."

1227. Meléndez, Concha: "Reseña de Hombres de maíz", Asomante, VI:2 (San Juan, P. R., abr.-jun. 1950), pp. 92-94.

Véase también: Handbook of Latin American Studies, 15, p. 203. "Novela reveladora del alma mágica del indio guatemalteco. Aunque el exceso de americanismos y la insistencia en imágenes rebuscadas interrumpen a veces el mundo extrañamente poético creado por Asturias, se trata de una de las mejores novelas indianistas de hoy por sus recursos técnicos y modernos y su preocupación social".

1228. Meléndez, Concha: "Asturias, Viento fuerte", Handbook of Latin American Studies; 1950, 16 (University of Florida Press, Gainesville, 1953).

Breve reseña, p. 218. "En esta novela el autor supera las anterionss, El señor Presidente $\mathrm{v}$ Hombres de maiz... Asturias consigue un equilibrio justo entre verdad y belleza; entre su maravillosa fantasía y su sentido de un mundo que avanza, dolorosamente, es cierto, hacia ticmpos de nueva justicia".

1229. Meléndez, Concha: "Viento fuerte", Asomante, IV:4 (San Juan, P. R., 1951), pp. 92-93.

1230. Meléndez, Concha: "El mito viviente en Hombres de maiz", Asomante, XXIV:3 (San Juan, P. R., jul.-sep. 1968), pp. 30-47.

"Como volver de un sueño termino este estudio... para estudiar a Miguel Angel Asturias - con excepción acaso de la trilogía bananera- hay que pensar que estamos soñando en conversación con los brujos de las luciérnagas".

1231. Mélèze, Josette: "Sagesse; un prix Nobel parle de son pays", Aits (París, oct. 1968) [entrevista en la cual MAA evoca a los mayas de hoy y de siempre].

1232. Melikian, Souren: "Art ancien; mes ancêstres mayas", Propos recueillis par...", Réalités, 268 (París, may. 1968), pp. 50-52.

Entrevista con MAA con motivo de la exposición de $\Lambda$ rte Maya en el Grand Palais de París, mayo, 1968. 
1233. Mena, Marta: "Miguel Angel", Diario de Centroamérica, supl. de Arte y Literatura, V:231. (Guatemala, 9 dic. 1967), pp. 4 y 6. "Nacionalismo sin fronteras, patria abierta a los cuatro puntos cardinales de la cultura... libertad sin desafueros... historia de amor a la ancestralidad... en un fondo geográfico, telúrico y cosmogónico".

1234. Méndez, Francisco: "Fama, palabra y magia de Miguel Angel Asturias", Revista de Guatemala, XVIII:2 (Guatemala, ene.-dic. 1960), pp. 18-45.

Aperçus espiritosos pero que encierran observaciones perspicaces. "Sus leyendas, sus narraciones, sus novelas y cuentos definen mejor que la más clara definición lo que él u atro quieran decir con esa 'realidad mágica', porque si bien tienen anécdota, cuentan algo y poseen lo conocido pedestremente por argumento, no están sujetos a la ley de gra. vitación común y corriente".

1235. Méndez, Francisco: "Fama, palabra y magia de Miguel Angel Asturias", Salón 13, I:4 (Guatemala, nov. 1960), pp. 99-119.

"Los personajes de sus obras de ficción... alientan vida de metáfora y por una suerte de sinécdoque la magia los hace hombres reales, sin dejar de ser meras figruras de ficción..." Véase asiento anterior.

1236. Méndez, Francisco: "10 años de literatura. La generación del 30", El Imparcial (Guatemala, 25 y 27 sep. 1943).

Conferencia. Hay que tecordar que en 1943 MAA aún no había publicado El señor Presidente. "El propio poeta Asturias, publicó en París sus embriagadoras Leyendas de Guatemala... tienen un inconfundible sello americano que bastaría a hacerlas perdurables si no tuviesen su propio valer como logro poético".

1237. Menéndez Mina, Gloria: "El espejo de Lida Sal", El Imparcial (Guatemala, 18 nov. 1967), pP. 17 y 24 [reseña].

1238. Menéndez Mina, Gloria: "Miguel Angel. Asturias: valoración de su obra", El Imparcial (Guatemala, 7 nov. 1967), pp. 3 y 13.

1239. Menton, Seymour: "Influencia en la novela guatemalteca", $R e$ vista Iberoamericana, XXV:50 (México, jul.-dic. 1960), PP. 309. 315.

Asturias, p. 314. "Rasgo muy fuerte de la novela guatenalteca de casi todas las épocas es la fantasía... El más aficionado de todos es Miguel Angel Asturias... mezcla muchos de los elementos legendarios de los maya-quichés con la realidad actual".

1240. Menton, Seymour: "La novela experimental y la república comprensiva de Hispanoamérica; estudio analítico y comparativo de Nostromo, Le diclateur, Tirano Banderas y El señor Presidente", Humanitas, Anuario del Centro de Estudios Humanisticos, I (Monterrey, México, 1960), Pp. 409-464 [enjundiosa investigación].

1241. Menton, Scymour: "Asturias, Los ojos de los enterrados", Hand. book of Latin American Studies, 24 (Gainesville, 1962).

MAA, p. 29. This book. "...completes the banana trilogy begun with Viento fuerte and El Papa verde. Although the themes and style are 
similar to the first two volumes, the lack of unity makes this the weakest of the three novels".

1242. Menton, Seymour: "Asturias" Mulata de tal", Handbook of Latin American Studies, 28 (Gainesville, 1966), p. 256.

MAA, p. 256. "A mixture of Guatemalan folklore, literary experimentation, and sex. Asturias' weakest novel".

1243. Miguel, María Esther de: "Los ojos de los enterrados", Criterio, XXXIII:77 (Buenos Aires, 1961), p. 77 [reseña].

1244. Miliani, Tomás: "Bonampak, Miguel Angel y la prosa musical de Asturias", Sexto Continente, 7-8 (Buenos Aires, nov.-dic. 1950), pp. 129-134.

Acotaciones que persiguen similitudes un tanto peregrinas entre Mriguel Angel Asturias y Miguel Angel Buonarroti. Con todo, apunta sugestivos enfoques... El lenguaje de MAA, "ya vivido de por sí, se inclina a una euritmia manifiestamente inquieta... lo acentúa cadencias, compases, filigranas y escarceos musicales, sobre la tónica de la imprecación, la invocación o la hosanna, el amor, el odio, la vida o la muerte... Los valores musicales del arte de Miguel Angel Buonarroti [se] identifican asimismo, en los acentuados pliegues, festones, rostros, cadencias, compases, filigranas y escarceos surgidos de pasiones encontradas, similares a los que se encuentran en el vate guatemalteco..."

1245. Molinari, María Angélica: "Distintas expresiones de la realidad americana: Valle-Inclán, Asturias y Ayala", Revista de la Universidad Nacional de Córdoba, $2^{\mathfrak{n}}$ serie, IV:1-2 (Córdoba, mar.-jun. 1963), pp. 115-126.

1246. Monteforte Toledo, Mario: "Carta a Miguel Angel Asturias", Revista de Guatemala, XVIII:2 (Guatemala, ene.-dic. 1960), p. 87.

"Sos todo lo mañoso y lo puro, lo pequeño y lo infinito de nuestra tierra. Sos trompudo como los indios y alto como los cerros; sos huevón como los hombres de la Parroquia y cuentero como las viejas de la Calle Ancha; olés a chicha y a cera de candela. Pero también olés a libro y a calle de ciudad despercudida $y$ grande. $Y$ es bonito que todo lo seás hasta las cachas..." Sin comentario.

1247. Monterroso, Augusto: "Miguel Angel Asturias, Premio Nobel de Literatura, 1967", "La cultura en México", supl. de Siempre!, 299 (México, 8 nov. 1967), pp. VII-VIII.

Prólogo al disco Voz viva de América Latina, de Asturias.

1248. Monterroso, Augusto: "Miguel Angel Asturias; presentación", "El Gallo Ilustrado", supl. de El Día, 248 (México, 26 mar. 1967), p. 8.

1249. Monterroso, Augusto: "Miguel Angel Aturias presentación", Gaceta Literaria, La Nación (Santiago, Chile, 3 dic. 1967), p. 13 [véase ficha anterior].

1250. Monterroso, Augusto: "Asturias; el escritor más joven de Guate- 
mala", Revista de Guatemala, XVIII:2 (Guatemala, ene.-dic. 1960), pp. 103-104 [MAA en sus dias chilenos, 1954].

1251. Moore, Ernesto R.: "El señor Presidente", Handbook of Latin American Studies, 12 (Cambridge, 1949).

MAA, p. 244. "This fulsome novel by a distinguished Guatemalan (b.1899) stylist and poet was spoiled for the teviewer by its blackand-white characterizations and its disjointed impressionistic descriptions. The gross realism of the story reflects the brutal behavior of a Central American dictator and his cohorts".

1252. Morales, Angel Luis: "La 'trilogía bananera'", Asomante, XXIV: 3 (San Juan, P. R., jul.-sept. 1968), pp. 48-67.

"Colocándose en la perspectiva de la mente mitica del nativo guatemalteco, Asturias parece rechazar los rígidos esquemas de una visión positivista del mundo, regida sólo por lo sensorial y lo racional, poniendo de manifiesto, por el contrario, todo lo que de misterio y de nıravilla oculta tiene la realidad..."

1253. Morales Benitez, Otto: "Personalidad y obra del Premio Nobel de Literatura; Miguel Angel Asturias; un escritor humano", El Espectador, "Magazine Dominical" (Bogotá, 17. dic. 1967), pp. 4-5 y 12 .

"Asturias compendia el mundo nuestro, elemental, que dimana del des. encadenamiento de las fuerzas contenidas... de sus hombres".

1254. Moynihan, John: "Two Novels by Miguel Angel Asturias...", The Sunday' Telegraph (Londres 24 sep. 196\%), p. 8 [breves reseñas de las traducciones inglesas de Viento fuerte y Mulata de tal].

1255. Morales, Leonardo C. de: "El señor Presidente", Saturday Review (Nueva York, 7 mar. 1964), p. 38 [reseña].

1256. Morales Santos, Francisco: "Miguel Angel Asturias y las generaciones jóvenes", El Imparcial (Guatemala, 2 sep. 1966), p. 11.

1257. Morejón, Nancy: "Diálogo con Claude Couffon", La Gaceta de Cuba, VI:63 (La Habana, feb.-mar. 1968), p. 6.

Afirma el escritor francés: "Actualmente en Francia, los escritores hispanoamericanos más leídos continúan siendo, Borges, Carpentier y Asturias... Creo que los franceses buscan en estos tres autores, visiones diferentes, aunque todas en cierto sentido las más insólitas: sea la ficción culta de Borges, el telurismo mágico de Asturias o el realismo barroco de Carpentier".

1258. Morello-Frosch, Marta: "Los ojos de los enterrados", Revista Hispánica Moderna, XXIX:1 (Nueva York, 1963), pp. 72-73 [reseña].

1259. Morse, Walter F.: "Foreign Desk; A Nobel Prize to Guatemalan", Cbicago Sun-Times (Chicago, 20 oct. 1967) [nota petiodística fechada en Estocolmo]. 
1260. Movil, José Antonio: "Miguel Angel Asturias, Corazón del pueblo", Revista de Guatemala, XVIII:2 (Guatemala, ene.-dic. 1960), PP. 101-102.

1261. Muñoz Cota, José: "El mirador de la revolución; Miguel Angel Asturias", El Nacional (México, 28 oct. 1967), p. 3.

1262. Muñoz Cota, José: "Miguel Angel Asturias en México", El $\mathrm{Na}$ cional (México, 24 oct. 1966), p. 3.

1263. Mutter, André: "Sobre Miguel Angel Asturias", Prensa Libre (Guatemala, 20 oct. 1967) [transcripción de un cable de París de la Associated Press].

1264. Navarro, Carlos: "La hipotiposis del miedo en El señor Presidente", Revista lbeaamericana, 61 (México, ene.-jun. 1966), pp. 51-60.

"El miedo, el terror omnipotente de la dictadura, constituye el protagonista principal de $E l$ señor Presidente".

1265. Navas Ruiz, Ricardo: "Tiempo y palabra en Miguel Angel Asturias", Quaderni lberoamericani, IV:29 (Turín, dic. 1963), Pp. 276-282.

1266. N. B.: "Porte-parole des indiens d'Amérique Latine; Miguel Angel Asturias reçoit le Prix Nobel de Littérature", Le Monde (París, 20 oct. 1967).

Reportaje. Suscrito en Estocolmo. Glosa de la declaración del Presidente de la Real Academia Sueca.

1267. Neruda, Pablo: "Nuestro deber", Novi Mir, 4 (Moscú, 1950), p. 201 [menciona a MAA].

1268. Nibaut, G. D.: "Miguel Angel Asturias; vivant, sécret, généreux", Les Lettres Françaises (París, 12-19 mar. 1953), p. 5.

1269. Noel, Martín Alberto: "Mulata de tal", La Prensa (Buenos Aires, 27 oct. 1963).

Reseña. "El estilo de Asturias corresponde en este caso a la indole casi onirica de su creación, mostrando un total desapego hacia las fótmulas lógicas de la sintaxis y haciendo de los violentados medios de expresión... otros tantos vehículos para el acceso a una visión genuinamente mágica del mundo americano".

1270. Niedergang, Marcel: "Miguel Angel Asturias; Un diplomate révolutionaire", Le Monde (París, 25 oct. 1967), PP. I y III.

Señala M. N. que los que hoy objetan que se le haya otorgado el Premio Nobel a un Embajador-Literato, se olvidan que siAA es ante todo un filósofo y revolucionario.

1271. Noriega, Augusto Enrique: "Saludo a Miguel Angel Asturias", Diario de Centroamérica, LXXXVII:26136 (Guatemala, 9 dic. 1967), p. 7.

Poema escrito en homenaje a MAA en el cual se intercalan los titulos de obras asturianas: 
"Miguel Angel de América hombre de maíz $y$ de ternura de leyendas $y$ de poesia Papa verde iluminado..."

1272. Noriega, Augusto Enrique: "Una gloria infinita le ha dado Miguel Angel Asturias a Guatemala", El Gráfico (Guatemala, 11 nov. 1967), p. 24.

Panegírico de aras que ya desde antes del Premio Nobel estaba consagrado por la traducción de sus obras "al inglés, francés, italiano, alemán, ruso, sueco, noruego, dinamarqués, vietnamita, portugués, estonio, checoslovako".

1273. Noricga Morales, Guillermo: "Ante el regreso de Miguel Angel Asturias", Revista de Guatemala, XVIII:2 (Guatemala, ene.-dic. 1960), pp. 93-95 [repaso de lecturas asturianas].

1274. Núñez y Domínguez, Roberto: "Las letras iberoamericanas se encuentran de fiesta", Excélsior (México, 22 oct. 1967), p. 8. [a1tículo sobre Asturias].

1275. Nye, Robert: "More Leaves From the Green Tree", The Guardian (Londres, 22 sep. 1967), p. 8.

Reseña de Viento fuette y Mulata de tal. Enjuicia la Mulata: "Overwrought and fierce, this is myth with flashing teeth but no bite". Prefiere, "The angry social documentation evident" en Viento fuerte.

1276. Ocampo Ramirez, Pedro: "Señor Presidente, un Nobel y un tirano", Excélsior (México, 20 oct. 1967), pp. 6 y 8 [comentarios sobre MAA y el Premio].

1277. Ocampo Ramírez, Pedro: "Un Nobel y un tirano", El Imparcial (Guatemala, 24 oct. 1967), pp. 3 y 9.

"Ahora recibe América Latina... el Premio Nóbel de Literatura... El que América de habla hispana ha esperado en vano para Pablo Neruda, para Alejo Carpentier, para Julio Cortázar, para Jorge Luis Borges. El que tal vez llegue un día a las manos de Gabriel Garcia Márquez, cuarido éste envejezca convenientemente".

1278. Ocanto J., Clemente: "El Papa verde", El Nacional (Caracas, 4 ago. 1955) [reseña].

1279. Olivier, Daria: "Pour vos vacances", Reforme (París, 17 jul. 1965).

Reseña de Mulata de tal. "La truculence et la verdeur rappellent à plus d'un égatd ce chef-d'ocuvte de la littérature mondiale: Les veillées du bamean, de Nicolas Gogol... une oeuvre exceptionnelle".

1280. Oliver, María Rosa: "El señor Presidente", Sur, XVII:177 (Buenos Aires, jul. 1949), pp. 73-77 [reseña].

1281. Olza Zubiri, Jesús: "Novelistas contemporánєos hispanoamericanos", Estudios Centroamericanos, XXI:219 (San Salvador, sep. 1966), pp. 215-218. 
1282. Orantes, Alfonso: "Miguel Angel Asturias y el Premio Nobel", Cultura, 46 (San Salvador, oct.-dic. 1967), pp. 11-18.

Censura a los que menosprecian a MAA y su obra. "Para referirse a Miguel Angel Asturias hay que estar enterado de sus grandezas y miserias, de su orıgen y vocación, su desenvolvimiento intelectual y superación".

1283. Orantes, Alfonso: "Tres poetas guatemaltecos contemporáneos", Cultura, 2 (San Salvador, mar-abr. 1955), pp. 56-69.

Sobre M. A. Asturias, L. Cardoza y Aragón, C. Briñas, Aquilata la poesía de maA desde los siguientes puntos de vista: polimorfismo, polifonismo, preciosismo y diafanidad.

1284. Ortegren, Gerd: "Klarvaken troll-karl", Van Kyrka Evangeliskt veckobland (Estocolmo, 5 oct. 1967) [comentario sobre sus obaas]

1285. Ortiz, Roberto: "La andiencia de los confines", El Imparcial (Guatemala, 22 sep. 1961), p. 14 [reseña].

1286. Ospovat, Lev: "Las páginas de luto y esperanza", La Gaceta Literaria, 23 (Moscú, ago. 1957) [reseña de Week-end en Guatemala].

1287. Ospovat, Lev: "Golos nepokorennoi Guatemaly; romany M. A. Asturias", Inostramaia literatura, 6 (Moscú, jun. 1958), pp. 182192.

"La voz de la Guatemala insumisa: Las novelas de MAA". Trabajo sobre su narrativa, "el más amplio y más completo que hay en ruso".

1288. Österling, Anders: "Kärlek till mytvärlden och hemlandets natur", Göteborgs-Posten (Gotemburgo, 20 oct. 1967), p. 10 [presentación de MAA].

1289. Österling, Anders: "La obra de Asturias es la epopeya de la lucha de su pueblo contra la opresión", El Gráfico (Guatemala, 20 oct. 1967), p. 13 [comentario del secretario de la Academia Sueca].

1290. Pacheco Herrarte, Mariano: "Recuerdos de tiempos pasados", El Imparial (Guatemala, 28 mar. 1968).

1291. Pagés Larraya, Antonio: "Lejendas de Guatemala, de Miguel Angel Asturias", La Razón (Buenos Aires, 29 mar. 1958).

Reseña. "Esas Leyendas de Guatemala, recogidas de memorias arcaicas, están hechas con más elementos de imaginería que de narración. Se nos escapa lo contado entre la avasalladora potencia de lo cromático".

1292. Palenque, A.: "Miguel Angel Asturias", Noticias de boy (Habana, 30 jul. 1959).

1293. Panduro, Leif: "United Fup", Politiken (Copenhague, Dinamarca, 20 jun. 1965) [reseña de Week-end en Guatemala].

1294. Panduro, Leif: "En tur i Helvede", Politiken (Copenhague, Dinamarca, 19 nov. 1966) [reseña de la versión danesa de El señor Presidente]. 
1295. Parrilla Barascut, Enrique: "Sensacionales declaraciones de Ydigoras; habla ahora el ex presidente del posible triunfo del canciller Arenales para la oNU", III, El Gráfico (Guatemala, 2 dic. 1967), p. 26.

Entrevista que contiene una sección titulada, "Cómo inspiré a MAA". Ydígoras afirma que le recomendó a Asturias que dejara otros poetas y que se inspirara en sí mismo.

1296. Paz y Paz, G. Leonor: "Guatemala y el Premio Nobel", Revista A. P. G., 27 (Guatemala, dic. 1967), p. 28.

1297. Paz y Paz, Roberto: "Miguel Angel Asturias, un guatemalteco universal", Revista Asociación Estudiantes Universitarios, I:1 (Guatemala, 1 jun. 1968), pp. 11-17.

Revisión de la obra asturiana con algunas "acotaciones para hallarle sentido". Lamenta que para el pueblo guatemalteco MAA "era y sigue siendo desconocido... y es prácticamente desconocida su obra en su totalidad".

1298. Pemán, José María: "Espejo de los días; Miguel Angel Asturias", Gaceta Ilustrada (Madrid, 10 dic. 1967).

El académico español al enfocar $E l$ señor Presidente lo caracteriza de la siguiente manera: "Tan castizo y casero es su realismo que, además de todo, Miguel Angel Asturias nos entrega un documento inapreciable para el estudio del lenguaje y el estilo coloquial... esos vo. cablos son recreaciones tan acabadas de coger del suelo húmedo del país que se adivinan como 'onomatopeyas' o imitaciones fonéticas de cosas, movimientos y personas".

1299. Pérez, Galo René: "Miguel Angel Asturias; Premio Nobel de Literatura 1967", Américas, XX:2 (Washington, feb. 1968), pp. 1-5 [este ensayo está publicado en inglés y español].

1300. Pérez Marchena, Juan: "Mulet y el Premio Nobel de Literatura", Impacto (Guatemala, 22 nov. 1967), pp. 2 y 20.

Polemiza irónicamente con el petiodista Augusto Mulet Deschamps, constante critico de MAA.

i301. Perujo, F.: "Il glossario dell'Uomo di mais". La Fiera Letteraria (Roma, 7 dic. 1967), p. 22 [reseña].

1302. Péus, Gunter: "Das buch der Woche", Hannoversche Allgemeine Zeitung (Hannover, Alemania, 20 oct. 1967) [reseña de la versión alemana de Hombres de maíz].

1303. Pevtsov, Yuri: "Dokumenty epokhy", Vsesvit, IV:7 (Moscú, jul. 1960), pp. 99-102 ["Documentos para nuestra época". Estudio de la obra de MAA].

1304. Piazza, Luis Guillermo: "Aforismos de un premio, alrededor de Miguel Angel Asturias", Excélsior (México, 24 oct. 1967), p. 7A.

1305. Pillement, Georges: "Miguel Angel Asturias y sus Leyendas de Guatemala", Repertorio Americano, XXII (San José, C. R., 1931), pp. 61-62. 
1306. Pinto Flores, Aquiles: "Guatemala en los labios del mundo, ceremonia de la entrega de los Premios Nobel", El Imparcial (Guatemala, 15-22 ene. 1968) [4 artículos relativos a los festejos $y$ homenajes tributados a MAA].

1307. P. J. V.: "Week-end en Guatemala", Letras del Ecuador, 106 (Quito, abr.-dic. 1956), p. 26 [reseña].

1308. Plá y Beltrán, Pascual: "Week-end en Guatemala", Revista Nacional de Cultura, XIX:119 (Caracas, nov.-dic. 1956), pp. 160161 [reseña].

1309. Pomerantseva, Elena: "Las letras latinoamericanas en la revista Literatura Extranjera", Casa de las Américas, 13-14 (Habana, jul.-oct. 1962) [MAA, pp. 100-101].

1310. Pomès, Matilde: "El Premio Nobel", La Nación (Buenos Aires, 14 ene. 1968), suplemento.

Descripción de un agasajo a MaA en un hotel de París, "en que se oia un coctel de lenguas tan variado, como los que servian en el profuso buffet".

1311. Pommier, Michel: "O stat"e Migelia Asturiasa", $V$ Zasbchitu mira, 18 (Moscú, nov, 1952), pp. 103-104 ["un artículo de MAA"].

1312. Poniatowska, Elena: "Los latinoamericanos no sabemos dar ni devolver nada a nuetros países", Novedades (México 16 mar. 1967), pp. 14 y 15 [entrevista con Asturias].

1313. Porras Smith, Afredo: "Asturias, Nobel", El Imparcial (Guatemala, 9 dic. 1967), pp. 17 y 23 ["Asturias ha sabido ser poetaluz aun cuando es poeta-sombra"].

1314. Pozo, Gerardo del: "El Premio Nobel", "Revista de la Semana", supl. de El Universal (México, 3 mar. 1968), pp. 2 y 6 [sobre Asturias].

1315. P. P. y B.: "Bolivar de Miguel Angel Asturias", Cultura Universitaria, 56 (Caracas, 1956), PP. $91-93$ [reseña].

1316. P. P. y B.: "Soluna", Revista Hispánica Moderna, XXIII:I (Nueva York, 1957), pp. 55-56 [reseña].

1317. Praag, J. A. Van: "Miguel Angel Asturias een van de heel groten", De Tijd (Holanda, 20 oct. 1967) [MAA, "uno de los muy grandes". Artículo, cortesía del autor].

1318. Praag-Chantraine, Jacqueline Van: "Miguel Angel Asturias; romancier social et visionnaire", Syntbèses, 242-243 (Bruselas, jul.ago. 1966), pp. 103-110.

"Il faut subir les récits de ce diable d'homme et non les tamiser au filtre de la taison..." 
1319. Prigogine, H.: "Chronique de la poésie", Symbèses (Bruselas, abr.-may, 1966).

1320. Queipo, Heliodora S.: "Fervor de gentil declamadora argentina", El Imparcial (Guatemala, 9 mar. 1968), p. 15.

Salutación a MAA. "Hierático Papa verde. Sumo Pontifice de la poesía, yo, lírica sacerdotisa del templo de las musas, te saludo en nombre de la mujer americana".

1321. Quijadas Urías, Alfonso: "Miguel Angel Asturias", Culturt, 46 (San Salvador, oct.-dic. 1967), PP. 73-75 [exaltación].

1322. Quintana, Epaminondas: "Convivencias con Miguel Angel Asturias; el bautizo en Paris en 1928 a la nuestra como generación de 1920", supl. homenaje a MAA del diatio El Gráfico (Guatemala, 11 nov. 1967), pp. 7 y 15 [cálida cvocación de los años universitarios y las bregas políticas de MAA].

1323. Rabassa, Gregory: "Bolivar", Cultura Universitaria, 56 (Caracas, 1956), pp. 91-93 [reseña].

1324. Rabassa, Gregory: "Soluma", Revista Hispánica Moderna, XXIII: 1 (Nueva York, ene. 1957), pp. 55-56 [reseña].

1325. Rand, Max: "Kolmannen maalman suurlähettiläs", Helsingin Sanomat, 265 (Helsinki, Finlandia, 20 oct. 1967), p. 15 [análisis de la obra de MAA].

1326. Remacle, Andrés: "Torotumbo", La Marseillaise (Marsella, I ene. 1966) [reseña].

1327. Reyes, Alicia "Tikis": "Miguel Angel Asturias y Alfonso Reyes", Boletín Alfonsino, 2 (Montevideo, 1967-1968), pp. 8-9 [glosa las relaciones epistolares de su abuelo con MAA. El revelador intercambio de cartas se inició en 1930. Véase también mi Asturias en México].

1328. Reyes Baena, Juan F.: "A su paso por Paris; cuatro intelectuales de América Latina", Cultura Universitaria (Caracas, jul.-sep. 1965), pp. 18-27.

Asturias, pp. 21-23. "Novelista de la magia. Religión, filosofía, politica se reducen al pensamiento ilógico infantil que marcó de aventuras y sortilegios el alumbramiento del continente americano".

1329. Rincón, Carlos: "Miguel Angel Asturias", Eco, XV:6 (Bogotá, oct. 1967), pp. 565-588.

Hondo anälisis de la narrativa asturiana. "Lo que sería decisivo subrayar es que si bien Asturias busca ajustarlo todo en su producción a la mitologia indígena, y subraya que cuando habla de mitos está hablando de algo viviente, el mismo escritor sostiene que esta literatura, y toda América Latina, no debe admitir ser juzgada exclusivamente por esos mitos. Y Asturias corrobora esa afirmación en su propia obra. La escritura suya, nacida de la desesperación ante el lenguaje, cumple con respecto a esa mitología una función esencial. Por la ten- 
sión que introduce en el seno de la obra matca con respecto a ella una distancia que nos da a ver. La ideología campesina convertida en obra en la novela se recusa sirviéndose de sus propias representaciones y denunciando sus propios límites. $Y$ a la vez la obra cumple una función ideológica".

1330. Ring, Edgar: "Entregado al progreso de la vida", Puente, Revista de la República Democrática Alemana, 3 (Dresden-Berlín, 1968), pp. 22-23.

Remembranza de la visita de MAA a la Universidad de Rostock. Exégesis de su obra y "su actitud de humanista combatiente".

1331. Roberts, Nesta: "Nobel Prize for His Excellency", The Guardian (Londres, 20 oct. 1967) [breve exposición de su biografía].

1332. Rodrigues, Danubio: "O escritor de protesto", Jornal do Brasil (Rio, 20 oct. 1967), p. 9.

Sobre MAA. "Um intelectual que utilizou a literatura para apontar o que éle considera os grandes dramas do continente em que se encontra o pequenino pais".

1333. Rodríguez González, Elly: "Aquilatando la auténtica dimensión del literato Miguel Angel Asturias; un valor americano pero no un dogma nacional", iYa! IX:778 (Guatemala, 9 dic. 1967), pp. 1 y 5.

"Consideramos que MAA es un poeta auténtico y un escritor de magrífica alcurnia... peto no es como tal un literato intocable o indiscutible".

1334. Rodríguez Monegal, Emir: "Universalidad de Miguel Angel Asturias", Mundo Nuevo, 19 (París, ene. 1968), p. 94.

1335. Ronfani, Ugo: "Malraux battuto da Asturias sul traguardo del Premio Nobel", Gazzeta del Popolo (Turín, 20 oct. 1967). Afirma el articulista italiano, "Forse le Antimemorie dello scrittore francese sono uscite troppo tardi... Ma anche Miguel Angel Asturias lo meritava, pienamente..."

1336. Rousseaux, A.: "Légendes du Guatémala", Le Figaro Littéraire, 438 (París, 11 sep. 1954), p. 2 [reseña].

1337. Rousseaux, A.: "L'Ouragan de Miguel Angel Asturias", Le Figaro Littéraire, 485 (París, 6 ago. 1955), p. 2 [reseña de Viento fuerte].

1338. Rousseaux, A.: "Le Pape vert", Le Figaro Litléraire (París, 17 mar. 1956), p. 2 [reseña de El papa verde].

1339. Roy, F. J.: "Miguel Angel Asturias; Légendes du Guatémala", Les Lettres Françaises, 498 (Paris, 7-14 ene. 1954), p. 2.

Reseña impresionista. "De la mezcla de las viejas creencias y de la fe nueva ha nacido un mundo extraño y maravilloso, que Asturias teconstruye sin dificultad pues no tiene más que oír interiormente el recuerdo de los cuentos que acunaron su infancia". 
1340. R. R.: "El espejo de Lida Sal", El Heraldo Culiural, 109 (México, 10 dic. 1967), p. 15 [reseña].

1341. R. T. A.: "Viento fuerte"; Libros de boy, 1 (Buenos Aires, may. $1951)$, p. 54.

Reseña. "MAA ha sido premiado justicieramente por la Sociedad Argentina de Editores... Al igual que en sus anteriores novelas, Asturias trata en forma poética problemas sociales centroamericanos... La novela, cuya trama es insuficiente, es compensada con creces por las descripciones plenas de vigor vital".

1342. Rudel, Ch.: "'El señor Embajador' des peuples d'Amérique Latine", La Croix (París, 21 oct. 1967), p. 2 [presentación de MAA].

1343. Rudel, Ch.: "Un diplomate en lutte contra la pauvreté de son pays", La Croix (París, $5 / 6$ nov. 1957), p. 8. Suplemento cultural [entrevista. Declara maA que tiene algunas obras en el "horno"].

1344. Russel, Dora Issella: "Miguel Angel, poeta", El Imparcial (Guatemala, 26 dic. 1954), p. 13.

1345. Sabatier, R.: "Les yetix des enterrés", Le Figaro Littéraire, 876 (París, 2 feb. 1963),.p. 5 [reseña].

1346. Sabatier, R.: "La Flaque du mendiani", Le Figaro Littéraire, 1056 (París, 14 jul. 1966), p. 6 [reseña].

1347. Sábato, Ernesto: "Testimonio", Propósitos (Buenos Aires, 26 oct. 1967).

Transcripción de la famosa carta al presidente de la $R$. Argentina en la cual Ernesto Sábato con valentia y coraje, protesta contra la detención violenta de Miguel Angel Asturias.

1348. Saint-Pierre, Minga: "Miguel Angel Asturias: la pasión por América", Elite (Caracas, may.-ago. 1967), pp. 8-10 [entrevista en París].

1349. Sainz, Gustavo: "El Nobel de Literatura en 1966, encuesta por..." El Día (México, 22 oct. 1966), p. 9.

1350. Sainz, Gustavo: "El espejo de Lida Sal", "La caltura en México", supl. de Siempre!, 323 (México, 24 abr. 1968), p. VII [reseña].

1351. Sainz, Victor: "Los ojos de los entervados", Ficción, 30 (Buenos Aires, mar.-abr. 1961), pp. 144-145.

Reseña. "Pinta Asturias... esta especie de friso solar, donde con un admitable estilo se mueven los personajes menos literaturalizados de la novela americana contemporánea".

1352. Salero, F.: "Viento fuerte", Sur, 200 (Buenos Aires, jun. 1951), pP. 98-100 [reseña]. 
1353. Salguero, Alvaro Hugo: "Un libro de Migucl Angel Asturias", Revista A. P. G. 27 (Guatemala, dic. 1967), pp. 29 y 78.

1354. Samayoa Aguilar, Carlos: "Emulo Lipolidón o una plaquette sin salida", Boletin de la Biblioteca Nacional de Guatemala, IV (Guatemala, 1935), pp. 664-666 [reseña].

1355. Samayoa Aguilar, Carlos: "Miguel Angel Asturias en la pista del recuerdo", Revista de Guatemala, XVIII:2 (Guatemala, ene.-dic. 1960), Pp. 88-92.

"Miguel Angel Asturias, gran señor de las letras, velívolo de los vientos sin rumbo, acaba de dar la vuelta al mundo en 40 años".

1356. Samayoa Chinchilla, Carlos: "Una gran novela guatemalteca; $E l$ señor Presidente", El Imparcial (Guatemala, 25 mar. 1947), p. 3 [reseña].

1357. Sanavio, P.: "Parla il te Maya", La Fiera Letteraria (Roma, 2 nov. 1967), pp. 6-7.

1358. Sánchez Guerra de Garza, María: "Una entrevista con el autor de Leyendas de Guatemala", El Imparcial (Guatemala, 28 nov. 1967), pp. 11 y 15.

Entrevista. Derrotero de su vida y obra. Asturias revela que su libro favorito es Hombres de nztiz. Lo escribió "sin hacer concesiones al lector".

1359. Sánchez Guerra de Garza, María: "Miguel Angel Asturias, Premio Nobel; una entrevista con el autor de Leyendas de Guatemala", El Maestro, 13 (Guatemala, ene.-mar. 1958), pp. 99-102 [reproducción del artículo publicado anteriormente].

1360. Sánchez, Luis Alberto: "'El Chompipe' Asturias, Premio Nobel 1967", "México en la cultura", supl. de Novedades (México, 7 ene. 1968), p. 3 [evocaciones].

1361. Sanctis, Sergio de: "Uno scrittore guatemalteco; M. A. Asturias", Comunità, 61 (Milán, 1958), pp. 63-69.

1362. Sandoval Samayoa, Mario Antonio: "La entrega del Premio Nobel", Prensa Libre (Guatemala, 23 dic. 1967), p. 11.

1363. Santa-María, Alejo: "Reseña cultural; Miguel Angel Asturias", El Universal (Caracas, 29 oct. 1967).

Subraya la estrechez económica en la cual ha vivido buena parte de su vida. "Esta pobreza voluntaria le concede mayor valor y respaldo moral al honor con que lo ha distinguido la Academia Sueca".

1364. Santana, Emilio: "Visita fugaz de Miguel Angel Asturias", El Nacional (Caracas, 18 feb. 1960).

1365. Sassone, Helena: "Los ojos de los enterrados", Revista Nacional de Cultura, XXIII:144 (Caracas, ene.-feb. 1961), pp. 237-239 [reseña. "Una indiscutible renovación"]. 
1366. Saunders, Tom: "Miguel Angel Asturias; a coup for Mosaic", Wimipeg Free Press (Winnipeg, Canadá, 30 abr. 1968).

Although Spanish and French critics (especially those of Faris) had been for years extolling the excellence of Asturias writings and pro. moting him for the Nobel prize, the award, when it came, was still something of a shock to the English - speaking world- not because his work lacked merit but simply because it was so little known".

1367. Saz, Agustín del: "Superrealismo y pesimismo en Miguel Angel Asturias", Papeles de Son Armadans, VI:17 (Palma de Mallorca, ag. 1957), PP. 135-146.

1368. Scherer García, Julio: "Habla M. A. Asturias candidato al Nobel: El eminente novelista dice que no se desilusionará si se lo niegan", Excélsior (México, 20 oct. 1966), pp. 1, 13 y 17.

"Un galardón -Asturias piensa en voz alta- es un hecho circunstancial. Lo que interesa fundamentalmente es la continuidad en el trabajo, los pasos en un mismo sentido, sin desviaciones".

1369. Scherer García, Julio: "Fija sus impresiones ante la posibilidad de ser Premio Nobel", El Imparcial (Guatemala, 22 oct. 1966), p. 2.

"Hay en Miguel Angel Asturias declaraciones inusuales. Una es el entusiasmo con que habla de su obra. No hay falsas modestias ni rubotes hipócritas. Cree en su trabajo, vive para él y por él... Asturias lee y relee, altera y modifica, vuelve al origen, si hace falta. En su cuarto de trabajo no cuentan los días ni los años".

1370. Schmiele, W.: "Miguel Angel Asturias; Die maismänner", Neue deutsche Hefte (Berlín, abr. 1957), Pp. 74-75 [reseña de Hom. bres de maíz].

1371. Schultz de Mantovani, Frida: "Leyendas de Guatemala", Cuadernos Americanos, VIII:6 (México, nov.-dic. 1949), pp. 286 289 [reseña].

1372. Schultz de Mantovani, Frida: "Miguel Angel Asturias llegó un dia a Buenos Aires", El Diario de Hoy (Guatemala, 1 jul. 1952).

1373. Schultz de Mantovani, Frida: "Mulata de tal", Cuadernos Americanos, XXIII:1 (México, 1964), Pp. 255-257 [reseña].

1374. Schultz de Mantovani, Frida: "Legendaria Guatemala de Miguel Angel Asturias", Clarin (Buenos Aires, 4 ene. 1968), p. I.

1375. Segala, Amos: "Entrevista con Miguel Angel Asturias; entre magia y compromiso político", "El Gallo Ilustrado", supl. de El Día, 281 (México, 12 nov. 1967), p. 1.

1376. Selser, Gregorio: "Porqué salió Miguel Angel Asturias de la Argentina", El Imparcial (Guatemala, 30 mar. 1968), pp. 13 y 17.

Selser narra, con lujo de detalles, cómo en la madrugada del 19 de abril 1962, sin orden de allanamiento, la policía argentina violó su domicilio y llevaron preso a MAA sin motivo, pese a que estaba muy en- 
fermo. Fue una "sacudida tan desgarradora" que cuando to pusieron en libertad decidió abandonar la Argentina. Este artículo se publicó, asimismo, en Marcba de Montevideo y en Propósitos (Buenos Aires, 26 oct. 1967).

1377. Selva, Mauricio de la: "Asteriscos", Excélsior (México, 10 nov. 1963).

Perspicaz reseña de Mulata de tal. "Miguel Angel Asturias se muestra en esta novela, con la misma fuerza creadora mostrada en cualquier otra de sus obras anteriores acogida por el éxito... Se encuentra en plena crcación, misma que en ningún momento puede identificarse con el reiterativo formulista que a ratos le atribuyen sus detractores".

1378. Selva, Mauricio de la: "Tres novelistas de nuestra América", Cuadernos Americanos, XX:1 (México, ene.feb. 1961) [Asturias, Pp. 292-295].

1379. Selva, Mauricio de la: "Mulata de tal", Cuadernos Americanos, XXIII:1 (México, ene.-feb. 1964), Pp. 255-257 [reseña].

1380. Sender, Ramón J.: "Un poeta de Guatemala", El Sol (Madrid, 13 jun. 1930).

Reseña de Leyendas de Guatemala, 1" ed. Madrid, 1930. "La unión de esas dos imaginaciones - maya y española-, como la de los cuerpos de razas distintas, produce frutos de verdadera belleza... Esa apariencia de vidriera - catedral o sinagoga- es lo que da al libro de Miguel Angel Asturias su singulat y característico don".

1381. S. G.: "Diamante tallado", Tiempo, 1330 (México, 30 oct. 1967) [reseña de El espejo de Lida Sal].

1382. Serrano Gómez, Gustavo: "En el país de Miguel Angel Asturias", El Imparial (Guatemala, 2 feb. 1968), p. 3.

Es impresionante la circunstancia ambiental dentro de la cual escribió e! lauteado novelista. No son las selvas del Catatumbo o del Caquetí o el Vaupés. La obra de Miguel Angel Asturias se desarrolla en el ambiente físico más amable de la tietra: en un clima de seda con aires suaves y aterciopelados".

1383. Shinoda, Hajime: "Nōberu bungakushō jushõ no Asutsuriasu no bungaku: Sokoku hakken de kaigan; Shuru kara seiji shõsetsu e", Mainicbi Sbimbun (Tokio, 20 oct. 1967), p. 5. Edición de la tarde.

"La lit:ratura de Asturias; Premio Nobel de Literatura. El despertar a través del descubrimiento de su pueblo: del surrealismo a la novela politica".

1384. Silva Villalobos, A.: "Lo temporal en nuestra literatura", El Nacional, supl. 730 (México, 26 mar. 1961), p. 3.

Crítica adversa de El señor Presidente. "El libro, en verdad, tiene momentos de interés, detalles poéticos exquisitos y párrafos descriptivos de gran valor. Sin embargo, en su estructura de novela, tiene graves defectos... [ia] secucncia de acontecimientos carece de naturalidad; sus personajes han sido encadenados con artificio. No se advierte la trabazón cerrada necesaria en la novela..." 
1385. Siliezar, Felipe: "Ludwig von Beethoven y Asturias", El Imparcial (Guatemala, 3 nov. 1967), pp. 9, 13.

No es una confrontación del músico alemán y maA como podría pen. sarse por el título. Es una zigzagueante nota periodística que culmina con la invitación a que el Ptemio Nobel radique en la acogedora Antigua.

1386. Sigal, Lore: "Strong Wind", The New Republic (Nueva York, 22 feb. 1969), pp. 22-27 [reseña de la versión inglesa de Viento fuerte].

1387. Silva, José Enrique: "Bolivar de Miguel Angel Asturias", Cultura, 5 (San Salvador, sep.-oct. 1955), p. 151 [fragmento de la reseña aparecida en La Prensa Gráfica].

1388. Slovenské pobl'ady, 12 [Revișta]. "Miguel Angel Asturias" (Praga, 1967), pp. 78-81 [homenaje].

1389. Smieja, Florian: "Miguel Angel Asturias; Premio Nobel 1967", Tygodnik Powszechnz (Cracovia, 5 dic. 1967), p. 2.

1390. Soler y Pérez, Francisco: "De un compañero de ayer; lo maya, lo folklórico y lo típico en la literatura de Miguel Angel Asturias", El Imparcial (Guatemala, 9 dic. 1967), pp. 17 y 23.

La cultura maya... es en MAA "Una floración de contingencias casuísticas que gritan desde la oscuridad de la sima, su mágica vivencia, su evo cosmogónico puesto como paladión en todos y cada uno de los personajes que aparccen en sus obras".

1391. Solórzano, Carlos: "Asturias y Galich", "La cuitura en México", supl. de Siempre!, 14 (México, 23 may. 1962), p. XX.

1392. Sommers, Joseph: "El señor Presidente", Books Abrodd, XXXVIII (Norman, 1964), pp. 439-440 [reseña].

1393. Sommers, Joseph: "The Indian-Oriented Novel in Latin America; New Spirit, New Forms, New Scope", Joumal of Inter-American Studies, VI (Gainesville, abr. 1964), pp. 149-166.

Medular exploración que abre nuevas brechas en la crítica asturiana. "Weaknesses notwithstanding, Hombres de maiz marks a new point of departure for the Indian-oriented novel, transcending the former stereo. type of superficial realism and frequently elementary social protest. An enlarged concept of the Indian is created, including his own peculiar world-view. For the first time in the novel, the technique of surrealism is introduced in treating this theme. It is unquestionably in accord with the author's aim to penetrate beneath the surface of Indian consciousness. The result is a deeper tragedy".

1394. Sopeña, Federico: "Asturias-Varese", Cuadernos bispanoamericanos, 224-225 (Madrid, ago.-sep. 1968), pp. 682-683.

1395. Sörensen, Lennart: "Tack, Svenska Akademien!", Kulturaktuellt $K \nu P$ (Estocolmo, 20 oct. 1967) [versa sobre política, literatura y exotismo en MAA]. 
1396. Soto de Avila, Pedro: "De un amigo de la madurez; Miguel Angel Asturias; el pocta enamorado de su Guatemala", El Imparcial (Guatemala, 9 dic. 1967), pp. 17 y 24 [evocación de cómo conoció a MAA y de sus subsiguientes tratos y convivios con él].

1397. Stil, André: "Notre pays quotidien", L'Humanité (París, 7 ene. 1963).

Reseña de Los ojos de los enterrados. "Le quotidien côtoyant aisément l'incroyable".

1398. Stil, André: "Magie du réalisme", L'Humanité (París, 22 jun. 1967), p. 8 [reseña de Torotumbo y El espejo de Lida Sal].

1399. Stolpe, Jan: "Under strecket; Man maste öppna ögonen", Svenska Dagbladet (Estocolmo, 20 oct. 1967), p. 4 [una amplia revisión de su obra literaria].

1400. Storm, Ole: "Aestec og partisan", Politiken (Copenhague, 20 oct. 1967) [semblanza y análisis de su obra].

1401. Suárez, Luis: "Asturias; ese caso!", Siempre!, 754 (México, 6 dic. 1967), pp. 34-35.

1402. Tauxe, Henti-Charles: "Miguel Angel Asturias, Prix Nobel 1967; un tragique dur et flamboyant", Gazette de Lausanne (Lausana, Suiza, 20 oct. 1967), p. 16.

"Cette double référence aux sources mythiques et à une actualité souvent déchirante et scandaleuse donne aux ouvrages d'Asturias une tonalité particulièrement attachante".

1403. Tauxe, Henri-Charles: "Miguel Angel Asturias; Prix Nobel 1967", La Gazette Littéraire (Lausana, Suiza, 21-22 oct. 1967), p. 22. "Dans le vaste dialogue qui, de nos jours, caractérise la culture mondiale, la littérature latino-américaine occupe une place privilégiée... ses écrivains nos attirent par la jeunesse émanant de leur démarche, par une intensité et une fraî́cheur qui parfois secouent notre distinction un rien ennugée de vieux civilisés... L'oeuvre de M. A. Asturias ne se conçoit pas en dehors du contexte du Guatemala".

1404. T. E.: "Nobelpristager og ambassadeur; Jeg er ansat af mine romaner", Politiken (Copenhague, 20 oct. 1967).

1405. Tejera, María Josefina: "Fantasía y tealidad en Mulata de tal de Miguel Angel Asturias", Revista Nacional de Cultura, 182 (Caracas, oct.-dic. 1967), pp. 68-72.

"Un universo de realidad legendaria donde una Mulata es símbolo del mestizaje racial y cultural de América".

1406. Teixeira de Salles, Fritz: "Miguel Angel Asturias e a novela política hispano-americana", Revista Brasileira de Estudios Politicos, III:6 (Belo Horizonte, jul. 1959), pp. 144-164.

"El señor Presidente é o contraste entre a grandeza da naturaleza e a mesquinharia dos seus filhos; entre a euforia da vida e a caricatura que dela fizeram os homens". 
1407. Thompson, Hunter S.: "The Faulkner of Latin America; First Look at an Old, Old Book", The National Observer (Nueva York, 27 ene. 1964), p. 17.

Pontifica el "crítico", "The best thing about Miguel Angel Asturias" first novel is the cover, by Everett Aison... The text of El señor Presidente is so bad that it is difficult to see why it was either translated from the Spanish or published in this country..."

1408. Tomat-Guido, Francisco: "El albajadito", Ficción, 38 (Buenos Aires, jul.ago. 1962), p. 103 [reseña].

1409. Tovar, Luis Gerardo: "Humilde y sencillo", La Hora (Guatemala, 30 dic. 1967).

Embajada de Guatemala en París. Como sorpresa, un día, docenas de jóvenes lo recibieron con las notas del Himno de los Estudiantes Guatemaltecos compuesto por Asturias hace medio siglo. Conmovido, "humedeció sus ojos", pero de pie los acompañó en las "últimas estrofas de su canción".

1410. Trigueros de León, Ricardo: "Perfil en el aire; Miguel Angel Asturias", Cultura, I (San Salvador, ene.-feb. 1955), pp. 103-108. Diálogo. Habla MAA. "Escribí el primer capítulo de El señor Presidente para una edición de Navidad de un periódico guatemalteco... Trabajé mucho en esta obra. La copié a máquina más de nueve veces. Muchos de sus capítulos los sabia de memoria..."

1411. Tufte, Leif: "Stormvaer over Guatemala", Aftenposten (Oslo, Noruega, 31 oct. 1968) [reseña de la traducción noruega de Viento fuerte].

1412. Tuñón de Lara, Manuel: "Un Romancier Social des Tropiques; Miguel Angel Asturias", Les Temps Modernes, 107 (París, nov. 1954), pp. 650-657.

1413. Tystad, Jan: "Et 'bananepos' fra Guatemala", Dagbladet (Oslo, 22 abr. 1967) [reseñas de Viento fuerte y El Papa verde].

1414. U. J.: “M. A. Asturias: 'Sturm' ", Sïddeutsche Zeittng, 292 (Munich, 7 dic. 1967) [reseña de Viento fuerte].

1415. Ulises: "La obra y el Premio Nobel de Asturias en España", El Imparcial (Guatemala, 24 feb. 1968), pp. 13 y 15.

"En España, en medio de los comentarios favorables, se deja sentir que ha existido cierto desconocimiento general de la obra del laureado... ¿Cómo es posible que este nuevo Cervantes sea menos conocido por nosotros, sus compatriotas de estitpe y de lenguaje, que Cela, Vargas Llosa y hasta que Rafael Pérez y Pérez?"

14.16. Ustvedt, Yngvar: "Indiansk talsmann", Dagbladet (Oslo, Noruega, 12 nov. 1966), p. 6 [reseña de la versión sueca de $E l$ señor Presidente].

1417. Uzeta, R. Arnulfo: "Con Asturias en París", Exsélsịor (México, 26 mar. 1968), pp. 1 y 13. 
1418. Valdés, Ivana: "Miguel Angel Asturias", Literární listy, 15 (Praga, 1968), p. 11 [entrevista].

1419. Valéry, Paul: "Carta de Valéry a Francis de Miomandre sobre Leyendas de Guatemala de Miguel Angel Asturias", Cultura, 46 (San Salvador, oct.-dic. 1967), pp. 29-30 [esta carta ha sido reproducida numerosas veces].

1420. Valladares Molina, Acisclo: "Miguel Angel Asturias", Mundo Hispánico, 243 (Madrid, jun. 1968), pp. 22-25.

Entrevista en la cual maA dice: "Le enviaré, en cuanto esté terminado, el guión de la película Una vida por México, biografía de don Benito Juárez. Estoy entregado de lleno a este proyecto..."

1421. Valladares Molina, Acisclo: "Detrás de todo hombre ha habido siempre una mujer", El Imparcial (Guatemala, 11 may. 1968).

Entrevista con la esposa de MAA, señora Blanca Mora y Araujo de Asturias. Recalcó conmovida:

"Nuestra felicidad estriba en una especie de amistad que nos une: identidad de fines $y$ tareas a realizar. Trabajamos intensamente en algo común: su literatura, La mujer ha de ser un verdadero ser viviente al lado del matido y no un simple objeto. Debe alegrarse y sufrir a su lado: vibrar como uno solo...

La mujer del attista ha de ser consciente de la obra que se realiza, de la hipersensibilidad del ser amado. Ha de saber valorar lo que escribir significa para el escritor: derramar sobre el papel mucho de su vida, plasmar heridas y gozos. ¡Crear!

"Creo que Miguel Angel encontró $\in n$ mi la paz necesaria para escribir y recobró el placer de hacerlo. Yo le incitaba a trabajar porque creía con todas mis fuerzas en lo que estaba realizando..."

1422. Valldesperes, Manuel: "Brújula de las letras y de las artes; Miguel Angel Asturias, Premio Nobel 1967", El Caribe (Santo Domingo, R. D., 21 oct. 1967).

Ponderadas observaciones sobre la novelística asturiana. "Miguel Angel Asturias es uno de los pocos novelistas latinoamericanos que no ha olvidado nunca la norma de impersonalidad que reclama la litetatura realista para que no caiga en la deformación tendenciosa y para ello, como él mismo ha dicho, se sirve de la imaginación y de la universalización del hombre..."

1423. Vallejo, Américo: "Papeles, Revista del Ateneo de Caracas", Igitut, II:6-7 (Córdoba, Arg., jun.-jul. 1968), p. 101.

Al reseñar el contenido del núm. 4 de esta revista el crítico se detiene a cantar aleluya en loor de MAA por sus "Leyendas de las tablillas que cantan". Exclama: "es una perla auténtica entre los fementidos intentos poéticos de tanto escribir actual".

1424. Vargas Llosa, Mario: "Un hechicero maya en Londres", Imagen (Caracas, 1-15 jun. 1967).

Entrevista con motivo de una conferencia que dictara MAA en Londres titulada: "La protesta social en la literatura latinoamericana".

1425. Vasconcelos, José: "Novela guatemalteca", Todo (México, 1 may. 1947), p. 11. 
1426. Vásquez Martínez, Edmundo: "Ha sido la palabra y no otras armas lo que ha acuñado nuestra cultura", Guatemala en Marcha, I:15 (Guatemala, 19 dic. 1967) [mensaje de la Universidad de San Carlos a MAA].

1427. Vásquez, Miguel Angel: "Miguel Angel Asturias; un sitio en la eternidad", Revista A. P. G., 28 (Guatemala, abr. 1968), PP. 34, 48 y 52 [el autor fue secretario particular de MAA. Reúne recuerdos, etc.].

1428. Vejde, Eva: "Asturias hopp-sitt lands befrielse", BergslagspostenBergslagemas Tidning (Lindesberg, 20 oct. 1967) [exposición general de su producción literaria].

1429. Velásquez, Alberto: "Riqueza idiomática y estilo de su obra", $E l$ Imparcial (Guatemala, 12 dic. 1967) [MAA].

1430. Venaisin, Gabriel: "Miguel Angel Asturias: Monsieur le Président; Roman guatémaltèque", Esprit (Paris, jul. 1953), pp. 155158 [reseña].

1431. Venegas, Roberto [Seud. de Mauricio de la Selva]. "Literatura y política", El Imparcial (Guatemala, 10 nov. 1967), pp. 11 y 13.

1432. Verbitsky, Bernardo: "El arte americanista de Miguel Angel Asturias", Negro sobre Blanco, 20 (Buenos Aires, ago. 1961), PP. 1-3 [exposición panorámica de su obra].

1433. Verdevoye, Paul: "Miguel Angel Asturias et le 'nouveau roman' hispanoaméricain", Conferencia en la Sorbona. Amphithêâtre Richelieu (Paris, 9 feb. 1968).

Se publicó posteriormente en Europa, 473 (Patís, sept. 1968), pp. 10-15. "Son originalité... provient du fait qui il a su mêler harmoniensement 'tant de rêve à tant de realité" ".

1434. Vian, Cesco: "Miguel Angel Asturias; Romanziere-poeta dei Maya d'oggi", Lingue e Cultura, II:2 (Milán, 1956), p. 1.

1435. Villagrán, Ariza, Victor: "Cima de cielos", El Imparcial (Guatemala, 17 nov. 1967), p. 9.

1436. Villaseñor, Raúl: "El espejo de Lida Sal", Vida Universitaria (Monterrey, 4 feb. 1968), 7.

"Dos maneras opuestas de entender lo circulante: la de raigambre amerindia y la europea-occidental..."

1437. Villatoro, Eduardo P.: "Asturias y los derechos humanos", El Gráfico (Guatemala, 10 dic. 1967), pp. 6 y 31.

"Si alguien ha exigido la reivindicación de los derechos humanos ha sido Miguel Angel Astutias, a través de casi la totalidad de su obra literaria, como escritor". 
1438. Villatoro, Eduardo P.: "Escritor comprometido", El Gráfico (Guatemala, 20 oct. 1967).

"Es imposible omitir la grandeza de su obra poética, especialmente cuando se lee Sien de Alondra, en cuyos versos está presente, tambićn, la imagen del explotado, del miserable..."

1439. Villelaur, Anne: "Miguel Angel Asturias; Le Pape vert", Les Lettres Françaises (París, 16-22 feb. 1956), p. 2 [reseña].

1440. Villelaur, Anne: "La otra América", El Nacional (Caracas, 6 may. 1956).

Cuatro novelistas americanos traducidos al francés: Carpentier, Verissimo, Amado y Asturias.

1441. Villelaur, Anne: "Miguel Angel Asturias et le réalisme magique", Les Lettres Françaises (Paris, 25 oct. 1967), p. 6.

Reseña de El espejo de Lida Sal. "Certes, Le miroir de Lida Sal n'apportera pas à ceux qui connaissent Asturias, une révélation, mais une confirmation".

1442. Viscovich, Iliana: "Comentario a La audiencia de los confines", El Imparcial (Guatemala, 2 oct. 1961), pp. 11-12.

1443. Vives, B.: "Le miroir de Lida Sal", Les Nonvelles Littéraires (París, 15 jun. 1967), p. 5 [reseña].

1444. West, Anthony: "Angels and Devils", The New Yorker (Nueva York, 28 mar. 1964), pp. 158-159 [reseña de El señor Presidente].

1445. Wiskari, Werner: "Guatemalan Novelist also a Diplomat; Wins Nobel Prize", New York Times (Nueva York, 20 oct. 1967). MAA, "Noted for works excoriating Latin American dictatorship and 'Yankee Imperialism' has won the 1967 Nobel Prize".

1446. Wolff, Geoffrey A.: "Miguel Angel Asturias; Art as Well as Politics?", Cbicago Sun-Times (Chicago, 25 oct. 1967), p. 49.

Reportaje sobre MAA. Concluye afirmando que "It seems to be the general opinion that he was given the Nobel Prize less for his literature than for the anti-Americanism imbedded in the literature. Should his art be honored? Until the evidence is available in English, we should withhold judgment".

1447. Wyld Ospina, Carlos: "Viento fuerte", Revisia de Guatemala, $2^{\text {q }}$ época, I:1 (Guatemala, abr.-jun. 1951), pP. 172-175.

Reseña. Admite que la novela le ha procurado momentos "de sabrosa hilaridad". Pero, afirma que Viento fuette "es ante todo... folklore "chapín"...El señor Presidente sigue siendo su mejor novela".

1448. Wyld Ospina, Carlos: "Una gran novela", El Imparcial (Guatemala, 24 feb. 1947) [reseña de El señor Presidente].

1449. Wurmser, A.: "Dante au Guatemala", Les Lettres Françaises (París, 15-22 abr. 1965) [reseña de Mulata de tal]. 
1450. Yepes-Boscán, Guillermo: "Asturias, un pretexto de mito", Aportes, 8 (Paris, abr. 1968), Pp. 99-116 [investiga la obra de Asturias a través del ingrediente colectivo de los mitos].

1451. Yepes-Boscán, Guillermo: "Asturias; "Ahora se sientan ustedes y nosotros les vamos a contar' ", Imagen, 14-15 (Caracas, 15-30 dic. 1967).

Sustanciosa entrevista, maA recalca que en Hispanoamérica, "hay una literatura que funciona, que existe, que vive, que tiene sus particularidades, que no es como la europea...

"Y no me canso de repetirles: Ahora se sientan ustedes y nosotros les vamos a contar. Ustedes ya nos contaron muchos años y nosotros sen tados oímos a Flaubert, a Víctor Hugo, a Cervantes. Ahora siéntense ustedes y somos nosotros los que vamos a empezar a contar".

1452. Yepes-Boscán, Guillermo: "Asturias: El lado sagrado de las cosas", Imagen, 14-15 (Caracas, 15-30 dic. 1967), suplemento.

Clarividente y vigoroso ensayo. "Acosado por el poder fulgurante de la palabra, seducido por la lógica del mito imantado por el lado sagrado de las cosas, esto es, por lo que de esencial y sustantivo hay en ellas, como lenguaje de un vasto libro, Asturias liberó una prosa y una temática que se cerraba sobre si hasta morderse la cola".

1453. Zälamea, Jorge: "Renuncia de la libertad", El Tiempo (Bogotá, 15 jun. 1952) [reseña de El señor Presidente].

1454. Zavala, Silvio: "Homenaje a Miguel Angel Asturias", "México en la cultura", supl. de Novedades, 982 (México, 14 ene. 1968), p. 3.

1455. Zbinden Louis-Albert: "Asturias: Un long cri contre l'injustice", Gazette de Lausanne (Lausana, Suiza, 27-28 abr. 1963), pp. 17 y 23.

Entrevista. "Quand je demande à Asturias s'il a de la haine envers les États-Unis, il me répond:

-Aucune. D'abord parce que j'ignore la haine, et ensuite parce que les États-Unis, c'est d'abord un peuple qui mange des bananes, mais qui n'est nullement responsable de la façon dont elles arrivent jusqu' à lui. Les ennemis sont les financiers, les gens sans scrupules des grands trusts économiques".

1456. Zelaya Bockler, Federico: "Mensaje de Miguel Angel Asturias", Diario de Centroamérica (Guatemala, 2 dic. 1967), p. 1.

Estimula a los escritores de su patria para que aprovechen "las esencias" guatemaltecas en sus creaciones literarias.

1457. Zelaya Bockler; Federico: "Mensaje de Miguel Angel Asturias; 'Lo que soy se lo debo a ese pueblo que ha sabido inspirarme'", Diario de Centroamérica, LXXXVII:26136 (Guatemala, 9 dic. 1967).

Una incitativa a los literatos guatemaltecos. "A los escritores les digo... que la novela necesita trabajo, trabajo y más trabajo... No hacer tabla rasa de los valorges anteriores... Me refiero especialmente a los novelistas y a los historiadores... Landivar, Milla,. Irisarri, el Padre Ximénez, Fuentes y Guzmán". 
1458. Zendejas, Francisco: "Yet... Miguel Angel Asturias", Excélsior (México, 28 sep. 1967), pp. 2 y 5, sec. B.

Reseña de El espejo de Lida Sal. "La ilusión se convierte en una serie de sobreposiciones, como esos montajes fotográficos logrados en el cuarto oscuro, que tan fácilmente engañan la mirada del observador".

1459. Zherdynivs'ka, M.: "Ochi pokhovanykh", Vsesvit, V:3 (Moscú, mar. 1962), P. 92 [reseña de Los ojos de los enterrados].

1460. Zuleta Alvarez, Enrique: "El realismo poético de Miguel Angel Asturias", Norte, VI:5 (Amsterdam, sep.-oct. 1965), pp. 107-111.

Lúcida exposición de su obra. "Cuando Asturias relata, su prosa se funde con la materia argumental y consigue la identíficación más intima entre significante y significado, al punto tal que no podria concebirse otra formulación de la realidad que no fuera la que el novelista ha elegido. Es que la índole del estilo narrativo de Miguel Angel Asturias es poética. Su realismo es poético; es decir, hay una transfiguración del mundo real expresado en una prosa poética que sirve totalmente a la intención novelesca".

(La preparación de este Homenaje a Miguel Angel Asturias estuvo a cargo de Alfredo A. Roggiano y Pedro F. de Andrea). 
